\title{
Proceedings of the operations research workshop for LGU health and population officials and researchers, August 9-13, 1996
}

Family Planning Service

The Family Planning Operations Research and Training (FPORT) Program

Population Council

Follow this and additional works at: https://knowledgecommons.popcouncil.org/departments_sbsr-rh

Part of the Demography, Population, and Ecology Commons, Health Services Research Commons, and the International Public Health Commons

How does access to this work benefit you? Let us know!

\section{Recommended Citation}

"Proceedings of the operations research workshop for LGU health and population officials and researchers, August 9-13, 1996," Workshops. Manila: Philippines Dept of Health, Family Planning Service and Population Council ANE OR-TA Project, 1996. 
Proceedings of the

\title{
OPERATIONS RESEARCH WORKSHOP FOR LGU HEALTH AND POPULATION OFFICIALS AND RESEARCHERS
}

August 9-13, 1996

Titay's South Beach Resort

Boracay, Aklan

\author{
Sponsored by
}

Family Planning Service

Department of Health

Republic of the Philippines

and

The Family Planning Operations Research and Training (FPORT) Program The Population Council, Manila Asia Near East Operations Research and Technical Asistance (ANE OR/TA) Project ${ }^{1}$

${ }^{1}$ The ANE OR/TA Project is funded by the US Agency for International Development, Office of Population, Health and Nutrition, under Contract No. DPE-3030-C-00-0022-00. 


\section{TABLE OF CONTENTS}

Page

Introduction and Summary

vii

Welcome Remarks

Marilou P. Costello, Ph.D.

1

Host Country Advisor

The Population Council, Manila

Workshop Goals \& Objectives

Edwin Reuel Ylagan, M.D.

Program Officer

The Population Council, Manila

The Family Planning/Reproductive

Jocelyn Ilagan, M.D.

4

Health Program: Recent Developments

Medical Specialist II

Family Planning Service

Department of Health

The Role of Operations Research in the

Eireen Villa

in the LGU Performance Program (LPP)

Senior Technical Advisor

Management Science for Health

Department of Health

Open Forum

\section{SESSION I: INTRODUCTION TO OPERATIONS RESEARCH (OR)}

OR as a Tool for Program Managers

Marilou P. Costello, Ph.D.

Diagnostic Studies:

Factors Affecting the FP Program FP

Drop-Out Rates in Bukidnon

An Analysis of FP Drop-outs in Bukidnon

A Situation Analysis in India
Prof. Lita Sealza

Research Associate, RIMCU

Xavier University

Editha Abocejo, M.D.

FP Coordinator

Regional Health Office X

Saumya Rama Rao, Ph.D.

37

Program Officer

The Population Council, New Delhi 
Intervention Studies:

Using Male Motivators to Reach Men

Integrating RTI Services in FP
Fely David, Ph.D.

Director

Social Science Research Institute

Central Philippine University

Edwin Reuel Ylagan, M.D.

\section{SESSION II: CONSIDERATIONS IN CONDUCTING AN OR STUDY: AN OVERVIEW}

Identifying, Defining and Justifying the Research Problem

Strategy Selection to Solve the Problem

Intervention Description

Objectives, Hypotheses

Operational Definitions

Study Design

Sampling and Data Collection

Analysis of Data

Dissemination and Utilization

of Findings

Open Forum
Michael Costello, Ph.D.

53

Research Associate, RIMCU

Xavier University

Saumya Rama Rao, Ph.D.

56

Edwin Reuel Ylagan, M.D.

Josefina Cabigon, Ph.D.

61

Associate Professor,

UP Population Institute

Betty Abregana, Ph.D.

Integrated Coordinator

Integrated Research Institute

Silliman University

Josefina Cabigon, Ph.D.

67

Virgilio Aganon

Consultant

The Population Council, Manila and

Josefina Cabigon, Ph.D.

Michael Costello, Ph.D.

and

Virgilio Aganon

Marilou P. Costello, Ph.D. 


\section{SESSION III: CONDUCTING YOUR CLUSTER \\ SURVEY: 1997 LPP BENCHMARK \#6}

Integrated Cluster Survey on FP/MCH

Eireen Villa

LGU Performance Program

Conducting a Cluster Survey with

Josefina Cabigon, Ph.D.

92

an OR Perspective

Virgilio Aganon

Fely David, Ph.D.

\section{SESSION IV: SPECIAL TOPICS FOR OR}

Gender Awareness and Reproductive

Health

Male Involvement in Family Planning

Cost Analysis and Program Sustainability

Open Forum
Aida Santos

Consultant

WEDPRO

Fely David, Ph.D.

101

Saumya Rama Rao, Ph.D.

103

108

\section{SESSION V: PREPARATION OF A CONCEPT PAPER}

Elements of an OR Concept Paper

Michael Costello, Ph.D.

\section{SESSION VI: PRESENTATION OF OUTPUTS}

An OR Study on the Low CPR of Benguet

Some Factors Affecting the Performance of Hospital-Based FP Clinics in Eight District Hospitals in the Province of Ilocos Sur: A Diagnostic Study to Increase the CPR
Esteban Piok, M.D.

Juliet Sacley

Provincial Health Office, Benguet

Felipe Almachar, M.D., M.P.H.

Rosalinda Quisada, M.D.

Provincial Health Office

Ilocos Sur 
A Study to Determine the Reasons for the Drop-out Rate of DMPA Users in Quezon City

An Analysis of FP Practice and the Provision of FP Services in the Province of Capiz

Open Forum

A Study on Low Coverage of Tetanus Toxoid (TT2+) in Bacolod City

A Diagnostic Study to Decrease the Number of Drop-outs Among MWRAs Who are Practicing FP in the Province of Tarlac

Open Forum

A Diagnostic OR Study on the Causes of Variation in the Performance of FP Services Among Rural Health Units and City Health Offices in the Province of Negros Oriental

An Assessment of the Effectiveness of Interpersonal Counseling Services to FP Clients

Open Forum

A Diagnostic OR Study to Increase Contraceptive Prevalence Rate (CPR) in Davao City

A Diagnostic OR Study to Know the Factors Affecting Low CPR in the Province of North Cotabato
Magdalena Ybañez, M.D.

Perla Dosayla, M.D.

City Health Office, Quezon City

Francisco Fuentes, Jr.

Cecille Tuazon

Provincial Health Office, Capiz

Emma Castel

Nilda Martinez.

City Health Office, Bacolod City

Develyn Florendo

Angelina Duque

Provincial Health Office, Tarlac

Filemon Flores, M.D.

138

Flordeliza Dublas

Provincial Health Office

Negros Oriental

Lorna Lagos

Redinah Poral

Provincial Health Office

South Cotabato

Miguel Oppus, M.D.

Elma Albay

City Health Office

Davao City

Charita Doyongan

Virginia Laguihon

Provincial Health Office

North Cotabato 
Non-Experimental OR Study to Determine the Factors that Cause the Decreasing Trend of VSS in Cagayan Province

A Situation Analysis on FP Service Delivery at MHCs and BHSs in Maguindanao

Open Forum

Providing Reproductive Health

Counseling to Post-Partum Clients

Evaluating the Effectivenss of Sangguniang Kabataan (SK) Members as Trainors in the Adolescents

Development Program

Open Forum

Closing Remarks

Appendices

List of Participants

List of OR Concept Papers

Pictorial Documentation
Wilson Puyaoan, M.D.

Edgardo Baguinon, M.D.

Provincial Health Office

Cagayan

Farida Uka, M.D.

Sabrina Abella

Provincial Health Office

Maguindanao

Vilma Mendez

Marilyn Jacot

Provincial Health Office

Misamis Oriental

Gil Mantilla, M.D.

160

Provincial Population Office

Davao del Sur

Jocelyn Ilagan, M.D.

and

Marilou P. Costello, Ph.D. 


\section{Introduction and Summary}

This report summarizes the results of the training workshop for health and population officials and researchers who gathered in Boracay, Aclan, Philippines on August 9-13, 1996 to discuss the tenets and applications of operations research (OR). This workshop was co-sponsored by the Family Planning Service of the Department of Health (DOH)and the Family Planning Operations Research and Training Program (FPORTP) of the Population Council, Manila.

Fourteen local government units (LGUs) were represented in the workshop: Benguet, Cagayan, Ilocos Sur, Tarlac, Quezon City, Capiz, Negros Oriental, Bacolod, Misamis Oriental, Davao del Sur, Davao City, Maguindanao, North Cotabato, and South Cotabato. They are all participants in the LGU Performance Program (LPP) of the Department of Health, which was undertaken as a response to the devolution of health services to local government units as mandated by the Local Government Code. Resource persons from the academe, research institutions, and the DOH elaborated on operations research in five sessions: Introduction to Operations Research, Considerations in Conducting an OR Study, Conducting the "Cluster Survey": 1997 LPP Benchmark \#6, Special Topics in OR, and Preparation of an OR Concept Paper.

The OR training workshop was guided by the following objectives:

1. To obtain an understanding of the different types of operations research and how these differ from basic research;

2. To demonstrate the usefulness of OR in program development and decision- 
making;

3. To review and enhance the skills of researchers for OR problem identification and justification;

4. To develop a list of feasible and relevant OR topics considered of high priority to the LGU participants; and

5. To enable the participants to develop a concept paper on a chosen OR topic at the end of the workshop.

Workshop activities were designed with a view towards enhancing the appreciation of LGU program managers for information-based planning in general and OR in particular. They were also intended to strengthen the capability of research institutions to undertake OR and to establish linkages between program managers and regional and/or university-based researchers.

The technical components of the workshop covered problem identification, definition and justification; strategy selection; intervention description; objectives/ hypotheses and operational definitions; study design and sampling; data collection and analysis; and the dissemination and utilization of findings.

In the light of recent developments, new topics and issues were also discussed. In particular, participants delved into the updated DOH Family Planning/ Reproductive Health Program, the role of research in the LPP, gender awareness and RH, male involvement in $\mathrm{FP}$, cost analysis, and conducting a survey with an OR perspective.

The discussions were substantiated by examples of research studies done in the Philippines and abroad. Open forums were provided for further inputs and clarifications. The final workshop output was the concept paper developed by each participating LGU according to its particular needs. These were orally presented by each team for comments and reactions from the group.

The five-day workshop ended with the hope that this is but day one of a long-term journey by the participants towards operations research. 


\title{
WELCOME REMARKS
}

\author{
Marilou P. Costello, Ph.D.
}

The Population Council, Manila

My task this morning is to welcome all of you to this Second Operations Research Workshop for LGU Health and Population Officials and Researchers. On behalf of the Population Council and the Department of Health, I would like to welcome and thank you for responding to our invitation. I know that despite your busy schedule you took the time out to come here, so I really appreciate your coming. I hope that when we all go back we can say that coming here this week was certainly worth our while.

During the course of this workshop you will be introduced to FPORT. And what is that? Well, to begin with, FPORT is an acronym for Family Planning Operations Research and Training Program, which began four years ago. FPORT was established in the Department of Health under the Family Planning Service coordinated by the Population Council. Funding for this activity is provided by a grant from USAID to the Asia Near East Operations Research and Technical Assistance Program of the Population Council in New York, which is an international NGO engaged in social science and biomedical research. The objective of this program is to improve through operations research and technical assistance the "quality, accessibility, and cost-effectiveness of family planning and maternal health delivery systems in the country and to strengthen the institutional capacities to use operations research as a management tool to diagnose and solve service delivery problems."

As you can see from this quotation, OR is not just something that we learn; it is something that has to be used. We are therefore expecting that, when you get out from this workshop three days from now, this will be a beginning towards using the things that you 
have learned here about OR and integrating them into your own program.

As I have said, the ANE OR/TA program in the Philippines was established here four years ago. Similar activities are also underway in several other countries, including India, Bangladesh, Egypt, and Indonesia.

We have some publications that we have provided you in your kit. These should give you an idea about the focus and the range of OR activities that have already been conducted under this program.

In a little while also, Dr. Ylagan, our Program Officer, will be explaining the objectives of the workshop. My own personal goal the next few days, though, is really quite simple. Basically, I hope to turn all of you into OR believers by the end of your stay in Boracay. This is my challenge, not only to the participants, but also to our resource persons. I think it won't be very difficult to achieve this goal, considering the beautiful and inspiring setting of this workshop and the highly qualified participants and resource persons that we have here, to say nothing of the most essential fact of all: that you are going to find OR to be very much worthy of your time and attention. OR, you will find, is not only interesting and intellectually challenging -- it is also very, very useful for program managers. And we can't ask for anything more than that, can we?

So thank you very much and, again, welcome to all of you. 


\title{
Workshop Goals and Objectives
}

\author{
Edwin Reuel Ylagan, M.D. \\ The Population Council, Manila
}

Good morning. The goals of this workshop are as follows:

- $\quad$ To enhance the appreciation of LGU health/planning officials and other FP program managers for operations research and information-based planning and policy-making;

- $\quad$ To build and sustain the capability of research institutions to undertake OR; and

- $\quad$ To facilitate and strengthen the linkage between program managers and regional and/or university-based researchers.

Specifically we expect that after the workhop participants will be able to

- obtain an understanding of the different types of operations research and how these differ from basic research.

- $\quad$ demonstrate the usefulness of OR in program development and decision-making.

- $\quad$ develop their skills for OR problem identification and justification.

- develop a list of feasible and relevant OR topics considered of high priority to the LGU participants and

- $\quad$ develop a concept paper on a chosen OR topic at the end of the workshop.

These are summarized in your kits but if you need further clarifications I will be happy to entertain your questions. 


\title{
The Family Planning/Reproductive Health Program: Recent Developments
}

\author{
Dr. Jocelyn Ilagan \\ Department of Health, Family Planning Service
}

I was tasked to give this morning an important update on family planning and reproductive health. Please take note that we have inputted into the outline some reproductive health concerns.

\section{Situationer:}

> we have a total population of $70 \mathrm{M}$;

> the women of reproductive age (WRA) is $18 \mathrm{M}$;

> the married women of reproductive age (MWRA) is $10 \mathrm{M}$;

> the total fertility rate (TFR)/average number of children is 4;

> the desired number of children is 3 ;

> the annual number of births is $2 \mathrm{M}$;

> the annual number of infant deaths is 100,000 ;

> the annual number of maternal deaths is 4,200 ;

$>\quad$ the contraceptive prevalence rate is 50.7\% (1995 Family Planning Survey); and

> our unmet need for family planning is 26\% (1993 National Demographic and Health Survey).

The general objective of the program is to be able to reduce the level of unmet need for family planning information and services particularly among high risk men and women of reproductive age. Please take note that we have already included the male population as a target group. For our specific objectives by the year 2000, the following conditions should prevail:

1) Service outlets are reliable.

2) Households with married women of reproductive age are aware of family planning and know where to get the services. 
3) The total demand for the unmet needs for FP is responded to.

4) The community-based service and information outlets are provided with program methods.

5) The participation of private sectors is maximized.

6) LGUs are active advocates and implementors of the program.

7) The commercial market for contraceptives should have been expanded.

\section{Policy Statements for the Family Planning Program:}

1) Improvement of family welfare with main focus on women's reproductive health, safe motherhood and child survival.

2) Rejection of abortion as a family planning method.

3) Freedom of choice.

4) Promotion of family planning solidarity and responsible parenthood.

\section{Strategies:}

1) Revitalization of NFP advocacy campaign and setting up of NFP centers

2) Social marketing

3) Mobilization through recruitment of volunteer and satisfied users

4) Responding to all barriers to carry adoption and continued use of FP and reproductive health services

5) Providing quality of care services

6) Wide availability of range of methods

7) Gradual institutionalization of the program

8) Integrating, networking and linkaging of family planning activities with other reproductive health services

\section{Program Directions:}

1) Reproductive health approach in the perspective of family planning

2) Family planning in the broader context of population development

3) Special needs of adolescents with greater involvement of parents 
4) Provide the widest range of family planning methods through public, private and industry-based and commercial outlets

5) Implementation of urban-specific family planning strategies

6) Focus on program sustainability

7) Conducting more area- and client-specific researches

8) Focus on LGU program plans:

- Health care family planning schemes at the community and industry level

- Financial assistance schemes by the LGUs

- Rationalized training program

9) Simplified family planning management information system strategy

10) Integrate/link family planning with the other elements of reproductive health

11) Expand the family planning and reproductive health services through outreach and community-based outlets and the non-traditional NGOs

\section{Reproductive Health}

The International Conference on Population and Development (ICPD) held in Cairo in 1994 reiterated the following:

1) Rejection of abortion as a method of family planning

2) Family planning not as a fertility-driven program but a health intervention program

3) Access to full information as a basis for informed choice

4) Promotion of family welfare and responsible parenthood

\section{Facts on Reproductive Health (WHO Reports, 1990-1991)}

1) Over 100M sexual intercourses daily - result in:

910,000 conceptions $50 \%$ unplanned

$25 \%$ unwanted

356,000 STDs

2) 100,000 unwanted pregnancies terminated everyday by induced abortions

$1 / 3$ performed under unsafe conditions

500 deaths everyday

3) 1370 women die everyday in relation to pregnancy and childbirth

4) 25,000 infants and 14,000 children 1-4 years old die each day 
5) 300M couples do not have access to FP services

\section{Health Situation of Filipino Women:}

1) Very slow decline in maternal mortality

- $\quad$ decline from 2.1 maternal deaths per 1000 live births in 1963 to 0.8/1000 live births in 1992.

2) Maternal deaths among mothers below 20 years old and above 35 years old

- MMR highest among mothers below 15 years old: 71.7 deaths/1000 live births

3) Leading cause of maternal deaths are:

- $\quad$ hypertension complicating pregnancy and childbirth $(30.6 \%)$

- $\quad$ postpartum hemorrhage $(27.2 \%)$

- $\quad$ septic abortion (10.0\%)

- $\quad$ other related complications (25.4\%)

- $\quad$ septicemia

4) Poor maternal nutrition

- $\quad 49 \%$ of pregnant and lactating mothers deficient in essential nutrients

- $\quad$ one out of three pregnant women is deficient in iron

- $12 \%$ of pregnant women have goiter (three times higher than the national average)

5) Life expectancy

- Women live 4.4 year longer than men.

- $\quad$ For men, life expectancy improved from 60.8 years to 62.8 years (1980-1990)

- $\quad$ For females, life expectancy remained constant at 66.4

6) Survival rates

- $\quad$ Higher survival rates for females (10/1000) than males $(24 / 1000)$

- $\quad$ Same pattern among children 1-4 years old 
7) Contraception

- Contraceptive Prevalence Rate (CPR) increased from 36\% in 1988 to $40 \%$ as of the latest National Demographic Survey in 1993.

8) Causes of death among reproductive women: heart disease, tuberculosis, cancer and pregnancy-related deaths

9) STDs/AIDs

- $\quad$ No. of males with HIV is fast increasing - 206 reported cases (Aug. 1993) with 146 cases in the $15-29$ age group.

- $\quad$ Reported five offsprings got the disease from their mothers these past nine years.

- Most common mode of transmission is sexual.

\section{Reproductive Health: Background Information}

The ICPD held in Cairo in 1994 called for the following:

1. Reproductive rights and reproductive health

2. Sexual health

3. Gender equity

4. End to discrimination against women

5. Acknowledgement of the roles and responsibilities of men

\section{What is reproductive health care?}

It has been identified as:

> The constellation of methods, techniques and services that contribute to reproductive health;

> Well-being brought about by preventing and solving reproductive health problems of adolescents, marginalized groups and other displaced people;

Involves sexual health - enhancement of life and personal relations; and

> Counselling and care relative to reproductive health and STDs and other RH 
problems of diverse groups. Reproductive health problems are exacerbated by poor environmental, economic and social conditions, especially in congested slum areas.

\section{What are the dynamics of reproductive ill-health?}

The dynamics that lead to reproductive ill-health (i.e. anemia, jaundice, vaginal bleeding, painful urination, edema, etc.) are the following:

- $\quad$ low legal, social and economic status;

- $\quad$ imbalance in power relationships that limits the choices and ability of women to protect their own health; and

- $\quad$ society's indifference to the neglect and abuse of women.

\section{Determinants of Reproductive Health}

1. Socio economic conditions

- $\quad$ education

- employment

- poverty

- nutrition

- $\quad$ living conditions/environment

- $\quad$ family environment

- $\quad$ access to safe water

2. Status of women

3. Social and gender relationships

4. Traditional and legal structures

5. Lifestyles

- $\quad$ sexual behaviour

- $\quad$ reproductive behaviour

- adolescent behaviour

- alcoholism

- $\quad$ smoking

- $\quad$ drug dependence

6. Health care services

- maternal and child care

- $\quad$ family planning

- $\quad$ medical knowledge and skills 
7. Breastfeeding practice

8. Biological, cultural and psychosocial factors

9. Reproductive health research

- technology development

- operations research

- $\quad$ epidemiological research

- behavioural and social research

- $\quad$ infertility research

\section{Why Reproductive Health?}

1. Reprodutive health is a crucial component of general health and it affects everybody;

2. It has a developmental and inter-generational component (from infancy, childhood, adolescence, reproductive years and beyond reproductive years) for both men and women;

3. $\mathrm{MCH}$ approach is too narrow to meet the important socio-demographic changes over time;

4. Women are claiming their right to have their health needs as "women", not merely as mothers;

5. STDs, HIV/AIDS have increased to epidemic proportions;

6. Adolescents in growing population groups have distinctive reproductive health needs;

7. Reproductive health needs of men also need to be addressed; and

8. We should prevent unwanted pregnancies through FP.

\section{Goals of Reproductive Health}

- To have healthy sexual development and maturation, as well as the capacity for healthy, equitable and responsible relationships and sexual fulfillment;

- To achieve reproductive intentions (e.g. desired number and timing of children) safely and healthfully;

- To avoid illness/disease, injury and disability related to sexuality and reproduction; and

- To receive appropriate counselling, care and rehabilitation for diseases and conditions related to sexuality and reproduction. 


\section{Guiding Principles on Reproductive Health}

1. Human rights

2. Ethics

3. Equity

4. Quality of Care

5. Participation

6. Partnerships

7. Integration

8. Optimal use of resources

9. Sustainability

\section{How Do We Operationalize the RH Approach to the FP program?}

1. Provide mix of contraceptive choices responsive to specific circumstances of each client and setting;

2. Develop information and services targetted to men and to their roles and responsibilities;

3. Offer post-abortion counselling and FP information and services;

4. Devise strategies that serve the special needs of young people, married and unmarried;

5. Work with other sectors to develop information and guidance for all individuals and couples on how to avoid unsafe sex;

6. Develop linkages with other closely related services such as those for the management of STDs, maternity and child care; and

7. Strengthen the referral system for the management of side-effects/complications.

\section{Issues and Concerns in Reproductive Health}

1. Weak understanding of the determinants of reproductive health

2. Inadequate skills of health workers and community volunteer workers to respond to the reproductive needs of families

3. Inadequate data-based information about reproductive health needs/status and service delivery 
4. Inadequate knowledge and skills among health workers to deliver appropriate reproductive health care services including FP

5. Lack of community involvement, especially of women, in planning, implementation, monitoring and evaluation of reproductive health needs

6. Most often, leaders, especially local government executives, health personnel and implementing agencies, are not sensitive to women's issues and reproductive rights especially in the choice of when to have children, how many and the method of their choice to space/limit their reproductive activity.

7. Poor and unsafe conditions at place of work leading to injuries that affect the reproductive health of the working men and women

\section{Role of Operations Research in Assisting Program Managers to Respond to These Questions}

1. Diagnostic Studies - provide a systematic view of policies and operating procedures that characterize programs

- $\quad$ provides baseline information for further inquiries

- $\quad$ client/provider transactions, etc.

2. Feasibility Studies

- $\quad$ testing the acceptability of a new policy, approach, procedure

3. Impact Studies - can be used to link managerial decisions and client outcomes

- $\quad$ impact of policy change on preparedness

- $\quad$ impact of improved preparedness on care giving

- $\quad$ impact of different levels of care on client-level outcomes

In conclusion, I believe that the primary role of operations research (OR) is to bring scientific clarity to the management of the Reproductive Health/FP program. 


\title{
The Role of Operations Research in the LPP
}

\author{
Eireen Villa \\ Senior Technical Advisor, MSH-DOH
}

I wish to thank the OR management for allowing me to explain LPP in this workshop and to delineate the role of OR in this activity.

\section{The Local Performance Program}

The Local Performance Program (LPP) is a component of the Integrated Family Planning Maternal Health Program which is aimed at improving the health of mothers and children through family planning and selected child survival interventions. Below is an illustration of the IFPMHP framework:

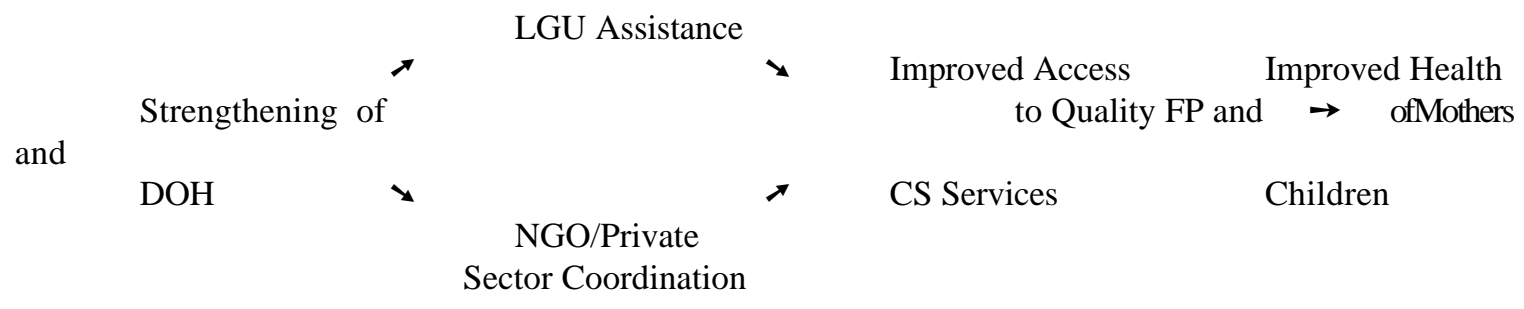

The LPP component is a response of the DOH to the devolution of health services to local government units as mandated by the Local Government Code. The implementation of the LGC brought about certain developments which call for DOH to continue to provide technical and other forms of assistance to LGUs to enable the latter to effectively manage local health programs and provide the needed services. The LPP therefore is intended to strengthen the capability of LGUs to manage and expand FP and selected child survival services. The following are the important features of the LPP:

\section{A. Results-Based Financial and Technical Assistance}

Financially, the program assists LGUs by supplementing existing funds budgeted for population, family planning and child survival programs. The funds are released through a 
performance-based mechanism: before the grant is released, LGUs have to meet annual performance goals or benchmarks that show progress, such as formulating a plan, training staff, and expanding and improving quality of FP and CS services. As the local programs grow stronger each year, the benchmarks, too, become more challenging. LGUs must achieve their benchmarks each year in order to continue receiving assistance through the LPP.

Technical assistance in the LPP starts with the orientation visits to the LGUs where the chief executives are oriented on the program, and the health and population program managers are oriented on the Situational Analysis and Inventory Guides. The subsequent conduct of planning workshops introduces the LGUs to the LPP Plan objectives and standards. Workshop participants begin to develop plans for comprehensive population, FP and child survival programs, including support for program management.

\section{B. Phasing-in of LGUs to the Program}

The program started in 1994 with 20 LGUs. In 1995, 10 LGUs were added, with another 19 LGUs in 1996. By 1999 (the last year of the program) a total of 75 LGUs shall have been covered by the LPP. LGUs (provinces and independent cities) are chosen and introduced into the performance program at the beginning of each year, based on population size and their commitment and capacity to implement population, FP and child survival programs.

\section{The Role of Operations Research in LPP}

I would like to discuss OR's role in the LPP. As previously mentioned, operations research is one of the areas for technical assistance to LGUs. Because it focuses on the dayto-day activities or operations, OR becomes an important tool for local health managers to strengthen local decision-making and improve management and provision of local health services. OR can help local managers identify and define the parameters of operational problems, field-test local interventions and measure the impact of these interventions. So far, there have been very few attempts to define operational problems at the local level and to develop LGU-specific interventions. While problems vary from one LGU to another, below are some common issues that would greatly benefit from OR: 
A. Planning. In the LPP, the LGUs are assisted to come up with a comprehensive plan responsive to their priorities and needs. OR is in the heart of developing this plan as the LGUs assess their situation, evaluate their performance and identify interventions to improve and address gaps/issues in their programs. Equipping the LGU program managers with an OR perspective will make a lot of difference on how they would analyze, review and use data and information for identifying and setting objectives, planning activities and designing appropriate interventions to be implemented. OR would be most useful as the LGUs look into the various facets of their operations such as the management of logistics, carrying out IEC activities, conducting program monitoring and technical supervision, training, and operationalizing their service delivery system. One specific area of concern during the plan development is the degree of local consultation done with the devolved units and other sectors. There have been attempts to involve municipal health officers in local consultation workshops but there may be other more effective mechanisms of ensuring inputs from the devolved units and the other sectors in the formulation of the provincial health plan.

B. IEC. Current attempts to help LGUs develop and implement IEC activities would require a very well-thought-of analysis of seemingly IEC-related problems. OR would play a vital role in identifying the causes and roots of these problems as they affect knowledge and behavior of the target clientele. A specific concern regarding IEC is the need to assess how IEC print materials are disseminated and utilized at the local level and to what extent these are making an impact on the behavior change of the clients. Other questions being asked are how the LGUs should develop their IEC strategies and what measures there are to evaluate the effectiveness of local IEC activities.

C. Quality of Care. The concern on ensuring that the services are not only expanded but are also delivered according to accepted standards raises some important questions. Ensuring quality of care is a very critical area where OR could contribute substantially by providing assessment tools on QoC and teaching the LGU program managers on what to look for as they assess the quality of their services. A specific area of concern is non-adherence to protocol despite the training provided. In addition, concerns as to the acceptable minimum performance standards for FP and reproductive health and how these standards should be effectively introduced, promoted and monitored at the LGU level could be areas for OR. 
D. Development of Urban-Focused Strategies. Considering that more than $50 \%$ of the population is now located in urban areas, there is a need to develop strategies directed towards urban work for FP and CS services. The strategy should answer questions like: What is the appropriate public and private sector mix for FP and CS services in urban areas? Assuming that NGOs and the commercial sector have a market niche, particularly in urban areas, how should the marketing of NGO services be addressed?

E. MIS. Since information systems serve as the primary source of information for local managers and the fact that FHSIS as currently structured is intended primarily to address DOH information requirements, there may be a need to develop information systems at the local level serving the needs of local managers. Questions on how that system would be structured and implemented can be a very important area of concern for OR.

F. Clarifying LGU-LGU Relationships. In most LPP-participating LGUs, the link and relationship between the provincial and the devolved municipalities have been affected by the devolution. OR can provide answers to questions like, how should the provincial health staff continue to provide support to the rural/city health units? What are ways to improve accountability at the local level for health services in a devolved setting? How should local health boards support local health services?

G. Operationalizing Integration Services. While there has been a lot of talk and considerable effort to promote the concept of integration, little attention has been paid on how this can be done at the service delivery level. It may be true that integration is not difficult at the service delivery level since it is the midwife who delivers most of the services, but still there are data that show this is not happening. More OR work needs to be done in terms of promoting and operationalizing the integration of FP and CS services.

H. Community Involvement. Successful FP and Child Survival programs depend a lot on the involvement and support of the communities. There have been a number of successful initiatives in selected areas, and OR may be the entry point for identifying ways on how these could be expanded and adopted by other LGUs. Other concerns which OR could provide response to would be on identifying which forms of community participation are effective. In particular, a good topic could be about preferring FP-specific volunteers over multi- 
purpose health volunteers.

I. Training. Training of health workers is a very important component of local health programs. While under the IFPMHP, a new competency-based curriculum is expected to address the problem of the extremely long duration of FP training courses. There are other training issues that need to be addressed, such as finding the appropriate structure for the LGUs' training function, effective ways of minimizing formal refresher courses but at the same time ensuring that health workers are continuously updated.

\section{Opportunities in the LPP to Support the Promotion of Operations Research}

OR definitely has a major role to play in the successful implementation of the LPP. Complementary to this, the LPP, by its features, also offers a lot of opportunities in promoting and supporting OR-related efforts.

A. Availability of Financial Assistance. Through the LPP grant, the LGUs will have resources to undertake and support OR-related initiatives.

B. Availability of Technical Assistance. Under the LPP, a cooperating agency is in place to provide technical advice/assistance to the LGUs. A number of tools have also been developed for the ready reference of interested LGUs.

C. Planning Activity. The LPP relies heavily on the development of comprehensive plans. There is always opportunity for promoting and enhancing use of OR especially during the assessment of the situation and the status of the program. This also serves as a forum for rationalizing the need to do OR as well as in identifying and pooling resources from other projects of assistance to OR efforts.

D. Focus on Performance and Results. Considering that the LPP emphasizes performance, this necessitates the identification of problems and development of interventions to address these operational concerns.

E. Focus on Local Decision-Making. As the LPP is anchored on one of the basic tenets of the Local Government Code which emphasizes local control over the management of LGU services, the importance of data-based decision-making is brought to the fore. 
F. Wide Range of Technical Assistance Areas. Since OR cuts across other areas of technical assistance such as IEC, training, MIS, logistics management, quality of care, and planning, the application of these various types of assistance needs to be defined and evaluated. As such, OR becomes a necessary companion to the other forms of technical assistance to LGUs.

G. Benchmark Disbursement Scheme. Since the LPP operates on a performance benchmark disbursement scheme, initiatives and efforts on OR will be fully supported and implemented by the LGUs once they become an inherent part of the benchmarks. 


\section{OPEN FORUM}

Ms. Cecille Tuazon, Capiz: You have mentioned that one of the problems of the service providers is inadequate knowledge and commitment to deliver services for the family planning program. In our case, we have already increased the knowledge and skills of our service providers through training. The problem is the religious beliefs of the personnel. Their religious conscience prevent them from properly providing family planning services. How do we deal with this situation?

Dr. Jocelyn Ilagan, DOH-FPS: Let me make it clear that one of the policies of the Family Planning Service is to respect individual rights, as well as religious and even traditional beliefs or culture. Instead of trying to change the attitude of personnel, perhaps we could give and disseminate information to our potential clientele. We should give them the necessary information on the different FP methods, including both natural and artificial methods of family planning. The clients or possible clients would already have the information at their fingertips. Then they would not need to rely so much on the service providers. Counseling is still very important, however.

Dr. Editha Abocejo, DOH-Region X: Actually, we have a similar problem in Region 10. When we have program implementors who are Catholics and who do not provide the service, we hold consultative meetings to remind ourselves of the objectives and goals of the program. We talk about our commitment as health providers. We emphasize that family planning is not only about contraceptives. If providers refuse to provide the contraceptives then they should at least refer the clients to other service providers. They can also inform the clients to use other methods such as natural family planning. Even rhythm can be taught if it would work for the client. The service providers should find ways to provide the necessary services. 
Dr. Marilou Costello, PopCouncil: My question is how common is this among the providers? Are there really that many providers who hesitate to provide services because of religious reasons? I don't know of any research at all that has looked into the FP attitudes of providers here in the Philippines and how these may affect their delivery of family planning services given that they recognize their Church's position on this issue. The other intriguing thing to me is that, if we look at a review of research findings, religion really does not seem to come in as a reason for use (or non-use) of family planning. So maybe the importance of this issue has been overemphasized. I think we should continue to discuss these questions because they are important ones for our country.

Dr. Fely David, SSRI: I would like to add something to that. I discovered two things in my last research. First, in one of the experimental areas, the nurse wouldn't go to the clinic if it is the IUD insertion period; and second, in a district in Iloilo, everytime a person comes in for ligation, the district hospital director would require a patient to bring with her a parish priest clearance. We have reported this to the DOH and I don't know what happened to this. This was an actual case. When UNFPA people attended our FGD, this mother who wanted ligation reported it and said "I wanted service but I was refused service." She did not have P3,500 to give to the private doctor to whom she was referred. This may not be the case in all LGUs. Probably in the twelve LGUs represented here, this may be true in one or two. It is true, by the way, that research indicates that there is no direct relationship between religion and family planning practice. After all, most of our users are Roman Catholics.

Ms. Eireen Villa, DOH-MSH: In one of our Technical Working Group meetings, we agreed that religion doesn't have anything to do with the practice of family planning. Yet you still hear anecdotal reports about service providers being "pressured" by the Catholic Church. But there is no documentation to show how prevalent this is. That is the first thing that we should really look into. When we had this consultative 
meeting on IEC in Cebu, some providers said that they were pressured and that the Catholic Church was very powerful. However we also saw that there are some tendencies to exaggerate actual figures. The workshop right now is on operations research. It is really on how you address your problem at the LGU level. For Capiz, you have been given the chance to come up with your IEC plan, right? Maybe IEC intervention won't be enough. Do we need to do some training? The purpose of this workshop is to help you develop that kind of perspective: how to look at your problems and take them into consideration during your planning. It is supposed to help you to develop an OR perspective on how to address your problems at the local level.

Dr. Filemon Flores, Negros Oriental: Sometime ago, the Population Commission Regional Director went to Dumaguete. He presented the population and development program, which was not focused on family planning alone. We invited her in one meeting of the Rotary Club where a Monsignor is a member, and he was so impressed with the presentation of Director Portel. He asked for materials on the population and development program. Included there were materials on family planning strategies, but more really on population and development. I think this strategy is a good one.

Ms. Emma Castel, Bacolod: I would like to address my question to Dr. Ilagan of DOH. You spoke earlier about improved maternal and child health service. My question is on TT immunization. There are changes in the EPI guidelines that created confusion among health personnel, causing our low performance in TT immunization. How can you help us on this? We find it hard to regain the confidence of our clients regarding TT immunization.

Dr. Jocelyn Ilagan, DOH-MCH: What I could do at this time is to raise your concern to the DOH Maternal and Child Health Services. For clarification of the guidelines on EPI services, perhaps we could distribute the information to the participants. 
Ms. Emma Castel, Bacolod: Thank you. In our previous Polio Eradication Program, TT immunization was included, and we immunized those who were 16 years old and above. We were very surprised that during the 1995 "Knock-Out Polio Immunization" they were no longer included because of the restraining order. Also, other religions say that the immunization causes sterility and abortion.

Ms. Flordeliza Dublas, Negros Oriental: One of the big issues confronting us in the field implementation of the family planning program is the management of complications. Recently we received a circular telling us that there are available funds for the management of complications. How soon can we avail ourselves of the funds? We have made a request during our planning sessions that funds be readily available right at the Provincial Health Office where it can be used right away if clients are confronted with these problems.

Ms. Eireen Villa, DOH-MSH: I can not answer for the DOH on funds for complications. I am not aware of that. The DOH-FPS was giving assistance before; they would course it through the Regional Health Offices through sub-allotment. If the same thing happens now, the mechanism of how the LGUs will access that sub-allotment at the regional level is something to be worked out with the region because you are now devolved. The region can not give directly to the province unless you have the MOA, etc. Maybe Drs. Abocejo and Ilagan can follow that up. The reason I am speaking up right now is because I want you to know that LPP funds can be budgeted for managing complications. While you are doing your plans right now, and if that is a priority need in your $L G U$, then you put that in. We always tell the LGUs that they just don't budget for that alone; instead, they have to consult the hospitals, COA and their accounting department on how they can fund the management of complications of patients. We always emphasize during planning to think in advance how we shall operationalize this issue. This is really a challenge to the LGUs because the national office wouldn't be able to help you on that. 
Session I:

Introduction to Operations Research 


\title{
Operations Research as a Tool for Program Managers
}

\author{
Marilou Palabrica-Costello, Ph.D. \\ The Population Council, Manila
}

In my discussion this morning I would like to remind everyone that we have two main types of participants in this audience. Some of you are program managers; others are researchers from the academe. This means that we have people here today with varied experience as far as the conduct and use of research is concerned as well as in the collaboration with other agencies beyond their own work setting.

This situation is important to bear in mind because it will this shape the contours of our discussion of operations research (OR).

My discussion this morning will go through a brief definition of OR and also the focus and objectives of operations research. I will then discuss some of the categories of studies that can be used in operations research and give you a brief overview of the methods and designs that are used in OR.

\section{Definition}

$\mathrm{OR}$ is a term we have heard for a long time. It is sometimes referred to as programmatic research. I will return to this reference to the "program" later on, but a good way to introduce OR is to go back to the distinction between basic and applied research. Whereas basic research is carried on for its own sake (basically to add to our store of knowledge), the latter, as its name suggests, is conducted for practical reasons--to produce findings that are applicable, practical, and immediately useful.

Question: Can we say that only applied research studies are practical and useful types of research? No. We must emphasize that these two types are not opposed to each other, nor are they mutually exclusive. According to Kidder et al., "Research on practical problems may lead to the discovery of basic principles and 'basic' research often yields information that has immediate practical applications. [The audience was then requested to give some examples of this.] 
To go back to the definition, OR is a form of applied research: it is research that is directed towards solving program problems. According to the OR handbook you can view OR in two ways: first, as "a primary means for supporting the essential planning, coordinating, training and evaluating functions of health and family planning programs", and, secondly, as "a process, a way of identifying and solving program problems." (Fisher, et $\underline{\text { al., }}$ p.1). These two quotations suggest that $\mathrm{OR}$ is both a problem-oriented activity and a "process" as opposed to a "one-shot" activity.

Other implications: The title of my talk refers to "OR as a tool for program managers" and this is very much true. Always remember that OR has been designed primarily for the purpose of helping the program manager come up with concrete answers to practical problems related to his/her program. It is "decision-making research."

You often hear government planners and program directors complain that research studies take too long to complete, so that, by the time the results are made available (or the study has been completed), the need for the information is no longer there. The research has been overtaken by events. This is why OR results must not only be relevant but also timely. In many cases OR activities should be completed within five to six months.

There is also a perception that OR is a "quick and dirty" kind of research. Since it is usually finished in a short span of time, people perceive it as not very "scientific". This, of course, is very incorrect. As you will see in later discussions, the types of design and methodology used in OR are no different from those used in any other kind of research. Conceptual and methodological rigor should never be sacrificed in an OR study.

Characterizing OR as a "problem-solving tool" has a number of implications:

1. The focus on the practical, day-to-day issues means that the program manager is ultimately in charge. It is his/her questions which must be answered.

2. The emphasis on timely results means that when the design calls for a longer timetable, there must be constant feedbacking to program managers during the course of the study itself.

3. Findings must be worded in easy to understand language accessible to nonspecialists. This enhances utilization of OR results. 
The first step in OR is problem identification and diagnosis. What are the problems of the program? Once the problem has been identified, we need to study and select approaches to try to solve the problem. The third step is simply to experiment, to try to test out one of these strategies, to see if in fact it does solve the problem. The fourth step is the dissemination of information - the lessons learned from the study. In other words, getting that information out to program managers. The final and in many ways most step is the utilization of information to make programmatic decisions and to improve the program. This is the ultimate test of a successful OR.

Implicit in all these steps is a close collaboration between the researcher and the program manager. Results are better utilized if there is a sense of ownership of the research by the program managers. The problem of relevance is addressed if program managers define the problem.

OR requires new perspectives for both the researchers and program managers.

For managers, they will no longer have to rely on hunches or the trial-and-error approach. They will have to think in terms of "the OR cycle" to improve their programs. They will have to systematically diagnose problems, identify solutions, test and evaluate a particular approach and then use the information to improve the program.

For researchers, they must learn to work in partnership with the program manager. This means focusing on the manager's concerns.

\section{Focus}

Because of its pragmatic orientation, OR takes a special focus. It cannot focus on all types of problems faced by the program, but only those which are under the control of the program manager.

Managers have several program components at their disposal:

(1) Training. For example, a study in Thailand analyzed a re-training program for village health workers designed to improve their outreach skills. A significant rise in their efficiency resulted. Immunization rates went up, women went to the clinics more often, etc. This exemplifies "re-training to produce a change." 
(2) Logistics. Logistics is getting the supplies out to different parts of the country. Now that we have devolution, there may be a problem when it comes to the distribution of commodities within LGUs. What can be done to improve this?

(3) IEC. Will our IEC campaigns actually have an impact? Do they lead to greater acceptability of services?-- and so forth.

(4) Service delivery. Are services being delivered competently? Are the needs of the client being addressed fully? Are the providers friendly? Are there enough choices of methods? Etc.

(5) Outreach. This is a very important component of the program, especially in a developing country. What is the effect of incentives on performance? How do we use outreach to motivate "high risk" groups?

(6) Supervision. For example, would heightened supervision increase the efficiency of barangay health workers or other program personnel?

(7) Management information system. We often collect information that is totally unusable. So we might need to change the information system or assess what information is really important to make a decision. We thus need to know the way in which program managers use the current MIS. An evaluation study of a new MIS might also be advisable.

So, these are the major areas that program managers have at their disposal to manipulate and to produce the result that they want. In other words, the emphasis is on increasing the availability of services, increasing the acceptability of services, and motivating providers to provide the services well. It might be good to bring up here the distinction between the supply and demand sides of family planning. The demand side (the clientele) is largely outside the control of the manager. The supply side (within the program) is therefore a better way to go for OR.

\section{Categories of OR Studies}

In thinking about OR, it may help to remember that there are three types of operations research studies, although these are not necessarily mutually exclusive. 
Diagnostic studies are often undertaken as a first-stage effort -- in order to define the problem more clearly. The handbook says: "These studies seek to determine the parameters of a problem situation affecting service delivery." This is very similar to an exploratory study where the nature of the problem is not fully understood. The key aspect here is the search for relevant program variables, so that, when these are manipulated, an improvement in service availability and acceptability is effected.

One example is the problem of continuation that was observed among DMPA users. FGDs of drop-outs and service providers were conducted and the results showed that side effects were the main reasons behind the clients' dropping out--either they were not warned about these or they were not given assistance once they asked for help. The service providers said they didn't know what to do or what to say to clients. They felt ill-prepared. These results suggest the need for an effort to deal with the side effects issue.

For example, we could improve counselling, train providers to inform clients of possible side effects, do this in a non-threatening way, use informed consent, develop good IEC materials to serve as reference for clients, etc.

Now if we want to assess the impact of a program to implement one of these strategies to bring down discontinuation rates, this could constitute your intervention study. So it is something like an experiment. We now know the variables to be manipulated but the intervention should to be tested for its efficiency and cost-effectiveness.

The third category, evaluative studies, are usually carried out after the intervention has been in place for some time. Unfortunately, very few programs are planned with an evaluation component. Very often we implement an intervention and then one or two years later we are asked, what impact did this program have? Unless you have anticipated and laid the groundwork for evaluation in the beginning it will be difficult to answer this question.

\section{Methods and Designs}

While a diagnostic study usually calls for a cross-sectional or retrospective design, the intervention and evaluative studies almost by definition have to be longitudinal. 
I will not really discuss the different methods of data collection here. Suffice it to say that we make a distinction between qualitative and quantitative data collections. Each has its own strengths and its own share of weaknesses. Whatever method is appropriate depends on the nature and objectives of the particular study. So also with decisions about data analysis. The decision to use, for example, multivariate statistical models should be based on the type of study being conducted, its overall goals, and the nature of the study problem, as defined originally by the program managers. 


\title{
Factors Affecting the Family Planning Program Drop-Out Rate in Bukidnon
}

\author{
Prof. Lita P. Sealza \\ RIMCU, Xavier University
}

\begin{abstract}
Background. This study involved interviews with a randomly selected sample of 389 family planning (FP) acceptors from 20 barangays in Bukidnon province. The respondents were currently married women who had either continued to use family planning since their initial acceptance (current users) or who had stopped using FP altogether (drop-outs). Findings from the present study may be expected to shed light on several aspects of the dropout problem, namely:
\end{abstract}

1. How extensive is this problem and how accurate are the DOH records in this regard?

2. How do FP acceptors view their local FP clinic and the services offered therein?

3. What reasons are given by the drop-outs for their decision to stop using FP?

4. What are the factors associated with dropping out?

The Extent of the Drop-out Problem. The study found that 30.8 percent of the women who had adopted FP at some time in 1992 dropped out of the program as of the survey date (September to October, 1993). This is somewhat lower than the 60 percent dropout rate which had earlier been reported for Bukidnon and may therefore indicate that the dropping-out phenomenon has become somewhat less pervasive in that province.

Views and Experiences Regarding the Local FP Clinic. As FP acceptors, the respondents were in a good position to assess their local program. In all, only 9 percent said that they were dissatisfied with their visits to the clinic. Another 53 percent said they were "satisfied" while 38 percent claimed to be "very satisfied." Clients who were "dissatisfied" reported nonavailability of supplies as their reason. A few respondents also tended to be critical of the local midwife for various reasons. 
A little less than ten percent of the respondents had never been given any lecture about FP. Another 61 percent had received a lecture about only one method. These statistics do not show that FP clients were being given a wide variety of choices.

Most respondents (83 percent) felt that their FP trainor was "friendly and approachable." They also gave favorable assessments with regard to the trainors' ability to clearly explain the method, to show how to use it, and to explain its advantages. There was, however, less agreement with the idea that the trainors dealt adequately with the method's disadvantages and potential side effects.

Exposure to IEC materials on FP was relatively high (only 24 percent said they had never been exposed to FP materials). Home visits by FP providers, however, were rare, with 76 percent of the respondents not experiencing these.

Respondents gave several suggestions on ways by which the program could be improved. The two most commonly cited themes were that, first, the clinic should have a permanent supply of contraceptives on hand and, second, that there is a need for an intensive FP information campaign (e.g. seminars, house-to-house visits). In line with this latter idea it was also suggested that FP acceptors could be mobilized to recruit more clients and that midwives and outreach workers should follow up the acceptors and monitor their progress.

Reasons for Dropping Out. More than half of all drop-outs said that they stopped using FP because of side effects. This response was particularly common among those who were using contraceptive pills.

Other reasons given were less common. These included the desire to have another child (5.0 percent), objections on the part of the husband (5.0 percent), poor health status (4.2 percent) and "too old now" (3.3 percent).

Factors Related to Dropping Out. These can be subdivided into factors which relate to (1) the individual acceptor, (2) the method accepted and (3) the quality of services provided by the local clinic. 
Client Factors. When drop-outs were compared to current users they were found to be significantly more likely to possess the following characteristics:

1. A lower level of educational attainment

2. A lower rating on a scale of household economic status (ownership of consumer items)

3. A smaller likelihood of having been employed during the past year

4. A greater number of previous pregnancies

5. Less favorable attitudes toward FP

For the attitudinal factor it is interesting to note that the attitudes of the husband were a better predictor of current use than those held by the respondent herself.

Various other factors (e.g. age, religion, ethnicity) were not found to be significantly related to current user status.

FP Method. Dropping out was highest among respondents who had accepted condoms (37.8 percent), followed by pill users (with a 34.3 percent drop-out rate) and IUD acceptors (every one of whom was still using some FP method as of the survey date). It is also interesting to note that the clients who were expected to return to the clinic every month for a new supply of contraceptives were less likely to stay with the program than were those who were required to return on a less frequent basis.

Program Factors. In general, provision of improved services ("quality of care") was found to be associated with lower levels of dropping out. Among those respondents who said that their FP trainor was "friendly and approachable", drop-out rates were significantly lower than for those who did not feel that way. Similarly, those who reported themselves as "satisfied" or "very satisfied" with local services were found to be less likely to drop out. A summary index of client-provider interaction was formed from various items. Current users gave significantly higher scores to their trainors on this scale than did the drop outs. Particularly important in this regard was the experience of having been told the advantages of the method in question (thereby strengthening client motivation for continued use) and its potential side effects (thereby helping the client to become less alarmed about these 
experiences when they did happen). Clients who were only given an orientation on one method were found to be less likely to continue using FP than those exposed to a wider variety of choices.

Interviews with FP Service Providers. Service providers were found to be well experienced. A good number of them had both theoretical and practical training in providing contraceptive pills and condoms. However, only 40 percent had been trained for IUD insertion and removal.

Facilities and Services in the Health Clinics. Most clinics observed the official opening time. The number of days alloted for family planning was not uniform. While some have FP service for five days, others offer this on only one day. Infrastructure facilities of the clinics were far from ideal. Eleven SDPs, for example, did not have piped running water at the time of the visit.

IEC materials were found to be available in almost all clinics. Most clinics were clean. Storage facilities for contraceptives were generally found to be adequate.

Visits by supervisors were not regular in some clinics. Services in all 20 clinics were provided free, although some would at times ask for a minimal donation.

Health Provider-Client Interaction. Most health providers were observed to be friendly and approachable. Discussion of possible side effects was, however, rarely carried out during the consultation. This supported the earlier contention of the clients concerning the infrequent discussion of side effects.

It was observed that in some consultations, some methods (e..g., IUD and condom) were overemphasized to the exclusion of others.

Program Implications. Some of the major implications of the study for the current FP program are:

1. The FP drop-out phenomenon continues to be pervasive in Bukidnon, although levels are perhaps not quite as high as is sometimes believed. The major problem in this regard appears to be the widespread belief that the various FP methods (especially pills) cause side effects. 
2. Some programmatic weaknesses were also uncovered, however. Acceptors were generally not given an orientation on a wide variety of FP methods. Discussions of the side effects issue were often missing. Home visits by program personnel were rare.

3. Respondents gave several suggestions for improving the program, focusing in particular upon improvements in the logistics system and a more intensive educational/motivational campaign.

4. The drop-out problem appears to be most prevalent among poorer and less educated women, housewives (i.e. those not gainfully employed), those with many previous pregnacies and with less favorable attitudes toward FP. Strengthened efforts to reach out to these groups will be needed.

5. Campaigns to bring about more favorable opinions toward FP should focus on husbands as well as on the wives.

6. Increased use of IUD should help bring about a decline in the drop-out rate. However, efforts to convince more women to use this method should not run counter to the goal of free and informed choice of method by the client.

7. Greater emphasis on high quality FP services (quality of care) will help reduce FP drop-out rates. Providers should be competent and friendly and concerned as well with fulfilling client expectations. They should offer a wider variety of FP choices, bringing out in a clear and objective fashion the advantages, disadvantages, and possible side effects of each method.

8. Some FP clinics are not well equipped. An effort to upgrade these facilities will help improve the delivery of services.

9. Some FP service providers have not yet been trained. For example, most are not yet prepared to provide IUD insertion and removal services. Training efforts should therefore be expanded. 


\title{
An Analysis of FP Drop-Outs in Bukidnon
}

\author{
Dr. Editha Abocejo \\ DOH-Region $X$
}

The UNFPA project in Region X started in 1992. We began by training trainers from the provinces. To ensure that they followed the protocol on how to conduct the basic comprehensive training and that the trainers truly followed the standard operating procedures for family planning, the regional people in charge of FP had to be present during the provincial trainings. We did this so that once the trainings were over, we would be able to discuss what was missed. There was a need to do so because most of the trainings did not provide enough information about the wide range of contraceptives, their advantages, disadvantages, side effects and complications. Lita's study has already given us a hint about this because the service providers are not always giving this information to the clients.

We also trained the service providers. We based the selection of the providers on a certain set of criteria, with those who had large population coverages given priority. Another group which we prioritized was composed of those who were far away and who were handling maternal death cases.

One difficulty that arose involved the provision of supplies. We are very happy now that all the facilities in the region, not only in Bukidnon, already have one month's supply of contraceptives. Although there are a few, about 5\%, which don't have this, this doesn't pose a major problem as they can always resort to emergency orders. This will be made even easier now with the LPP benchmarks.

Another important thing we did was to identify the need for groundworking as far as these family planning and $\mathrm{MCH}$ programs were concerned. If you look at the devolution atmosphere, especially at that of our midwives and nurses, you will see that the midwives are unable to handle the job loads. One midwife would be in charge of handling 3-5 barangays. These midwives have such difficulty going to their barangays because they lack funding support for travel. One of the effects of this is the lack of follow-up of dropouts. To reverse this, last year, we began to revitalize the previous outreach program of POPCOM by 
establishing the so-called barangay FP coordinators. Bukidnon has already identified the FP coordinators and POPCOM has agreed to spearhead the training.

Another function of the FP coordinator would be that of a re-supplier. Even before the revision of the CDLMIS, the region had already started the dispense-to-user record. This time we will have the FP coordinators link with the DTUR. The coordinators and volunteers will now dispense contraceptives to the clients in their barangay. We introduced this practice because one past problem was that they could not go to the area to get their supplies. In addition, Lita's study showed that women who have to keep going back to the clinic were likely to eventually drop out.

The FP coordinator is expected to be in charge of following up dropouts, referral and counseling. Many women wish to have ligation but don't have anyone to accompany them, so the coordinator may go with these women. We will also train our coordinators on how to educate people during the purok household classes. They play many other important roles as well.

One thing I would like to do would be to address the major concerns of the region. Aside from the problem of the dropout rate, we need to raise the level of the voluntary surgical contraception (VSC) performance. Women who have had complications and therefore are at a greater risk should be the priority for the program. We also have to address the reproductive health cases and the NFP need of the LGUs. Thank you very much. 


\title{
Situation Analysis in India
}

\author{
Dr. Saumya Ramarao \\ The Population Council, New Delhi
}

I am happy to be with you today. What I would like to do now is to share with you the process by which we did a diagnostic study in India, called the situation analysis. The reports on this have been written and I've brought a few copies with me so I'll leave them with Jovy and Jackie at the last table so you can have a look. Since I've got only five copies, I request that you share them among yourselves.

To give you a kind of background on the study that I am presenting, I would like to refer to what Irene was saying earlier this afternoon, about the Philippines having a major USAID project. We also have a big project in India: it is a 300 million-dollar project spread over ten years and the focus is in one major state in India, Uttar Pradesh, which has a population of more than two times that of the Philippines. The population is about 145 million and it has one of the lowest CPR levels in India, so there is a special initiative that is being started to improve the quality of services, to improve the contraceptive prevalence rate, to reduce fertility, and so forth. These are the major objectives of this ten-year program. The Population Council is one of the agencies that is working under this project.

When this project was started in 1992, the most common reasons as to why the CPR levels were low were the same kind of reasons that we've been hearing all day today: the workers don't work, they are not trained, we have problems with Uttar Pradesh, the doctors are not able to go on field visits, workers are not able to go on field visits, we don't have contraceptive supplies, the monsoons have washed away the roads, etc. We can see, therefore, that there is a whole range of reasons why contraceptive levels are low. All these reasons are valid, but they may not be valid in all the cases, all the time. In order to understand which of these reasons are more important, and to be able to prioritize the steps that program managers can take to resolve the particular situation, a situation analysis was undertaken. 
Before going further, let me just define what I mean by situation analysis in this presentation today. Situation analysis measures the readiness of the public sector system to deliver services. In this analysis, you visit service delivery points, which, in the Philippine context, would be, the RHUs, or your barangay health station. What you do is that you go to these centers, and you find out their readiness to provide services. You also identify the services that are being provided, the personnel, whether they have been trained, what their level of knowledge on various aspects of service delivery is, what sort of information they are providing to clients, etc. You also go to clients and you find out whether they were really told about these things. In other words, you match the responses given by the service provider and that of the clients. Based on this information, you get to know the capability of your service delivery points to provide services.

When this big USAID project started, not much was known about the situation in the public sector. The situation analysis therefore had four main objectives. The first was to measure public sector service infrastructure and support capacity. The second was to measure the elements of quality of care in the public health sector. The third objective was to assess the availability of contraceptives through village health practitioners (VHPs), retail outlets and NGOs. We were not just concentrating on the public sector. We also wanted to know if a person in a particular village wanted to access contraception and whether people were able to access contraception, either through the public or the private sector. The fourth objective was to assess the involvement of the VHPs in providing MCH/FP services. By this, I mean to say, that in India (as I'm sure in the Philippines also) we have a number of doctors who are trained in the indigenous system of medicine. These doctors are usually the first level of care that is available in a village and so the idea was to tap them for providing $\mathrm{MCH}$ and family planning services.

To meet these four objectives, we used nine data-collection instruments. Respondents included various types of health personnel: doctors, nurses, midwives, and their supervisors. Other respondents included users of family planning, shopkeepers, and VHPs. This survey was conducted in two districts in Uttar Pradesh, each district having a population of 3-4 million. The number of primary heath centers covered was roughly about 20 in each district, the sub-centers covered were about a hundred, the villages covered were about 200. More than 800 shopkeepers were interviewed while the number of VHPs was about 150. More than 1,200 FP clients were interviewed. The survey was done last year, during the months 
of April to June. What I'll do now is to present to you the results from one particular district studied in this survey. I've also decided to limit myself to certain important variables, those which I think are of interest.

One of the objectives would be to find out what is the access to contraceptives. We are talking about the types of contraceptives available in the private sector.

What we found out was that only about a fifth to a quarter of the villages had a trained birth attendant, 25\% had VHPs, and a third also had shops selling condoms. In terms of the public sector services, the primary health centers provide sterilization, vasectomy for men, tubectomy, laparoscopy, minilap for women, IUD insertion, abortion, and STD/RTI testing.

These are the immediate concerns of how a service is provided. For instance, if you look at the data for IUD insertion, you'll find that over three-quarters of the primary health centers covered did provide IUD insertion service, and in $82 \%$ they had trained staff and the equipment was available. This was one important finding that came out from this situation analysis. We than looked at what happens with IUD insertion services at the sub-center level. We found that in $82 \%$ of these centers, the working equipment needed to perform these services was avalable in only $37 \%$ of the sub-centers.

The question is, therefore, how is the nurse/midwife providing the service? There were two explanations for this discrepancy: one, that the auxiliary nurse/midwife (ANM) was, in truth, rarely providing the service, and simply claiming that she was, and the second, was that some actually do provide the service, and just borrow equipment from other centers, or they wait for their supervisors to bring equipment and then they provide the service.

I have also mentioned that situation analysis also looks at the infrastructure available at the health centers. You cannot provide good quality services if the infrastructure is not available. What we found at the sub-centers was that most of them were one-room centers. There is little or no privacy to speak of, as all the services are done in one room: counseling, examination, etc.. In addition to this, the sub-centers were usually located in rented buildings, which usually meant that it was a room in somebody else's home. As a result, the family members would walk in and out while the clients were being examined by the nurse/midwife. 
Only $40 \%$ had a waiting area for the clients which was protected from the sun and the rain; drinking water was available in only $22 \%$ of these sub-centers; and only $7 \%$ were electrified. It becomes very difficult to provide the services for IUD insertion if the only source of light is natural light. Looking at the grim data, I suppose by now you will be very thankful that you work in the Philippines, and not in India!

Let's now look at the kind of the equipment that is available at the sub-centers. The most commonly available equipment were needles and syringes, so in over $90 \%$ of the subcenters, the nurse/midwife could give injections. There was a thermometer in three-quarters of the centers, but there were no sterilizers available in more than $80 \%$, so there were no autoclaves. These were the immediate types of problems that turned up.

We also looked at some elements of quality of care. To do this, we wanted to find out the level of technical competency of the various levels of providers. We asked both the nurses/midwives and doctors questions on the oral pill, and surprisingly ( although I hesitate to say this in this gathering of doctors) the nurses and midwives performed much better than the doctors! Primarily, this was because the doctors were not the ones who were prescribing the pills.

We asked similar questions to gauge the level of knowledge about the IUD and sterilization. [Dr. Ramarao then reviewed some of the findings from their study on this.]

When we talk about promotional activities that should be carried out, the first thing that we need to look at is the kind of IEC materials that were used at the various service delivery points (SDP), both primary health centers and sub-centers. The transparency shows you the data which compares the sub-centers and the primary health centers. One obvious fact was that any type of IEC material tended to be concentrated at the primary health centers and very little went to the sub-centers. In terms of materials, the only material that was generally available was the poster. In terms of messages, there were very few that dealt with family planning, as most dealt with subjects such as breast-feeding, nutrition, etc.

One of the main uses of the SA was the replication of this study in other centers and over the district and the entire state. In fact, they wanted us to do a similar analysis which covered the entire state. 
The study helped us to identify and remove several bottlenecks, especially those regarding the distribution of equipment from the state level to the health centers. Once these were removed, the flow of supplies was easier.

What I've presented here today is one way of looking at a system of providing better quality services. We looked at the service delivery points, we looked at the particular health centers to say what their capacity to provide services was. This may not, however, be the only way of looking at how to provide better quality services. There are several others. Let me give you an example: you can look at the system of health service delivery. Under this system, there are several sub-systems. First, personnel: how are the personnel being selected? How are they being trained? How are they being supervised? Who supervises whom and what type of supervision should it be? You could also study the logistics system, or the MIS, or the IEC, etc. The examples are unlimited. 


\title{
Using Male Motivators to Reach Men
}

\author{
Dr. Fely David \\ Central Philippine University, Iloilo City
}

Let me begin my talk by tracing the history behind the implementation of this OR. In 1993, the Department of Health was working with Save the Children. This is an NGO which a big program in Iloilo, covering Guimaras and some areas in the Iloilo province. They were having problems with their FP program because they noted that the CPR was quite low in the province of Iloilo and Iloilo City. In fact, at that time, it was about 25\%. They had a series of consultations on this and also undertook a review of literature. Susan Dawson from Australia volunteered to do this review of related literature and to search for possible interventions which could improve the CPR. In her review, she said that a lot of studies conducted in Nepal, Pakistan, and other places used male motivators as participants in the FP programs, and suggested that we should try it in the Philippines.

Susan also thought about doing OR to address this problem, particularly since previous research seemed to show that, in the Philippines, decisionmaking and family planning is largely influenced by the men. Because of this, they said that it would probably be good to involve the men in the family planning program. Consequently, the intervention study involving male motivators in Iloilo province was born. The program was eventually implemented in 1994. After one year of consultation and search for funds, UNFPA decided to fund the project, and it finally was able to take off.

I want to stress the fact that the involvement was an OR process because they identified the problem, they thought of a possible intervention, and they wanted to test the effectivity of the intervention. Another point is that, from the time the research project was conceptualized until the project implementation was finished, the program managers and the researchers worked very closely together. The implementation also started with further consultation with the municipal health offices. With their help, we selected different areas where the experiment would be conducted. There were three such areas. In the first they trained BHWs to be FP motivators and communicators. The second had the male motivators, and, finally, the control group was an area with no intervention. The trainings were conducted separately in two batches: 70 BHWs in Maasin, and 70 male motivators in Anilao. 
All of this was conducted after a lot of negotiation. We had the LGUs sign memos of agreement because we wanted to emphasize sustainability and we wanted the involvement of the local government units. Because expenses for the trainings were shouldered by the LGUs, it was only the research costs which were shouldered by UNFPA. The implementation was provided for by Save the Children. After the training, the mobilization, motivation, supervision, and monitoring was implemented within 18 months. Then there was another survey.

We conducted a total of four studies. The first one was a qualitative study on the perceptions of men and women in the community regarding participation in decisionmaking. We wanted to find out who the real decisionmaker was. We also looked at communication patterns and social networking patterns in order to find out how men motivate other men to believe in certain ideas. The results were used by the DOH for developing the training modules. After this, we did the baseline survey for the contraceptive prevalence rate as well as knowledge and attitudes about family planning. Midway through the eighteen months, we conducted a midterm evaluation to find out the status and progress of the project implementation. Again, throughout this whole process, we were working closely with the program managers. At the end of the project we did a post-project survey to re-examine the CPR and the knowledge and attitudinal variables. In addition to this final survey, we also did a qualitative evaluation regarding perceptions of health providers on the program: whether they thought it would work or not, etc.

What were the findings of all of these researches? They showed that the CPR increased in the two experimental areas. We had expected that the male motivators would be effective and this expectation was confirmed, but we also found out that the increase in the area with BHWs was significantly greater than that in the area with the male motivators. This does not mean to say that the male motivators were ineffective; rather, that it would appear that trained BHWs were more effective than trained male motivators.

We must, however, interpret this with caution, as I must say that there were some problems in implementation. The problem basically dealt with the dropouts of motivators among the men. While there were 68 of the 70 BHWs that continued to motivate, only 41 of the original 70 male motivators continued to do so. We thus found out that, on the average, one active male motivator was able to motivate more people than an active female 
motivator. Overall, however, the BHW group was doing better.

In other words, we found that the male motivators could be very effective if we select active motivators. An active male motivator and an active BHW would probably show comparative results. Why would this be so? Our research showed that men would be more inclined to be motivated by men than by women. Secondly, men really need to be the ones to be motivated because they are the ones who are consulted by the women when they want to make a decision regarding family planning. Although the decisionmaking findings show that the decisionmaking was generally conjugal, many of the households held the position that once conflict arises in a participative decisionmaking process, the male has the final say. Considering this scenario, the study concluded that the men are good "targets" of the family planning program, and at the same time, good candidates for program implementation.

The main point that I am emphasizing here is that this is a case where OR truly helped in making decisions as to whether a certain intervention would be effective or not. In fact, UNFPA has already given a go-signal to Save the Children to expand this project in another area and utilize men as part of the family planning program. 


\title{
Integrating RTI Services in FP
}

\author{
Dr. Edwin Ylagan \\ The Population Council, Manila
}

The proposal that I am going to summarize today is entitled "Providing RTI Services at the LGU Health Centers: An Intervention Study on Syndromic Management". How was this proposal developed? Literature on RTIs has revealed that a large number of women are, in fact, suffering from reproductive tract infections. This is true not only in countries like Egypt and India, but in provinces such as Davao, where two-thirds of the women are actually suffering from some form or another of gynecological morbidity. We also know that the women rarely seek active treatment, as they feel that it is a part of their natural processes or, in many cases, they are asymptomatic. We also found out that there is no standard management that is being given to the women at the health centers. One reason for this is that standard approaches are often thought to be too expensive. But now an alternative has been suggested--the syndromic approach.

The syndromic approach was developed by the WHO. In this approach, the health service provider will diagnose and manage the patient based on the constellation of symptoms that the client is presenting. Many of the health centers were found to be poorly equipped, and most of the service providers were really nurses and midwives. The first visit of a woman, therefore, will probably be her last if the RTI is not treated. The syndromic approach model will enable the health service provider to manage the patient properly.

In developing this proposal, we have made several consultations with the various services of the Department of Health. A paradigm shift occurred after the ICPD and Beijing conferences. Most of the policy makers are now setting their targets differently: instead of demographic ones, they are now concentrating on the reproductive health approach. This is true even in the $\mathrm{DOH}$, as Dr. Ilagan told us this morning. During our consultations with the $\mathrm{DOH}$, we found that there are already many projects that concern women's health. One of these is the Women's Health and Safe Motherhood Project, and another is the Urban Health and Nutrition Project, which has an RTI component. They are also involved in training service providers in the use of the syndromic approach. In their case, they planned to simply train the service providers, but we suggested that they go one step further and really test whether these interventions can make a difference. In the projects that I mentioned, they would simply train wholesale, with no thought of evaluation. 
I would also like to mention at this point that we undertook some initial diagnostic studies. We went to Novaliches Health Center and observed how the service providers actually managed the patients with RTI. The first thing we found was that most of the cases were referred to STD centers, simply because the service providers were not familiar with proper management procedures. Secondly, the type of management varied from health center to health center. In many cases, the treatment provided was inappropriate.

The overall objectives of the proposed intervention study are to assess and enhance the effectiveness of the syndromic approach toward diagnosing RTIs and to improve RTI management within the FPMCH program of selected LGU health centers. After consulting with the various services of the DOH such as the FPS and the STD/AIDS unit, we identified three areas: Quezon City, Cagayan de Oro City, and Misamis Oriental. One of the factors behind the selection of these areas is that they are also under the LPP program. Some of their health centers have also actually been upgraded through the UHNP. We also took into consideration the OR capability of these areas.

The study has several sub-objectives. The first is to better understand perceptions and health-seeking behavior of men and women in the community with regard to RTIs. We are not only involved in training the service providers on the syndromic approach. We would also want to increase community awareness so that they would be able to utilize the service that is going to be installed. The second sub-objective is to assess the ways in which the FPMCH providers in the LGU health centers currently manage clients with RTI symptoms. The third sub-objective is to assess the readiness of the health center in terms of laboratory equipment, supplies and personnel to manage RTIs using the syndromic approach. The fourth subobjective is to evaluate the impact of the proposed intervention with regard to the following components: the training of service providers in the syndromic approach to the diagnosis and management of RTIs, use of simple laboratory tests to supplement the syndromic approach and community education campaign to increase awareness and utilization of RTI services. The fifth sub-objective is to determine the cost of RTI service delivery.

A series of trainings, involving both didactic and practicum methods, is currently being developed for the service providers. We will also be introducing a module on RTI for presentation in regular community fora, as coordinated by LGU health personnel.

We plan to implement this particular proposal within a period of fifteen months. The 
initial phase is going to be a diagnostic situational analysis type, and after that, we will be conducting trainings for the service providers and the medical technologists, as well as orienting the community health volunteers so that they will be able to generate the community awareness that is needed. The study will adopt a quasi-experimental research design. This means that there will be control areas where we will also be making observations -- i.e. areas where we did not train personnel. This should allow us to be able to see, over time, what the effect of our intervention was. (We can do this by comparing the control and the experimental areas.) Afterwards, there is going to be an evaluation of all these results, and also a statistical analysis. We will then hold a dissemination utilization workshop, not only for the program managers in the areas concerned, but also in a larger forum composed of various other LGUs. 


\section{Open Forum}

Dr. Michael A. Costello: This is not so much a question as just a small comment. One of the findings of the Bukidnon study is that home visits are "very rare." This is not too surprising since various studies have shown that volunteer workers always end up like a magnet, getting attracted to the health center, while the whole idea was to have outreach programs, and going on home visits. In a still wider perspective, this whole idea of quality of care has, as one of its philosophies, the idea that you don't have to have a hang up about always going out to get new acceptors. All you have to do is focus on the ones you've already got, do a good job on them, and they're going to stay in the program. You'll still have a high level of acceptance because you'll reduce your drop-out level. If you've got a woman out there in a faraway barrio, use your volunteer worker to go there, interact with her, to follow her up, and keep her in the program. This will pay off in the long run, according to most of the articles I've read.

Dr. Miguel Oppus: This is with regard to the barangay health workers and the FP coordinators in Bukidnon. We were also contemplating on doing the same thing in Davao, by having health workers assigned to barangays. Doing so, the health workers would become specialized on FP. There would not be any need for them to know " a little of everything" anymore. But this didn't fit the prevailing model, so we decided not to push through with the proposal.

Dr. Michael A. Costello: I want to go all the way back to something Eireen said. This was her comment about how sometimes we collect a lot of data, and we become inundated by data, and we can't process it and figure out what's going on. In Marilou's program, I thought she had a very useful experience with something called the DMPA task force. This was a sort of a "thinktank" which focused on the reintroduction program of DMPA into this country. I think what may often be 
needed in the LGUs is a family planning task force that could meet once every two months or so to somehow institutionalize the interaction between researchers and managers. Maybe managers can't really digest all of the information because it's not really their job: they are thinkers, not digesters. Of course a little bit of money needs to be set aside to give a small honorarium to local researchers to set up meetings. I agree with Eireen's point that we use up all of our energies collecting this data, but then nobody ever sits down to think about it, to talk about it, to brainstorm about it, and I'd like to see more of that.

Dr. Betty Abregana: I must say that I listened to all the presentations today and I could very well identify with a number of the elements presented, as I have had similar experiences in the studies that I have been conducting. Previously, I have not been involved in population studies, as my own field is more on environment and women's studies. Even so, a number of the researches I did were really in response to the requests of program managers. The most recent study funded by USAID was on coastal resource management, and there was a need to arrive at an environmental communications strategy. Therefore, a study had to be done in order to formulate an appropriate environmental research. What I want to know is whether this could this be considered operations research.

Dr. Marilou Palabrica-Costello: I think that the key element here is to ask yourself what really is the purpose for doing this particular study? Will it be used for decisionmaking? It has to be the program manager who will ask this question. From the very beginning, it should not be just a researcher saying, "I am going to do this study because it will be useful for the program manager." I would not consider that to be $O R$. It has to be something that the program manager is asking for, which the researcher will respond to. The program manager should be clear on the fact that he/she will use that study to make a decision, to try an intervention, and to evaluate it to improve his/her program. In other words, it is done to directly answer a particular question.

Male Participant: Before I came here, I had a different perception about Operations Research. I interrelated it with statistics. I thought that statistics was 
already operations research. Now I've found out that they are two different things after all. However, aren't there some related activities between the two?

Dr. Marilou-Palabrica Costello: Yes, you are right. But research and statistics are not identical. Statistics is only a way of analyzing your data and making sense out of it. As a matter of fact, some of the more useful researches that I know do not make use of very complicated or sophisticated statistical methodologies. Some operations researches simply call for qualitative data collection, especially diagnostic studies, where you have to go deeper into the subject matter, and you need people to come out and talk about their feelings. Sensitive topics, for example, are not quantifiable. Sample surveys may not be the best way to get at this sort of information. Rather, these types of data have to be gathered through in-depth interviews, focus group discussions, and the like. It depends, therefore, on the type of problem that you have.

Dr. Josefina Cabigon: Any research output that is utilized by the program manager to improve service delivery is considered to be operations research. Once there is a research result that is utilized by the program manager in planning and improving the plans, it is already considered operations research.

Dr. Saumya Ramarao: It was during World War II that OR really got started. One of the problems being dealt with concerned how you could route army defense supplies to various battalions which were spread in different parts of the country. And so, you see, we can apply operations research to many fields. We are applying it to the health field. Others apply it to agriculture or rural development. Another application of operations research is the role it plays in city planning. The best train and bus routes are being decided through using operations research. Where should the bus stops be? What should the passenger load be at each stop? All these questions are being answered through the use of operations research. 
Dr. Marilou Palabrica-Costello: Yes. What we are trying to say is that operations research is truly generic.

Dr. Josie Cabigon: The question that seem to be emerging is: why is it specifically family planning operations research? History shows that there was a sharp rise in the population in the 60's and 70's, so most countries tried to apply operations research to family planning. This was also the reason why they were able to come up with a family planning handbook. 
Session 2:

Considerations in Conducting an Operations Research Study: An Overview 


\title{
Identifying, Defining and Justifying the Research Problem
}

\author{
Michael Costello, Ph.D. \\ RIMCU, Xavier University
}

\section{Identifying a Research Problem}

According to Fisher, et al a problem is: a) a perceived difficulty; b) a feeling of discomfort with the way things are; and c) a discrepancy between what someone believes should be and what is. A potential research situation arises when there is a perceived discrepancy between what is and what should be; when there is a question about why the discrepancy exists; and when there are at least two possible and plausible answers to the question.

One of the five studies originally funded by PopCouncil was in Davao. The Davao study had to do with outreach workers. There had been an earlier study of barangay health workers (BHWs) and one of the questions was: have you ever been visited by your BHW? That was a study which had to do with the tuberculosis campaign, if I remember correctly. The study found out that a high percentage of the respondents were saying things like, "Do we have a BHW here?" "Who is she?" So there was a discrepancy. We hope that the BHWs are going out to the community, being missionaries who are very zealous in meeting people and talking to them about the programs in the $\mathrm{DOH}$. The reality was very different. Local people weren't even aware that they had a BHW, one, much less having ever been visited by one.

Chapter 2 of the OR Handbook gives several examples of potential research problems. One of these has to do with setting up an intervention to correct some logistical problems that crop up during the monsoon season. [See Fisher et al, p. 5. Dr. Costello went on at this point to review this example, as it is found in the Handbook.]

In this example, there are several possible and plausible reasons for the problem situation. One or more of these reasons might be correct. Therefore, this is a potential research situation. In some situations, it is relatively easy to identify the problem, to define 
it, hypothesize the reasons for it, and to conduct research to determine which reason is correct or more nearly correct. The reasons for the supply and logistics problem in the above example could probably be determined fairly easily and certainly would not require an expensive research study. Other cases, though, might be more complicated.

\section{Defining a Research Problem}

In order to define our research problem more carefully, we are going to need some additional information. This leads us to two important questions. First, where can we find this sort of information? The Handbook suggests four possible sources:

$\begin{array}{ll}* & \text { by reviewing the related literature } \\ * & \text { by examining current service statistics and agency policies } \\ * & \text { by talking to knowledgeable informants; and } \\ * & \text { by deducing probable explanations from existing theory }\end{array}$

The second question deals with the sort of information that we should look for. Several suggestions about this are given, namely;

* $\quad$ incidence/prevalence of the problem;

* differentials (sociodemographic or economic groupings, ecological variations);

* $\quad$ suggested causes of the problem;

* $\quad$ suggested solutions for the problem; and

* areas in need of further research (unanswered questions).

\section{Justifying a Research Problem}

Problem justification has more to do with finding a way to convince the funding agency that your problem is really important and is worth spending time and money on. Of course, we all have our own pet ideas and we think our idea is great. But you are going to have to convince the hard-headed program managers or nothing further is going to happen.

In justification, what are we looking for? Several issues are particularly important. First, will it affect a lot of people? Second, does it have prospects for success? Third, is this a big problem? Fourth, is lots of money being wasted? Fifth, is this a special problem in your place? If so, bring it out. You are like a lawyer advocating your case. One last thing 
is, again, to keep working for a close interaction between the researcher and program manager. As you read through the chapter you will notice that this is emphasized repeatedly.

A good way to come up with a real problem is to go out and talk to people who are implementing the program. Actually, sometimes even they have a hard time putting their finger on the problem but it can come out in your interaction with them. That's the nice thing about these workshops. One thing the PopCouncil is trying to do is to institutionalize linkages between researchers and program managers because out of that linkage something totally new emerges. Working together in partnership we can get all sorts of new, very practical problems to identify, define and justify. 


\title{
Strategy Selection to Solve the Problem
}

\author{
Dr. Saumya Rama Rao \\ The Population Council, New Delhi
}

What I'd like to do now is to spend a few minutes talking about strategy selection. I'll be using the example from Iloilo City which Mike referred to earlier.

What do we mean by strategy selection? What we have done so far is to identify and justify the problem. We said, yes, this is a problem, it affects so many people, it is very serious and therefore we must take steps to solve it. So what I'm going to talk about now is the process by which you decide on the steps to solve this problem. That is what we mean by strategy - the procedure to solve a problem.

Now for every problem there are several solutions. Which particular solution should one take? The very first step will be to identify all the potential strategies that could solve your problem.

Having done that, what you do in step number two is to say, which of all these is the most appropriate? What do we mean by "appropriate"? For one, it's got to be a strategy that is under the control of program managers. It is something that you people can do to improve service delivery. It's a variable that you can change. You can maybe train your workers better, or train them to provide better quality services. Maybe counselling can be improved, and so on.

Let's go now to step number three. We'll take Iloilo City for an example. Sometime in 1985, the number of family planning acceptors in this city dropped considerably, and this cost a lot to the city. Because of this, a research study was conducted to find out why there was this sudden drop in the number of FP acceptors. So what I'm showing you here are the three most important findings of the study.

Finding number one was that even though there were a number of health workers and volunteers working under this program, most of the volunteers in the field were not involved in family planning. They were involved in other work like $\mathrm{MCH}$. 
The second finding was that very few of them had actually undergone some type of training in their work. Because of this they were not actually doing the FP motivation work and therefore they were not able to recruit acceptors.

What also came out was that in those barangays where there was good supervision the volunteer workers did very well. Where the supervision was a little lax, the program performance was also poor.

Several strategies were therefore suggested. These activities were: (1) all volunteers under the program were given signboards which they can place outside their centers so that they could attract acceptors; (2) the Iloilo City Health Office and the City Population Office collaborated more closely, so the link between these two different units strengthened; and (3) a client referral system was developed between these two offices.

A fourth program innovation was to provide management and supervision courses to all the people involved in the service. And last, they decided to train health workers.

These are possible strategies that could be implemented. This study was a diagnostic study. Its objective was to study the situation and point out the problems and the things that one could do.

One variable that is under the control of all program managers is provision of training. So when you do your literature review you'll find that training has a definite impact. There are other approaches you can take as well.

Let's assume that you have chosen a particular strategy. Then you say, let's justify it. Has this particular strategy worked? So you talk to your researcher and you look at your literature review and say, yes, this strategy does work because it has been successful in barangay X or it has been working in Region I or II where a similar problem existed.

The next matter to think about is whether or not it will be easy to put that strategy in place. It is already fine to say you've go to do something. But if it is very difficult, or is very expensive, or if you don't have the personnel to do it, there's a problem. It should therefore be a solution that is easy to implement. The third thing is that it should be 
sustainable. That is, it is not a one-shot activity where you do it once and then forget about it. It's got to be repeated over time to maintain the program. Keeping these things in mind, let's look at the example of the DMPA drop-outs. [The participants were grouped together at this point and given five minutes to suggest potential strategies for overcoming this problem. The results are shown in the accompanying table.]

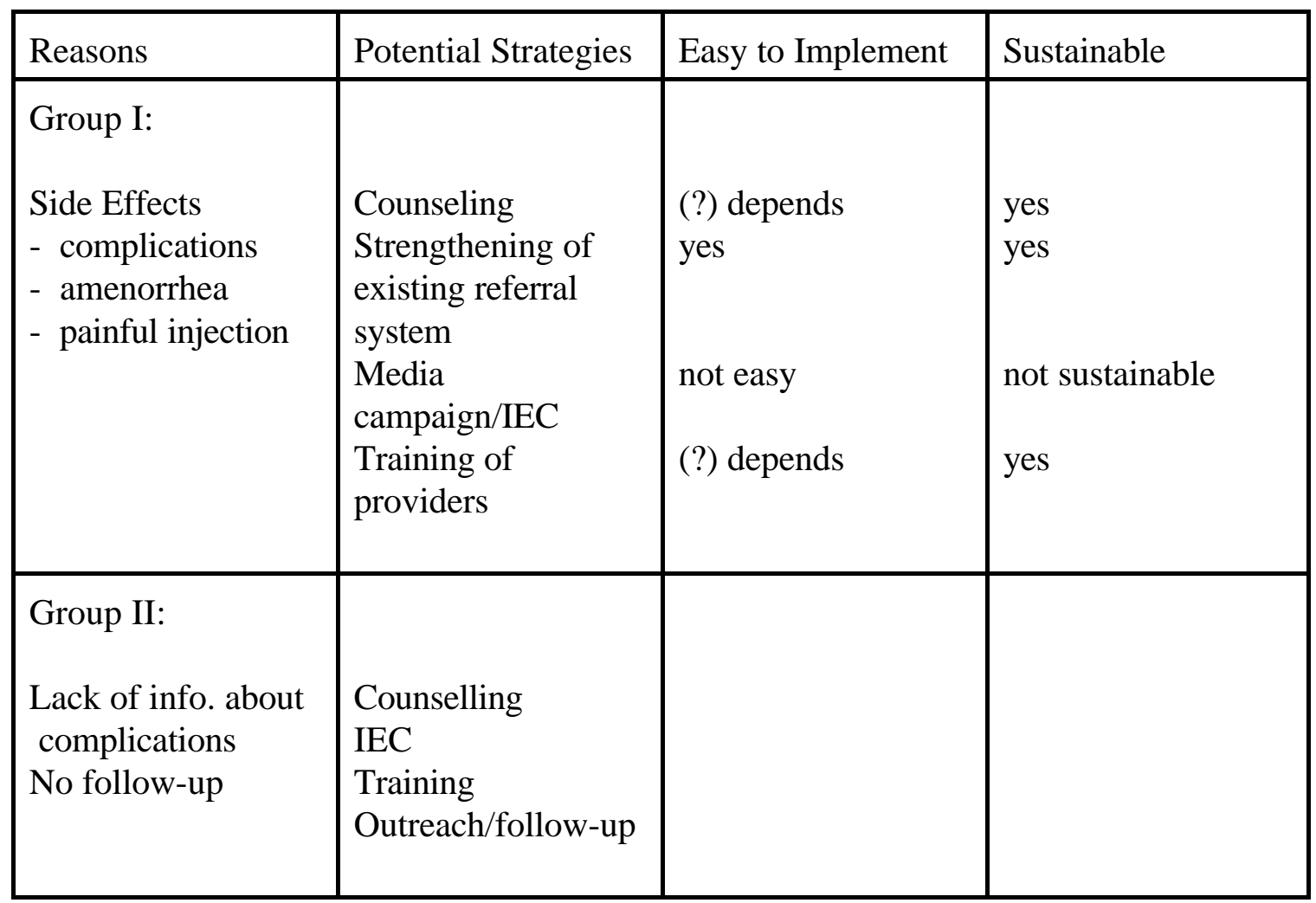

I hope that this exercise has given you all a general idea about how you would select a strategy, particularly in light of its sustainability and the ease with which it could be implemented in the field. 


\title{
Intervention Description
}

\author{
Dr. Edwin Reuel Ylagan \\ The Population Council, Manila
}

Yesterday, Fely and I gave you examples of intervention studies. I would like to repeat that intervention studies test new approaches to overcoming a program problem and that they test new service delivery modes. In the exercises that you went through, you learned how to identify some problems and their possible causes and reasons.

In intervention description, essentially you should elaborate on the following questions:

\author{
WHO WILL DO? \\ HOW MUCH OF WHAT? \\ TO WHOM? \\ WHEN? \\ WHERE? \\ FOR WHAT PURPOSE?
}

More specifically it is important to answer in detail the following questions:

\section{A. Who will be responsible for implementing the intervention?}

- $\quad$ organizations or institutions (like the Quezon City Health Center or the Provincial Health Office)

- $\quad$ categories of people involved, whether they are nurses, midwives, doctors, or barangay health workers

- $\quad$ role of each person in the implementation of the intervention

\section{B. Where will the intervention take place?}

- Be specific about the actual location of the study intervention. Will the intervention be implemented in the entire province, in one district, in ten villages, in four health center clinics? Be sure to mention the location of the study sites. 


\section{What activities will be initiated?}

- Describe the sequence of events. For example, if you are going to train field workers, your first activity should be to specify the nature and duration of the training. Afterwards, if there will be a series of meetings with the community, indicate the frequency and the purpose of these community meetings. Finally, in your intervention, if the field workers will have to visit six households per day, you should indicate that.

- You should also indicate the level of intensity for each activity. For example, if we are going to have an IEC campaign, indicate the type of media -- are we going to use radio spots, are we going to put up posters, are we going to distribute pamphlets in the community? Mention intensity of the media -- 100 posters, three radio spots per day for six months, etc. Specify who will produce the posters, pamphlets, radio scripts. In short, be detailed and specific.

[The PopCouncil's RTI proposal was then reviewed at this point to illustrate the above points, i.e. to give a prototype description of a planned intervention.] 


\title{
Objectives and Hypotheses
}

\author{
Dr. Josefina V. Cabigon \\ Population Institute, University of the Philippines
}

Now, inasmuch as we are moving towards the preparation of your own research proposal, from now on, try to think of the topic that you would develop into a research proposal. So it is important to remind ourselves of our goal -- why are we in the LPP? The formulation of your topic should be in relation to the goals of the LPP. Which brings me to my topic: research objectives.

The objectives of your research topic should always be in line with what the LPP is all about. What is the goal of LPP? This is what is called the ultimate objective. Now how does "objective" differ from "strategy"? And how does "strategy" differ from "activity"?

The objective is something ideal, something we hope to attain. But how do we attain it? That's where strategy comes in. Strategy is the way by which you solve a particular problem to attain a particular objective. For its part, the activity is the step-by-step process to implement the strategy.

\section{Objectives}

A. Definition: expected contributions and outcomes from the study

B. Types

1. Ultimate - expected and hoped for contributions/outcomes which are useful in improving service delivery activities or formulating/reformulating policy

2. Immediate - what will happen or what will be done stated in terms of:
a. Who will do?
b. How much of what?
c. To whom?
d. When?
e. Where?
f. For what purpose? 
For example, we could state the immediate objective of a proposed study as follows:

"In 1997, The Provincial Health Office and the Department of Social Services and Welfare will conduct a survey of 210 mothers with children less than 5 years old in Bataan to ascertain the level and extent of community participation of mothers in maternal and child health program activities."

But we need to also know the ultimate objective of this study, which is "to increase community participation in maternal and child health program activities."

\section{Hypotheses}

A. Definition: statements about expected relationships (direct or indirect) between two or more variables

B. Types of Variables

1. Dependent - $\quad$ the main interest in a given study which depends on one or more variables

2. Independent - that which causes or determines or influences the dependent variable, whether directly or indirectly

3. Intervening - $\quad$ that through which the independent variable acts upon the dependent variable

For example, a certain program intervention like an IEC campaign (independent variable) influences maternal KAP on primary health care (intervening variable) which in turn has an impact on infant and child morbidity (dependent variable).

Relevant hypotheses should always be stated in positive terms:

1. Barangays in towns will have lower infant and child morbidity rates than barangays in rural areas. 
2. An IEC program using video/film showing, television and printed materials will increase mothers' knowledge about primary health care.

3. The work performance of service providers trained specifically in the provision of primary health care will be better than the work performance of similar service providers without training in primary health care.

4. The presence of primary health care facilities in rural areas will further motivate mothers to participate in the primary health care program of the government.

5. Mothers with higher levels of knowledge about primary health care will have lower levels of infant and child morbidity than mothers who are not as knowledgeable about primary health care. 


\title{
Operational Definitions
}

\author{
Dr. Betty Abregana \\ Silliman University
}

As we go into the formulation of hypotheses we have to know very well what is it exactly that we want to find out. As we just heard, we are actually dealing with variables here. In doing so we will be using terms in research that may not be used in the same way that we use them in everyday conversation. That is why researchers should be able to come up with the specific meanings behind the particular terms and concepts that are used.

I think one way of better understanding this concept is to differentiate an operational definition from a nominal definition. The term "nominal" is from the Latin nomen, meaning "name", like using a word loosely, for example.

But is a nominal definition enough for the conduct of research? Suppose we wish to know the level of family planning knowledge among our health and FP workers. Now if we use a dictionary definition of knowledge, it simply refers to the possession of accurate and wide-ranging information, and since we're talking about family planning then maybe we'll limit our definition to knowledge of locally available contraceptive techniques.

Now given the nominal definition, do you think this is directly measurable? Can you measure "possession of accurate and wide-ranging information" if we use that definition? If I look at somebody can I just say he is in possession of knowledge about family planning services or contraceptive techniques? No, you cannot possibly measure that concept the way it is presented.

How can we possibly measure "possession of accurate and wide-ranging information"? What are ways by which we can measure this? You might conduct an interview which means that you need an instrument, like a questionnaire on family planning. Is that a better way of measuring knowledge? Maybe yes. Maybe giving out a questionnaire is the most efficient way of getting information. So in this case, we say that our operational definition of family planning knowledge is the number of correct answers our respondent gives to 20 questions on family planning. 
Notice then, that from a nominal, conceptual definition of "possession of accurate and wide-ranging information" we select a particular measure or indicator. What is the rule or procedure to be followed?

One is, we decide to whom we will ask the question. In this case, we make a survey of a number of family planning and health workers, our target group. Every correct answer is given one point, and a wrong answer is given no point. The next step is counting the number of correct answers and determining the level of knowledge of the respondent or interviewee. So, in an operational definition you engage in an operation to come up with a concrete, verifiable, measurable response.

In having all the possible answers you actually have two choices. One approach is to classify persons as to whether they have a high or low level of knowledge, i.e. simply into two categories. A better approach, though, would be to have different categories of information. Like how many among the 200 respondents got results of 15-20, how many got 8-14 or 1-7, indicating high, medium, or low knowledge, respectively. You can also identify later on what possible action plan you can have based on the operations research. Maybe it is not good to lump people with low knowledge together with those with high knowledge; there should also be differentiation in the training program.

We have now the steps in operationally defining your study variables. First is, give a clear nominal definition of the concept. Then draw up a list of possible indicators which could be used for measuring the variable. Will you do a performance test? Will you do a demonstration test? Or is it more efficient if you use a questionnaire so that you can readily collect data from the target group? The third step is to select the most accurate indicator/procedure given your budgetary and time constraints. Finally, specify the steps to be taken in coming up with the measure.

[Other examples of operationally defined variables, as taken directly from the $\underline{\mathrm{OR}}$ Handbook, p.27, were then discussed by Ms. Abregana.]

The handbook also distinguishes between the operation definition of terms and the operational definition of variables . Variables are anything that can take on two or more 
values. Family planning knowledge can be a variable because it can take different values -low, medium, or high. In comparison, term represents a specific homogeneous category. Thus, if we define a person as a family planning user in our operations research, this can be operationally defined as any currently married woman aged 15-49 and any currently married male aged 15 and older who says she or he has used a modern method of contraception at least once during the last month. Again, as was mentioned there is no single or definitive definition, it all depends on how you would like to manipulate the variables for your own purposes. 


\title{
Study Design
}

\author{
Dr. Josefina V. Cabigon \\ Population Institute, University of the Philippines
}

I. Definition: invesitgator's plan of action for answering the study question(s)

\section{Characteristics of a Good Study Design}

A. Ethical: does not violate people's rights and dignity and does not deny people the level of quality of services that they should have.

B. Capable of obtaining the most reliable and valid data possible given the constraints of funds, time, personnel and equipment.

1. Reliability - consistency, stability or dependability of data

E.g. Age data from the following two questions to be the same:

Question

$\underline{\text { Answer }}$

a. How old are you? I am 47 yrs old.

b. In what month and year were you born? In August 1949.

2. Validity - $\quad$ reliability, trueness and accuracy of data

Same example of age data: Birth certificate indicating August 1949 as the respondent's month and year of birth.

3. Threats to Validity

a. History - unplanned events that are not part of a given project being studied but which occur and affect the study results.

E.g. During the duration of the project being evaluated, other intervention activities from other projects were implemented so the effects of intervention activities of the project being evaluated cannot be distinguished from the history effects of the other projects. 
b. Selection $\quad-\quad$ differing characteristics of two groups being studied: e.g. a study of the effects of intervention activities by comparing the control and experimental groups cannot ascertain if differences are due to a selection effect rather than to the intervention per $\underline{\text { se. }}$

c. Testing

- $\quad$ repeated questioning of the respondent on the same items, thereby making it somewhat easier for him/her to answer better the same questions in the second test, thus, the effects of the training activity prior to the second testing cannot be distinguished separately from the effect of the first test.

d. Instrumentation - changes in the measurement instrument (e.g. questionnaire) in obtaining the same information in two surveys will affect the observed difference between the two surveys. Thus, the effects of the intervention activity between the two survey periods cannot be distinguished due to the effect of the change in instrumentation.

e. Maturation - $\quad$ respondents becoming older, more experienced, more knowledgeable, and more resistant as time passes.

f. Mortality - $\quad$ some respondents in the first survey could no longer be located either due to migration or mortality; if those lost to follow-up cases greatly differ from those interviewed in the second survey, then the effects of the program intervention cannot be distinguished separately due to the resulting bias.

A good study design should be able to overcome the six validity threats discussed above.

[The major study designs were then presented and discussed briefly by Dr. Cabigon, see the OR Handbook, pp. 32-37.] 


\title{
SAMPLING
}

\author{
Virgilio Aganon \\ Professor, Miriam College
}

Let us think of ourselves as doing some research in the barangay and trying to find out a certain measure, e.g. the percent of women practising a modern contraceptive method. One way to do this is to ask all the women in the barangay if they are practising some kind of modern family planning method, like the pill and IUD. We sum that up, divide by the total number of women of reproductive age, and that would be the percentage of women practising family planning.

Since we asked that question of all the women in the barangay, that is a population value. If every woman answered the question truthfully, then we call that the true value $(\boldsymbol{\mu})$. In our studies we are after the true value, but actually we can never really know it, since our resources are limited. As such, we cannot ask that question of every woman in the barangay. We just take a sample, say, of size n. When we summarize the data, we now have what we call a sample value.

If the sample was taken through a probability sampling, which we shall later define, the difference between the population value and the sample value is the sampling error. The difference between the population value and the true value is the non-probability sampling error.

For example, let's look at the average age of women in the barangay. We ask every woman how old she is as of her last birthday. Everybody answers, and then we average that by the total number of women, and we get a figure, say, 35. Now if everybody answered truthfully, the true value says 35. But you and I know that not everybody answers that question truthfully. As a result, we have a certain amount of non-probability sampling error.

Now suppose we take a sample of women in the barangay and ask the same question and get the mean. We get a value, say, 32. The difference of this and the population value is the sampling error. 
Generally there are two ways of drawing a sample: probability sampling and nonprobability sampling.

We can operationalize a probability sample by using a table of random numbers. To be able to generate a probability sample, we must have a listing of all the 700 women in Barangay Masaya. We call this the sampling frame. There must be no double listing in the sampling frame (each woman is listed only once). Assuming that we need a sample of 100, we get this sample by using the table of random numbers.

We can start with any number in the table. Take three digits at a time. Since we have 700 elements, we must take three digits at a time (700 being a three-digit number), so it is possible to have a number from 001 to 999 . Take the first three-digit number, and if it is anywhere between 001 to 700 , then that number is part of the sample. Proceed to the next three-digit number (going either left or right, but be consistent about it) and if it is not within 001-700, then proceed to the next number, and so forth. We do this until we get 100 of these three-digit numbers within 001-700. The names corresponding to those selected numbers is your random sample of 100. Any procedure other than this is not a probability sampling.

We use sampling because, one, it is very expensive to do a population study asking, say, 700 women or 63 million Filipinos or 30 million Filipino women. Another is that we may not have the time to gather the data from the population. Besides, if you have a smaller sample, you could control even the non-probability sampling error through training of interviewers, a better-designed questionnaire, and so on. The sampling error comes in due to the sampling procedure.. There will always be a sampling error. But a non-probability sampling error comes in due to the vagueness of the terms used in the questionnaire, the interviewer himself or herself, the time of the interview, the duration of the interview, and so on.

The probability sampling methods that we often use are: simple random sampling, systematic sampling, stratified sampling, cluster sampling, multi-stage sampling, probability proportional to size sampling. These are just terms for now. I'll explain them later on. 
An example of non-probability sampling is haphazard or fortuitous sampling . We see this often on TV when the emcee would ask a question, say, "How do you feel about Marimar?" and asks anyone from the audience, or when somebody stands in a corner and asks any passerby whether he or she uses a particular brand of soap.

Another type of non-probability sampling is model sampling . Suppose a biologist wants to find out the population of butterflies in Boracay. First, he runs around, catches a butterfly, marks it, and then releases the butterfly. Then he continues the process, marking every butterfly he catches and releasing it. After a day or two he comes out with statistics of how many butterflies were caught once, were caught twice, and were caught thrice. Using this proportion or using a model, he could come up with an estimate of the number of butterflies in Boracay. Model sampling is also called the "capture-recapture" method.

Another type of non-probability sampling is purposive sampling - Suppose you want to know the perception of people about a particular issue, say, if they are in favor of the Southern Philippines Council for Peace and Development. There is no scientific method involved, you just ask the key leaders, all the churchmen, and so on.

To improve on that, we can use a quota sampling - Instead of using a table of random numbers, we just fix a quota for a particular sample, say, $50 \%$ of them should be women, and so many percent of them should be of the ages $0-5,5-15$, and so on , to mirror the age structure of the population. So if we have reached the quota for a particular age group, then we stop, and complete the proportion in the other age groups.

But we shall not be making use of these methods for our purposes because we cannot use these to make an inference to the total population. They are good for getting information qualitatively but that's all. For example, the Kinsey Report used haphazard sampling, involving anyone who was willing to be asked about his sexual history. Even though it is not a probability sampling, it has shed some light on the sexual problems of Americans.

Now let us go back to the 700 women in Barangay Masaya to learn about probability sampling. If we select a sample of 100 from the listing of 700 women using a table of random numbers, that is simple random sampling. 
Using the same sampling frame, since we need only 100 women, the ratio is 1:7. Let's say, though, that instead of using the table of random numbers 100 times, you use it only once. Get a number anywhere from 1-7. If you get a 2, that's your first respondent. Then you add 7 to that, that's your second respondent, then add another seven, and so on until you get 100 numbers. That is systematic sampling.

Stratified sampling is used when the population could be divided into a number of classifications which you think would have a significant value with respect to the other classifications. A clear stratification would be "men" and "women". Suppose the response to a particular medical procedure might be different for men and women. It would be practical to divide the population into strata of men and women. The main distinction here is that one stratum is very much different from another stratum with respect to the phenomenon you are measuring. Which means that when you conduct stratified random sampling, you must have a listing of your population by stratum.

Probability proportional to size involves sampling proportional to the size of the stratum. If stratum one is $70 \%$ and stratum two is $30 \%$ of a population, then for a sample of 100, you get 70 from stratum one and 30 from stratum two.

Cluster sampling involves clusters. A barangay could be divided into five clusters or five sitios. One selects clusters and measures the elements of each cluster. A cluster is similar to any other cluster, like sitio one is just like sitio two and sitio three. But within a cluster, the elements are dissimilar from each other.

Now how do we derive a sample? The sample size would depend on the variability of the phenomenon, the margin of error we are willing to accept, and the probability that we would exceed this.

The maximum variance of a proportion is when the probability is .5 . So if the probability of women using a modern contraceptive method is $50 \%$, then that is the maximum variance. Using that property, the variability of that phenomenon, then you have a measure of its variation already. 
Say that we want to get our sample from the 700 women of Barangay Masaya with a margin of error of $\pm 5 \%$ and which will be exceeded $5 \%$ of the time. Out of 700 , the initial sample size $\left(\mathrm{N}_{0}\right)$ for this is 384, (see pp. 44-46 of the OR Handbook). Adjusting that for the population size of 700 , that means you need a sample of 248 . You will use the table of random numbers in getting this sample of of 248 women.

Now if you want to relax the margin of error to $71 / 2$ percentage points, you'll have a smaller sample size, 138. You relax it some more to $\pm 10 \%$, you'll have a sample size of 85. This is a direct application of the formula that you have in the OR Handbook, in the section on sampling. 


\title{
Data Collection
}

\author{
Dr. Josefina V. Cabigon \\ Population Institute, University of the Philippines
}

\section{Types of Data}

When we talk of quantitative data collection methods, our goal is to measure the level or pattern of a particular issue to attain a generalization. This implies, therefore, a distinction between quantitative and qualitative techniques.

A. Quantitative - main concern is precise quantitative measurement of program operations or of your variables

1. Sample survey or structured interview using a standard questionnaire for all sample respondents which is characterized as follows:

a. in simple language

b. with precoded responses to questions

c. without embarrassing or painful questions

d. without information-loaded single questions

e. without ambiguous wording of questions

f. concise but comprehensive

g. asked of all respondents in exactly the same way

h. pretested in an actual field situation

i. interviewers to be completely trained in the content, intent and meaning of the questions and in administering it in the field

j. to be accomplished in one to four visits of a prospective respondent if not available for the first visit

k. to be accomplished by a substitute respondent for cases that cannot be located

1. asked when the respondent is alone

m. completely accomplished, edited for errors, omissions and discrepancies. 
2. Service statistics - management information system in a given organization, for example, the $\mathrm{DOH}$ service statistics from the Field Health Service Information System

3. Self-administered questionnaires - useful in situations where literate respondents are gathered together or used in a highly literate populace

4. Secondary data sources (censuses, previous surveys, vital statistics or other official statistics)

B. Qualitative - the main concern in this case is descriptive information and further explanations of emerging levels and patterns to give greater depth of meaning

1. In-depth interviews

2. Focus group discussion of 8-12 participants on a particular topic

3. Direct observation of operations (e.g. clinic, activities of field-workers, and administrative procedures) by highly skilled observers and analysts

4. Content analysis of written materials

C. Summary of what to do in data collection:

1. Review your study objectives, hypotheses and variables, the types of information required, and the data gathering techniques appropriate to your research problem.

2. If you use a survey as a data collection method, see to it that all characteristics of a survey questionnaire as enumerated above are present in you survey instrument.

3. If you use a combination of quantitative and qualitative approaches, be sure that they complement each other.

4. Prepare a description of your data collection procedures and include this in the proposal. 
D. Data quality checks

1. Ask two or more questions that give the same type of information for data reliability.

2. Train interviewers in probing skills for difficult or sensitive questions.

3. Employ field supervisors to ensure quality of your data.

4. Do spot checks to ensure quality of data.

5. Employ statistical checks for errors or for consistency of response (e.g. machine editing and frequency analysis)

\section{E. Confidentiality of Information}

1. Maintain the confidentiality of all information given to you by the respondents.

2. Assure the respondent that the information he or she gives will be kept confidential. 


\title{
Analysis of Data
}

\author{
Michael A. Costello and. \\ Virgilio Aganon
}

After collecting your data you've got to have a plan on what to do next. A typical plan is outlined on the first series of overheads prepared for this session.

\section{Preliminary Steps for Analyzing OR Study Data:}

1. Check for errors

a. Field editing (e.g. callbacks, completeness checks)

b. Spot-check of codes and key punching

c. Machine editing ("cleaning" the data)

2. Coding for computer analysis

a. Decide which questions/indicators to code

b. Prepare a set of coding instructions

3. Keypunching onto diskettes(s)

4. Review project objectives, hypotheses and conceptual framework

\section{Planning the Statistical Analysis: Four Sequential Steps}

1. Variable Transformations

a. Missing Values (no response, not applicable)

b. Recodes (e.g. collapsing categories)

c. Counts (e.g. number of consumer goods owned by R)

d. Scaling ( a way of lumping together many questions, after first demonstrating that they are all good indicators of the same underlying concept).

e. Mathematical transformations (e.g. housing density = no. of persons in the household/no. of bedrooms) 
2. Univariate Analysis

As the word implies, this means analyzing your data one variable at a time. For instance, very often reports present profiles of FP acceptors in certain places. We sometimes look at their age, the type of family planning they've adopted, etc. In this analysis, there are three types of measures that are commonly used:
a. Measures of central tendency
b. Measures of dispersion
c. Frequency distribution

3. Bivariate Relationships

Here we are trying to see if there's a correlation/connection between two variables. This is not the same as cause and effect. It's only a beginning, a first step towards figuring out cause and effect. The main tools which can be used here are the following:

a. Measures of strength of the association

b. Tests of statistical significance

4. Multivariate Relationships

These are techniques that enable a researcher to study the effect of controlling for one or more variables.

a. Associational measures/significance tests

b. "Controls"

i. Cross-tabulations

ii. Multiple regressions, logit, etc.

There are three levels of measurement which are commonly used in the social sciences:

1. Nominal measure

2. Ordinal measure

3. Interval measure

[See pp. 56-58 of the OR Handbook for a further discussion of the distinctions involved here.] 


\section{Other Levels of Measuring Variables:}

4. Time Series Analysis - This is used if the data you are working with changes over time. For example, you might have measurements of contraceptive prevalence rate for month 1 up to month 18. If you find out in the observation that it goes up after a certain period you might want to see why that happened. It is shown in the OR manual wherein there was a program conducted and after the 6th or 7th month it shot up dramatically (see Table 10.1). To measure the effect of that special program would be to get the measurements before and after it took place.

5. Cost-Effectiveness Analysis - This involves a simple formula of dividing program cost and program effects. This seems quite simple but trying to translate the program costs and program effects into pesos is quite difficult. You will have to decide how much of her time that a health clinic doctor provides to the FP program as well as other services could be charged to the program. In terms of program effects, how do we measure these? You have a problem of defining FP acceptors and of measuring the contraceptive prevalence rate (CPR). But the more difficult part really is how to translate into peso terms the couple years protection (CYP) or the births averted.

6. Several other approaches are discussed in the OR Handbook. Basically these are just computations of rates like use-effectiveness analysis and fertility analysis which really amounts to having the right kind of information for a numerator and a denominator. The typical situation in the program is that there are data for the numerator because you monitor this, but nothing is available on the denominator. You may have to conduct a survey to ascertain the total number of women, to be able to measure the different fertility rates and use-effectiveness rates. Another approach might be to try to use census data to estimate this information. 


\title{
Dissemination and Utilization of Research Findings
}

\author{
Marilou Palabrica-Costello, Ph.D.
}

\section{Introduction}

You will recall that, in my first lecture, I stressed the importance of disseminating and utilizing OR study findings.

Let me now re-emphasize this idea. An OR study does not end when the investigator writes and submits the final report. No. It has to be communicated, understood, and acted upon.

You can't just assume that these processes will automatically take place. Why not? Because

1. Final reports are often too long -- the program manager doesn't have time to read them.

2. Final reports are often too technical and may not be understood.

3. Even if you condense and simplify the final report, how do you know it will ever cross the desk of the real decisionmaker? For example, what if there are many program managers, like in a devolved set-up? You can't just leave these things to chance.

4. Even more follow-up will still be needed to go beyond dissemination to reach the goal of utilization.

\section{Dissemination of Research Findings}

One implication of the above is that the researcher and the program manager must work together to plan a dissemination strategy.

This strategy must be built around three major decisions. The first of these is to identify the potential users of your study findings. Note that it might be possible at this point to identify two or more types of users. If so, separate strategies will be needed for each. 
For example, a one-page summary ("Executive Summary") of findings and implications will be needed for top-level decision makers, whereas a Research Dissemination Seminar might be more appropriately aimed at middle-level management. It can also be fruitful to develop news stories/ press releases for informing members of the general public.

A second decision will be to select those findings that will be of most interest and utility to each subgroup.

Your final decision has to do with the dissemination process. What type of communications strategy (seminar, research abstract, journal article, press release, etc.) will you use? As the handbook notes, "a good strategy will typically involve multiple media channels used repeatedly over a period of time to reach the largest audience possible."

The above comments should not be taken as downgrading the importance of the final research report. This, of course, is a very important document since it contains the evidence to back up all the claims being made in the seminars, press releases, and executive summaries.

So let's spend just a few minutes on the question, "How can I write an effective final report?"

The next overhead suggests several answers to this question. To begin with, a very first consideration is, again, to identify your target audience. Reports written for program managers should not be the same as those written for scientists and academics. This latter group will want to scrutinize your study design, data collection procedures, statistical techniques, etc. But the program managers couldn't care less. They want practical advice about upgrading their program.

Okay, let's assume for now that the main target audience consists of program managers. If so, several implications follow:

First, don't overload the report with technical considerations (e.g., sampling design). Such materials should be hidden away in a series of technical appendices. Second, be sure to include a section on implications for programs and policies. Do a good job on this, too. 
(This may mean that the researcher will have to spend some time finding out just how the program is operating at present.)

Third, don't delay. Don't submit decision-relevant findings after the decision has already been made. One way of ensuring this is to prepare brief interim reports on study findings as they come out.

Fourth, prepare an Executive Summary.

Finally, "keep it simple." This means avoiding technical jargon and complicated statistical tables. Use clear words and relatively simple presentations of data -- e.g., bar charts, graphs, etc.

\section{Utilization of Study Findings}

Okay, you've finished the final report and held the dissemination seminar. Should you stop there? No! There is still the final step: utilization.

This is probably the weakest area of most OR studies. In part this is because other considerations come into play at this stage -- e.g., political and social factors will usually affect decision making much more than the results of scientific studies.

Nonetheless, OR findings can make a difference. For example, the many research studies which have been conducted on the effects of cigarette smoking in the U.S. have changed laws and public opinions about this practice.

Here in the Philippines, the PopCouncil's OR study on DMPA use has already had a major impact. Data from the ten pilot provinces were used to come up with an estimate of the demand for this contraceptive that can be expected for the nation as a whole within the next three years. They were used in planning for the optimal number of vials and syringes to be distributed.

The handbook lists several strategies for improving the prospects that findings from an OR study will actually be used. These are presented on the next overhead. 


\section{Some Suggestions for Increasing the Utilization of O.R. Study Results}

1. Identify the decision makers most likely to be interested in the study. Keep them informed about the study from its very beginning.

2. Continue involving these key decision makers in every stage of the study. (Ownership is a prerequisite for utilization.)

3. Do a good job on the section of your study report(s) entitled "Implications for Programs and Policy."

4. Make your dissemination seminar a vehicle for achieving greater utilization.

a. Allow plenty of time for reactions/suggestions/comments from the program managers in attendance.

b. Use discussion groups. The goal will be to develop an intra-agency action plan. 


\section{OPEN FORUM}

Dr. Perla Dosayla, FP Coordinator, Quezon City: What is the difference between strategy and particular activities?

Dr. Saumya Ramarao: The language one uses is very critical. By strategy, all we mean is a list of potential solutions that one could take which would result in a particular activity. A strategy is a process for solving, which is after all a particular activity. Maybe to get a more Filipino context, Marilou, could you fill this question?

Dr. Marilou Costello: I think this sort of misconception or a lack of common consensus on terms is because we have used them very loosely in the Philippines. We talk about planning a national strategy or a department planning strategy. So there could be some confusion because we call them strategies but the issue we are really talking about concerns concrete activities. This is where the misconception lies. We have always thought that: first, you have the level of policies, then strategies, then you have activities. However, here in operations research we talk of strategies as though they are specific activities. To some extent, therefore; it becomes a matter of perspective, whether if it is at the policy level or at the level of the program managers. The difference might lie in who is talking, or from whose perspective. We can use it both ways but what is important is we understand the level that we are talking about. There must be some kind of a consensus among yourselves so that you know that strategy is the specific set of activities that you have formulated to deal with a problem. That might be your meaning but that might not be the meaning for the people around you. So there might be a need for some kind of levelling of understanding of what you mean.

Dr. Betty Abregana, Silliman University: I'd like to offer a possible resolution of that confusion. When we say "strategy selection to solve the problem", this is really more in the context of OR. We begin by 
identifying the problem, followed by the discrepancy, the research problem, the reasons. And now we want to explore possible strategies to solve the research problem. This will be the basis for the following steps in the OR process, which include formulating the hypothesis, operational definitions and so forth. We should be guided by these strategies.

Dr. Michael Costello: I just wanted to go back to counseling and why I thought it will not be "easy to implement," to use Saumya's phrase. The bigger question here is, again, to define your terms. What do you people mean by "counseling"? If you mean having some information to give a mini-lecture to the client, well, okay, I guess it's easy enough. But my understanding of counseling is that it involves a lot of listening, drawing out from the client what she is thinking, being very patient and empathetic. That is really a skill that you can't get in a three-day training and once you are in the field I don't know if you will have time for it. Real deep-down counseling, I think, would be a little be hard to implement in a typical health center. That's why I said I had doubts. But the question is, again, define your terms. There are different types of counseling. That's a very big word. Narrow it down.

Dr. Saumya Ramarao: Okay, well I think that what we are heading towards is that we are now getting to the nitty-gritty of OR. You're beginning to see that it is not so easy to do. And you will see that it's getting to be progressively harder. But overall, you will become victors, I assure you. It is a learning procedure. 
Session 3:

Conducting your Cluster Survey: 1997 LPP Benchmark \#6 


\title{
The Integrated Cluster Survey on FP/MCH LGU Performance Program
}

\author{
Eireen Villa, MSH-DOH
}

\section{Introduction and Rationale}

In collaboration with other government agencies (e.g. POPCOM, NSO) and cooperating agencies at the national level, the $\mathrm{DOH}$ is implementing benchmarks geared towards the strengthening of the national systems for providing FP/MCH services and expanding the contribution of the NGO/private sector in the provision of FP services. These benchmarks are focused on the following:

* $\quad$ Setting policy directions and standards

* Expanding service coverage

* Improving quality of care

* Increasing contribution of NGO/private sector in the provision of services

* $\quad$ Ensuring sustainability of the program

Figure 1 provides an overall view of the major benchmarks which have been incorporated within the LGU Performance Program. For its part, table 1 lists all of the LGUs participating in this program, as classifiedby region and batch.

Upon the advent of devolution, the responsibility of planning, implementing and monitoring the health program has been transferred to the local government units. Strengthening, therefore, the LGUs' capability to plan, implement and monitor their health program is paramount. One vital element needed is accurate and up-to-date information in order for the LGUs to monitor the health status of their population and to evaluate the use and effectiveness of their programs. Data are needed by the LGUs on how services are utilized to better manage service delivery. They also need data on the effects that services have had on their population for program planning.

On the other hand, developing and maintaining health information systems as sources 
of these kinds of information is quite difficult. The burden for service providers in collecting volumes of data is well known not only in the Philippines but also in other countries. Compounded with the effects of devolution, the LGUs are experiencing more difficulty in maintaining this health information system. Delays in data collection and submission, incomplete reporting, and breakdown of hardware support are just few of the problems encountered by the LGUs.

In this regard, policy makers and program managers at the national and local level are beginning to depend more on surveys and special studies as the sources of more accurate information to address their needs. The conduct of the cluster survey is, therefore, timely because the LGUs can generate information as a basis for planning, implementing and monitoring their programs. Along the same vein, the LGUs' appreciation of and skills in research would definitely be enhanced.

\section{Previous Cluster Surveys Done by DOH and LGUs}

The conduct of cluster surveys is not something new to the DOH and to most of the LGUs. Even prior to devolution, this has been done, especially on Family Planning and MCHS programs. The coverage and administration of these surveys, though, were varied, and continue to improve.

[At this point Ms. Villa reviewed the six cluster surveys which were already conducted on MCH and FP topics during the 1990s.]

\section{Purpose/Objectives of the Cluster Survey}

1. To generate more accurate and up-to-date information as a basis of the LGUs for monitoring and evaluating their programs and in planning interventions to address whatever problems may be identified;

2. To develop the research capabilities of the LGU program managers as they plan, implement and monitor their health programs. 


\section{Minimum Set of Indicators to be Collected}

1. Contraceptive Prevalence Rate (CPR): Percent of women of reproductive age who are currently using program and non-program methods of FP

2. Fully Immunized Children (FIC): Percent of living children between 12-23 months who have been vaccinated before their first birthday (three times for polio and DPT and once for both measles and BCG)

3. Tetanus Toxoid Plus (TT2+): Percent of pregnant women and mothers of reproductive age (15-49) with children under 5 who have received at least two doses of tetanus toxoid

\section{Milestones}

- Preparatory Phase August, 1996 - March, 1997

(This will involve consultations, reviews of the survey design, orientation of the participating LGUs, and, collaboration with the research institute)

- Actual Conduct of the Cluster Survey

April - June, 1997 (old LGUs)

June - August, 1997 (new LGUs)

- Utilization of Findings/Results

July - September, 1997

- Submission of Report to DOH-OPHS

September, 1997 


\title{
Conducting a Cluster Survey with an Operations Research Perspective
}

\author{
Fely David, Ed.D. \\ Gil Aganon \\ Josefina Cabigon, Ph.D.
}

Eireen has already mentioned that the cluster sampling technique will be used in your benchmark study. You should keep in mind as well that you should really use an $\mathbf{O R}$ approach, which is why there is this initial networking between the managers and the researchers.

There will be additional special topics to be presented tomorrow, particularly topics on gender and reproductive health, cost analysis and sustainability, and also a topic on using men as FP outreach workers. Why do we have these topics? The minimum information that you need in your cluster survey has already been defined. There are only three minimum requirements. However, this bare minimum may not be enough. You may have additional concerns as well. The question now is: "Can you add more information?" If you look at your problems, you will immediately have some ideas about factors that contribute to low CPR. You need information about knowledge, attitudes and skills. These should also be considered in designing your survey.

Another thing that can be thought of is: After a cluster survey or an OR diagnostics study, you discover that there is still a problem. You want to address that problem with an intervention and may plan to do an intervention study later. Perhaps this won't be an LPP project anymore. Instead, it might be an LGU project. The LGU may want to fund a study to test whether an intervention suggested by the cluster survey can be addressed. It could also probably come from PopCouncil if they have money for that or from any other source. For instance, DOH has ENHR and it funds research . Also don't hesistate to contact a research institution to help you develop this particular OR study if you really need to test this intervention. In essence what we are saying here is you are not limited to the cluster survey, you can go beyond that even after the conduct of this benchmark study. We have now created what we call an "OR research culture" among you. 
You as program managers are now required to have a benchmark to address programmatic problems. It is required by LPP national that you have to provide the benchmark on immunization, CPR and tetanus toxoid (TT+). That is the problem situation which requires a cluster survey using an OR perspective. The concerns here are the level of immunization and full immunization coverage of children and mothers in your province. The World Health Organizatin has modified the complicated mechanism of cluster sampling. They now have the WHO cluster sampling design which is also called the EPI sampling design or the 7 by 30 sampling design.

The immediate objective of WHO was to estimate immunization coverage through the examination of approximately 210 children selected randomly at thirty groups of seven children each for the strengthening of immunization services for children in developing countries. This can be translated for your own province. Clusters can be in terms of barangays, sitios or municipalities. The ideal way of clustering is in terms of barangays since that is the smallest political unit in our country. You also have to note that the smaller the population size of the barangay, the lower its chance to be selected.

In your province the lowest sample size is 210 . You can draw 30 barangays randomly, proportional to the population size. Then for each of the 30 cluster barangays find seven children in the households who are immunized, fully immunized or not. This is also the concept in the measurement of contraceptive prevalence. You only need 30 barangays and ask 7 women whether they are using a currently using or not currently using a family planning method. You will need researchers like us to help you combine the three types of measures in one survey.

In simple random sampling the required sample size is 96. The equivalent of this figure using cluster sampling is 210. Why? Because simple random sampling is probability sampling while the World Health Organization cluster sampling procedure is not wholly probability sampling. The only probability sampling there is the first stage where the 30 barangays are selected at random proportional to size. 


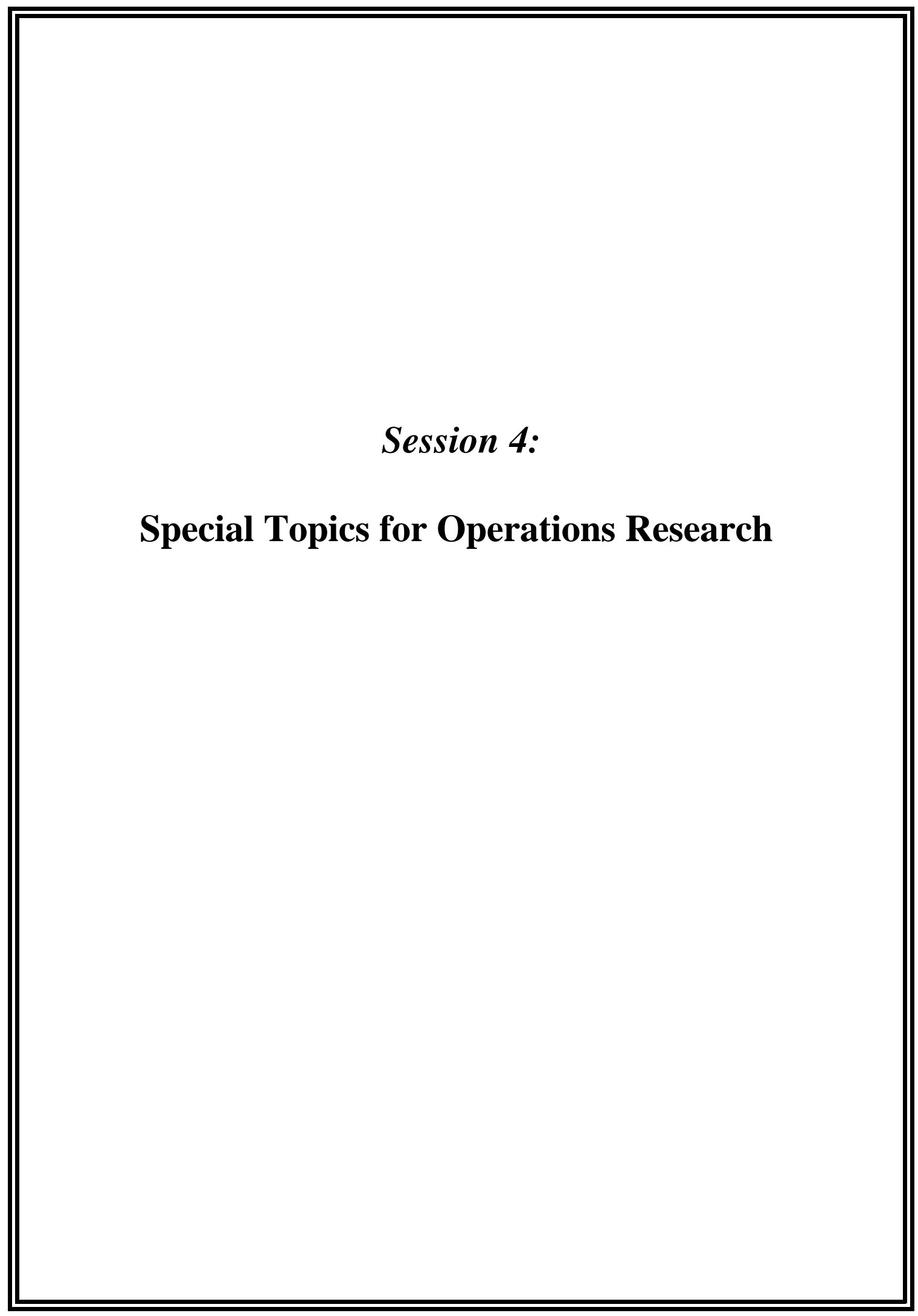




\title{
Gender Awareness and Reproductive Health
}

\author{
Aida Santos \\ Consultant, Women's Education, Development, Productivity and \\ Research Organization Inc. (WEDPRO)
}

Last night I went through your concept papers and saw some of the issues that you listed down. If I were to sum up all the things that you said so far, you have, at least to me, three major categories by which you can subdivide all the issues on why there are drop-outs, why the number of drop-outs is increasing, and the like. These are institutional, technical and human problems.

Institutional because some of you said there are rumors coming from other sections of society, and the Church is particularly mentioned. The state has its intervention vis-a-vis family planning or population issues. Under institutional you also have the GO-NGO collaboration. One of the issues raised here is that the NGOs are not reporting information/data from the field.

The other category that I saw is technical -- infrastructures, facilities, etc. In most cases we know that our budget is small and facilities suffer. In some areas family planning clinics have a lot to be desired. I know that in some clinics there is no privacy for counseling. Women find it hard to open up to doctors, especially about family planning. Resources are an extremely crucial issue in arresting/decreasing drop-out rates. We will attempt to provide a more expansive framework in looking at gender vis-a-vis your issues.

The third issue is human. A lot of problems put there have to do with a lack of commitment. A group said that there is a lack of positive attitude in the client-provider relationship. Well, I suppose we should be realistic about whether the nurse/midwife/volunteer is overburdened. They might say, what am I getting from all of this? It is attitudinal, it is probably a question of commitment, but then you begin to wonder what can be done about it. For example, one of the common problems among the concept papers is client-provider relationships. How can we change these? How can you as a program manager/decision-maker make a dent in terms of what is really happening in the field?

Now, back to what I was saying, what is the connection between our entire OR activity and the issue of gender? Well, I was hoping that in the course of the discussion we 
can:

(1) Flesh out some issues in family planning using a gender lens. I always say that in this time and clime especially after Cairo and Beijing I think these are the milestones in your concerns internationally and globally. We have to use new eyes in looking at family planning. I think it is essential that we do this especially because these are international agreements. In the global community, the Philippine government is committed to uphold some of the key discussions and agreements in Cairo and Beijing.

(2) Give a human dimension to quantitative data and information. For example, you said X percent are drop-outs, so what? What is it really? Maybe there is something beyond numbers to understand the core human problems of family planning. Family planning is one of the most private, intimate issues that has become a public concern in a way because we're really talking about sexuality and relations.

(3) Provide a basic framework of reproductive health issues using gender as an approach.

One of the things that came out very clearly in Cairo and was re-emphasized in Beijing is that we have to look at family planning and at health issues with reproductive health as a perspective. That was agreed on by all those who attended the conference.

What is the meaning of reproductive health? I am quoting this from the document in Cairo: "Reproductive health is a state of complete physical, mental and social well-being and not mainly the absence of disease and infirmity." Many of you are medical doctors, I don't have to go deeper into this. You know that the biological aspect of ill-health or good health is really a component of the entire social being of that person. We should look at health not just in the usual biomedical sense. There is a lot of research going on which look at how we can have a sense of what is called wholistic health.

Family planning, of course, is part of this. Remember that family planning deals with reproductive health. For example it is said that people should be able to have a satisfying sex 
life. It is nearly impossible to have a satisfying sex life if : (1) you're a woman who's constantly burdened with a fear of getting pregnant; (2) you're constantly thinking if your husband is faithful; (3) you're sick or not feeling well; and (4) you have taboos or sexual hang-ups.

In family planning we should be talking not just of fertility but infertility as well. On the whole, we have not really done much in terms of infertility. There are people - men and women - who also have infertility problems.

One volatile issue I know that is not openly discussed but is coming out in qualitative research is the issue of violence. There are a lot of women who cannot say no to unwanted sex and therefore, in the end, to unwanted pregnancies. This is because of the threat of violence.

To reiterate the question of rights, implicit in having a satisfying sex life and in knowing when and if you want to have children is the right of men and women to be informed and to have access to safe, effective, affordable and acceptable family planning methods of their choice. The reality in the field is quite different. Why? Because I know of some areas in the country where the service providers are made to push for certain methods of contraception. So where is choice of contraception here? Or do you have a choice if your husband doesn't want condom and you want to choose condom?

The right and access to appropriate health care services will enable women to go through pregnancy and childbirth safely and provide couples the best chance of having a healthy infant. Being pregnant and protecting yourself is a concern. A lot of hospital admissions are related to termination of pregnancy complications. In fact, there's a UPPI national study on abortion that is coming out, and the findings are extremely interesting: one of these is that about 250,00 - 750,000 women have abortions annually.

Reproductive health care as defined in the conference is the constellation of methods, techniques and services that contribute to reproductive health and well-being through preventing and solving reproductive health problems. The thing here is, we can have the best facilities but if women don't go to your clinics or are not accessing your services, there must be real problems. It has nothing to do with the technical aspect anymore. Maybe it has something to do with the human dimension. 
As a women's health advocate, one of the things I'd like to see is an integrated approach to reproductive health care. In other words, we must not see family planning as a separate from STD or HIV/AIDS. You see, Asia will be the HIV/AIDS pandemic area in the year 2000 and beyond, whether we like it or not. I think poor management of health will be contributory to HIV infection. That is an area where I do a lot of advocacy.

I would like to flesh out in what sense you can you look at gender and link it up directly or indirectly to your work. One of the things most women say when they go to the clinic is "Marami akong ginagawa, hirap na hirap na ako, marami akong anak." (I have many chores, I'm overburdened, I have many children). I'd like to reiterate that women have triple roles: reproductive, productive, and social.

[Ms. Santos then proceeded to elaborate on these three roles. These are very difficult to balance properly, especially in the context of the growing number of single-headed households, particularly due to migration and overseas contract work.]

There are other issues as well. On marital rape, a lot of married women we've interviewed would say, "Siyempre ganoon talaga iyon. Kahit ayaw mo, kailangan dahil responsibilidad mo yan." (Of course it is always like that. Even if you don't want it, you have to do it because it is your responsibility). There's no concept of female autonomy, even in marriage.

What about the legal status of women in marriage? Does she lose all her rights to her bodily/sexual integrity? What does the law say about this?

Benefits, rights and welfare policy are also involved. You can look at these issues not just in terms of your own community or your own clients but also in terms of the women in your own workplace, in your own clinics.

I would like you to think of at least four ethical issues:

(1) Human subjects. I remember someone saying that there are no longer any 
objects of research. They are human subjects and therefore they have rights. Even as we come to them with good intentions about research we should be able to see the ethical issues. Ethics in research is now a very central issue, such as respect for persons and their autonomy and protection. A lot of issues involved in family planning are delicate or intimate issues. How do you as researchers/program managers/implementors come as near and use the data as much as possible and yet maintain the principle of autonomy of the subjects?

(2) Protection - How do you protect? If, for example, the issue of violence comes out, how do you maintain protection at the same time be knowledgeable about the parameters of rights?

(3) Beneficence - This is basically maximizing benefits and minimizing harm. I think you can relate this to your work. One example I can think of is when you give information on some method of contraception. Can you really directly inform your clients about the possible side effects?

(4) Justice in terms of equal treatment of subjects. To begin with, there is the researcher-subject relationship. Is it fair or equal? Is it a two-way process? Take the clinic set-up, for example. Do you always ask about and are you sensitive to her needs?

There are some other ethical issues which apply specifically to biomedical research.

- $\quad$ Emotional outburst/psychological upset. This happens during interviews or in counseling when the woman is provoked into something like trauma or in situations where confidential information has to be ensured. There are complaints from women about insensitive doctors getting angry when they go to the hospital already hemorrhaging because of a terminated pregnancy. So they don't go to clinics anymore.

- Presence or absence of persons in authority. When a woman is sharing an intimate thing you have the responsiblity to be sensitive and not to speak about her or laugh at her experiences. For you it may seem trivial but the 
mere fact that she's with you is a gift, as it's not easy to share personal information with strangers. Maybe as doctors/medical practitioners we are so used to these things but for ordinary women it is hard. If we are living in that kind of setting day by day, sometimes we become insensitive. According to the data we gathered from Region VI, many women are saying that providers, researchers, and decisionmakers are sometimes insensitive.

Interviews as a potential source of stigmatization of the respondents. This happens both in the research and clinic settings. For example, a woman is saying that she had an infection, and then she is asked about the cause of the infection. But how can she say she had sex? It depends on the respondent if she would still continue her story. Facial expression is crucial in counseling. You don't even have to say much in counseling; your body language tells a million words.

Cynicism due to a lack of feedback mechanisms. Do we have feedback mechanisms so that our participants in research actually participate? Or do we have feedback mechanisms in the clinic setting if there are findings later on? 


\title{
Male Involvement in Family Planning
}

\author{
Dr. Fely David \\ SSRI, Central Philippine University
}

I would like to begin by asking two questions. First, are men involved in FP at the present setting that you have? If yes, in what ways and why? The second question is, should men be involved in FP? If yes, in what ways and if no, why? I leave those questions hanging and I'd want you to respond to this later on. To do that let me raise some facts. Based on research, decisionmaking at home in Filipino families is still generally conjugal. So when you ask who makes the decision on this and that, husbands and wives would answer, we do this thing together. However, despite the joint or conjugal norm there are decision domains. When we ask about decision domains of women it would concentrate on home management: what to buy, what food to prepare, who will clean the house, who will go to market, etc. The decision domains of the men are: investments, financial resources, and sex.

What about the husband's domains aside from investment and sex? We also found out from research that when it comes to FP, although the woman says she decides whether to practice FP or not or decides what method to practice or not, when it comes to conflict, the decision of the husband prevails.

Let's look at our data on family planning. Maybe because of our culture or because of our perceptions, if you will look at the prevalence rate, the highest rate are the womenoriented methods. I'm not yet talking about the DOH-endorsed NFP, because you need husband participation when you practice BBT. We do not have any data on this. But on rhythm, calendar, pills, these have high prevalence rates and are really still womancontrolled. In my most recent study, vasectomy is almost zero in some areas in Iloilo. Qualitative data also confirmed that men do not want it. Why? Because they have misconceptions that if they undergo this they will lose their "macho image".

Let us relate these research findings to our decisionmaking patterns and our relationships. Let us also look at our patterns of human interaction. Women can not even talk about sex - we have sexual taboos. For instance, it is so easy for us to say "sexual intercourse". But try to say it in your dialect. You can not because it's taboo. But why is it that while the women can not talk openly about this, the men can among themselves? You listen to their conversation over bottles of beer; listen to their conversation while working in 
the field; they even talk about their sexual adventures. Do you often hear this type of talk among women? No. But men can talk about this openly. Women would also want to preserve the privacy of their sexual adventures/experiences with husbands. We want to keep it in our hearts, never mind if we were satisfied or unsatisfied. But we never tell other people about our dissatisfaction and frustrations. In other words, we women would not be very effective FP communicators if our targets were the men. We have reservations because of our culture. One finding we have is that men can be more convincing to men than women could.

And then of course, there is the question of formulating policies from the upper level down to the local level. Unless there are policies and mandates, it's very difficult to make people move, particularly when you are in a government system or an NGO system. So there has to be some legal or policy basis at least. We also need to develop IEC materials which promote male involvement in FP. Overall, then, there is a great need to improve, install and maintain family planning services that would promote and sustain male involvement in family planning. 


\title{
Cost Analysis and Program Sustainability
}

\author{
Dr. Saumya Rama Rao \\ The Population Council, New Delhi
}

Often when we talk about programs it all comes down to money. Do we have money to do this? Some people think that money is an important consideration, and so at some point we have to talk about resources. And this is what my presentation is about -- resource management. I would like to present a few thoughts on how cost analysis is usually done in OR projects. This will not be exhaustive, but only an introduction.

What is cost analysis? It is a decisionmaking tool which can be used by policy makers and program managers. You should think of it as an additional type of OR which will guide you in making decisions. What type of decisions will you make? For one, it will tell you about where you should put your money. When I say money, it kind of summarizes all the different inputs that one will require for a program. It could be supplies, personnel, time, equipment, etc. It also tells you what will be the cost of financing a program, how much resources you will require to set this whole thing in place. It also informs you how long to sustain a particular program. Basically, cost analysis helps you answer questions such as these.

I would like to share with you an example of a cost analysis that was done in Peru. In this country, the OR question was: Should family planning services be provided through fixed clinics, CBD (community based distribution posts) or "health posts"?

What they did was, they calculated the cost of providing services at each of these three sites. They calculated what is known as the CYP (couple years of protection). CYP is that amount of protection that a couple would be provided if they used contraception. What they found out was that it cost $\$ 12$ to provide one CYP at the fixed clinics; $\$ 6$ at the $\mathrm{CBD}$, and $\$ 16$ at the health post. Based on this, they figured out that the CBD point was the most cost effective means in delivering the CYP. This is one example where you could use cost analysis to help assist you in making decisions. 
Another type of concern where cost analysis can help is in line items. When you have a program there are several line items on which money is spent. You would like to know how much each of these costs. An example of an OR done in India is this program where family planning services were being provided within a cooperative structure. Costs were estimated for each components of this approach. Results were as follows:

$\begin{array}{ll}\text { Training } & 9 \% \\ \text { Field visits } & 20 \% \\ \text { Personnel costs } & 34 \%\end{array}$

For instance:

(1) Should additional staff be hired?

(2) How should prices be set for services?

(3) What component of total cost should be recovered? and

(4) Should services be integrated?

Let us go back to theoretical concepts now. You can think of the program delivery as a system with several components. You take INPUTS and these inputs are somehow PROCESSED and they come out as OUTPUTS/OUTCOMES:

\section{INPUTS $\rightarrow$ PROCESSES $\rightarrow$ OUTPUTS/OUTCOMES}

What are examples of inputs? These could be your supplies/contraceptives, clinic space or they could be labor/time spent by midwives, barangay health workers, medical workers and so forth. Now these inputs are put in several clinics and health posts so when they combine in certain ways you get certain outputs, which are your service deliveries. This could be the number of clients you are able to reach or the number of IUD insertions one does or the number of counseling sessions. Once you've got this, you also have an output which is a longer-term one, and this is what we call an outcome. This would probably be: in the community, the knowledge of family planning has increased, or it could be fewer pregnancies over time. 
All of you must have heard of the term "cost effectiveness". Cost effectiveness is a very simple concept: it is a ratio where you have cost as the numerator and effectiveness as the denominator. This effectiveness is the measure of what I called an output/outcome in the previous slide. A sample of cost effectiveness would be something like about $\$ 12$ for one CYP in the previous topic. That is a sample of a cost effectiveness ratio. Or you could ask, what is the cost of immunizing a child against six diseases or the cost of recruiting a family planning acceptor?

Usually when you do cost effectiveness, you do it when you want to compare different ways of reaching the same objective. For instance in our earlier example -- the service could be provided at three different sites. It is the same service provided to the community, but it could be provided at the CBD, fixed clinic, or at a health post. You want to find out what is the cheapest way of reaching the particular output.

There are various ways to define costs. Usually, we concentrate on financial costs. These could be expenditures made on goods and services, excluding the cost of items that the program does not pay (donated inputs). A broader definition would be economic costs. In this, what you do is include all the items that are used in that particular program. Let me give you an intuitive sense of what an economic cost is. It is not just a reflection of what you just spent or taken from your pocket. It is the value of the most productive alternative use of the same resources you are using.

The next type of cost is the difference between those costs that are direct and those costs which are indirect. Direct costs are explicitly identified with the service or product, and by product, we mean giving out IUD, pills or condom. Indirect costs can not be linked directly with the service or product. Examples are salaries of administrative staff (accountants, payroll officers, janitors) and office supplies.

Another type of cost classification could be between joint and non-joint costs. Most of the time you find that there are certain costs that have spread over clients in your health center. There are other costs that are associated with those products that are delivered for just one client. Let us go back to our DMPA example. A woman is being injected with DMPA. Probably before injection, you give her a swab and then give her the shot. That particular injection and that particular swab are being used by just one client. So it is given 
directly to that particular person and therefore it becomes non-joint. There are also some costs which could be spread over all the clients. If your clinic is in a rented building, the rental costs are being spread over the clients. Therefore, they are known as joint costs.

Apart from this there are two more types. Recurrent costs are costs of inputs that will be repeatedly used. Examples are medical supplies and salaries. There could also be capital costs, which are costs of resources generally over one year. Examples are your X-ray machines, emergency equipment, and so forth.

The final classification that you could think of is between average and marginal costs. As you all know, average cost is the total cost divided by the number of units of output. The word marginal means additional to one. So you think how much will it cost to provide the service for one more client? So you say, I am already servicing 120 IUD users per month. And you want to know how much it is going to cost to serve an additional client, the 121st IUD user. That is what you mean by marginal cost.

These are the various types of costs that you'd be considering when you are doing your analysis. Let us think the usual data sources. Most people look at: (1) budget outlay; (2) actual expenditures; and (3) estimates. The items here are usually personnel, supplies, equipment, building, training, IEC.

On sustainability, the program should be able to cover recurrent costs. Researchers for the past ten years have brought out three basic strategies by which a program can be sustained. One could be community financing. For instance, let's say you have gone to your barangay and you've told the influentials in that barangay that they must start bearing a portion of the costs. Maybe they can take on a certain percentage. So you give them ownership of that program. Maybe this is a very good example for LGUs because you have to be concerned now about where you are going to get resources and how you are going to sustain the program. Since you are in the initial stages now, you can think about three or four years down the line on how to keep the program going. Are you going to consider charging the clients who come in? And then think about which services you are going to charge the client for. Maybe you give FP services free but you start charging your $\mathrm{MCH}$ services. Or you could probably charge them for whatever services they used. These are certain things that you should be considering. The third strategy that has been found to work 
is in industries, if you can convince employers that providing FP and health care is a good service that they are providing their employees. You can convince them that the benefits of a healthy employee overweighs the amount spent on sick leave or the amount that is spent in treatment. If they can balance these kinds of costs and benefits then maybe employers will be happy to take on some of the costs and therefore the services can be provided at the worksites rather than at your public sector outlets.

In the video we were watching two days ago there was a program in Indonesia. The Indonesian program is essentially a free program, but then they started thinking that the government cannot keep providing these services free because the number of users is becoming bigger. So now if the services are to be spread over more people, if the continuation rates are increasing, if the number of new users is increasing, if the population size is such that you are going to have bigger cohorts to whom you are going to provide the services, then you have to think about whether you will still be providing these services for free. 


\section{OPEN FORUM}

Dr. Michael A. Costello, Research Associate, RIMCU: I have a question for Aida. I couldn't agree more with what you're saying about counseling, about the role of the person in authority and the need to listen and body language. I think that is all very good, but I am not certain about some things. Are you going on to say that these are gender issues? Because I am just wondering if it is more an issue of power or authority. I noticed that because I am involved in running a school and very often I hear the teachers talking to the pupils. After a while, the pupils get the idea that the teacher is acting like he/she already knows everything. He or she doesn't want to listen, or already has the answer. So would you like to comment?

Ms. Aida Santos, WEDPRO: It's not a gender issue per se but I flashed those overheads just to show some of these power issues related to counseling in a clinic setting or even in research. Women can be as sexist as men, and power is at the core of these gender issues. It is a power relations issue. I was in a training where a midwife was sharing her experience in IUD insertion and she said, "Kasi ho may quota kami, etc." (We need to meet a quota). The doctor, who happened to be male, disagreed and said, "Hindi iyan totoo" (That is not true) and looked angrily at her. It was very obvious to the process documentor that it was true. This was a power relations issue as well as a gender issue because he is a male and more so, a doctor.

Dr. Saumya Rama Rao, PopCouncil, New Delhi: I would like to share with you something related to the point that you brought up about the relations among service providers. In the government health program in India, we have both male and female workers. The job responsibilities are a bit different, but in terms of designations they are equal. When we go to a meeting, we notice that the female workers invariably sit on the ground and the male workers sit on the benches. And they'll be saying, "Hey, you, tell what you have done." In truth, the doctor who is in charge of the meeting is actually the 
boss. The male workers feel that the female workers work for them. That is one example about variation in how workers are treated even with the same rank and the same pay scale.

Dr. Baguinon, PHO, Cagayan: What about violent sex, which is usually caused by husbands who are heavy drinkers, drug addicts, or of a jealous nature. How do you solve these problems?

Ms. Aida Santos, WEDPRO: There are researches emerging in crisis centers, and we are finding out that alcohol and drugs are just aggravating factors. In other words, there are men who don't need drugs or alcohol to commit these violent acts. The other thing that's coming out which is more of a question to crisis centers is this: If we accept that alcoholism and drug addiction are the causes of violence, therefore most of the offenders of rape cases would be absolved because of these aggravating factors. But that is a very dangerous conclusion, considering that many children are raped by drug addicts. Rape or violence is actually about power relations. The feeling that you can violate somebody is something that is socially constructed.

Dr. Marilou Costello, PopCouncil: I would like to bring back the discussion to the service delivery setting. What do all these discussions mean to us as service providers or program managers? For me this brings us back to the idea of a model of service delivery that is client-focused. We need to understand the context of the client. Last night we were discussing a proposal of a project to be conducted in Davao del Norte. Like you the project proponents were participants in a seminar like this. As a result, they developed a proposal which they submitted to PopCouncil for funding. The idea was that they are going to do an intervention to enhance their counseling program. We were grappling with the idea of trying to bring in the perspective that Aida shared with you this morning. How can we bring that into the counseling? It is very difficult being sensitive to your client without having preconceived notions about what FP method that client should choose. It is an attitude that you want your provider to learn. The challenge here is how we can incorporate these ideas into our own service delivery setting. That is where OR could come in. 
Cecille Tuazon, EDD Coordinator, Capiz: According to Dr. David, the culture in the Philippines is such that women are submissive to their husbands. But I think that at present, Philippine culture has become modernized and women's liberation is practised. Women now are not always submissive to their partners. We can fight for our rights and we have become equal with men. What can you say about this?

Dr. Fely David, SSRI-CPU: I think we are hearing an ideal answer. People who have already gained a certain level of gender awareness will have that kind of perception. The truth is that the women are still really submissive, especially in the grassroots.

Aida Santos, WEDPRO: We do know in the Constitution what are equal rights before the law, etc. In the real world, however, this is not applied. In all the focus group discussions and trainings that I attended, the data are proving otherwise. It is very hard to change cultures, traditions, and consciousness.

Dr. Mike Costello, RIMCU, Xavier U.: Two comments. Aida said that it takes a very long time to change cultures, and so a sort of a parallel idea is that it takes a long time to change the basic personality, the deep psychological sub-stratum of an adult. I mentioned that because of a comment on Fely's presentation, she said the "role of men." You used two terms, "male" and "men" as though they are synonymous. I think they're not synonymous because for me, man means an adult. So I am just wondering, if you forgot to bring another dimension, which is "boys" -- kids or children who happen to be male. A topic which wasn't brought up is the whole idea of adolescent sexuality or population education. If you want changes in the culture, it is hopeless to talk to somebody who is over twenty. You have to start with the young people and give it ten to fifteen years. I am saying that this is also something to consider because I don't think it has come out very strongly in this workshop. 
Dr. Fely David, SSRI-CPU: Yes, I agree with Mike. If we're talking of changing cultures, one of the recommendations I had in my dissertation was that we really have to go back to curriculum, education and instruction materials or probably even go back earlier, say, educating the parents to educate their children. One of the things that came out of the Women's Development Plan was about these policies and mandates on the curriculum materials that have to be changed or reoriented towards gender-oriented issues.

Aida Santos, WEDPRO: I'd just like to share one finding. There are researches on the adolescent sexuality that indicate that boys aged 16 to 18 have their sexual initiation from women who are into prostitution and they do not use contraception or practise safe sex. As you know, teenage pregnancies are also on the rise. The challenge to us, then, is to recognize the issue of adolescent sexuality. The FP program that we have right now is so focused on marriage. What do you do now with adolescents or single men and women who are sexually active? We know that this is a delicate topic to tackle because of our traditions. However, if you want to be truly effective managers, implementors and service providers, these are the harsh realities not just in the Philippines, but all over the world.

Dr. Marilou Costello, PopCouncil: We have program managers here, so what I would like for us to do is to think in terms of how their programs can respond to these issues, particularly in terms of providing services to adolescents. Is there something that can be done at the level of LGUs or health systems, given the constraints of your own service delivery system?

Dr. Jocelyn Ilagan, FPS, DOH: I would like to comment on the extent to which service providers are being trained in gender sensitivity. Presently, this type of training does not exist. But we also recognize that this issue should be a part of the changes that should be made. We do hope that with this increased awareness, perhaps there could be some form of initial change. We do not expect an overnight change, but the 
point is that, it is about time that we move towards this direction. There should already be an initial change coming from the grassroots level.

Dr. Marilou Costello, PopCouncil: Thank you, Jojie. I think what she is trying to emphasize here is that there is already a realization. In fact, a policy paper has been developed on this, and it was explained in our first OR workshop in Puerto Galera by Dr. Quintong. The paper discussed the recognition of a shift, a paradigm shift, towards reproductive health.

Virginia Laguihon, FP Coordinator, North Cotabato: Because there is a tie-up between the Department of Health and the Department of Agriculture it might be more cost effective if they could integrate the concept of gender sensitivity into the farmers classes of the DA. Most of their participants are male, so they have to integrate the idea that males are the best motivators.

Dr. Marilou Costello, PopCouncil: If you would excuse me, I believe there might be certain misconceptions here. We should be very careful in saying that "males are the best motivators". There should be some qualifications to that, right? I think Fely would disagree with that conclusion. In some situations this may be true, especially in reaching other men, but I think even her own research did not show that kind of general conclusion.

Dr. Saumya RamaRao, PC New Delhi: You sometimes hear the suggestion that agricultural workers or people who come to farmers meetings would form good FP motivators. What is the cost of utilizing these people? These are very good examples that are coming up. Here you have BHWs that are being provided honorarium and now you are going to have another set of motivators who would be members of this farmers group. A decision has to be made whether the giving of honorarium should be continued for these BHWs. Or should the resources be channelled to these volunteers from the farmers group? You have to think about whether it is a viable alternative. You can do cost analysis to help you decide. 


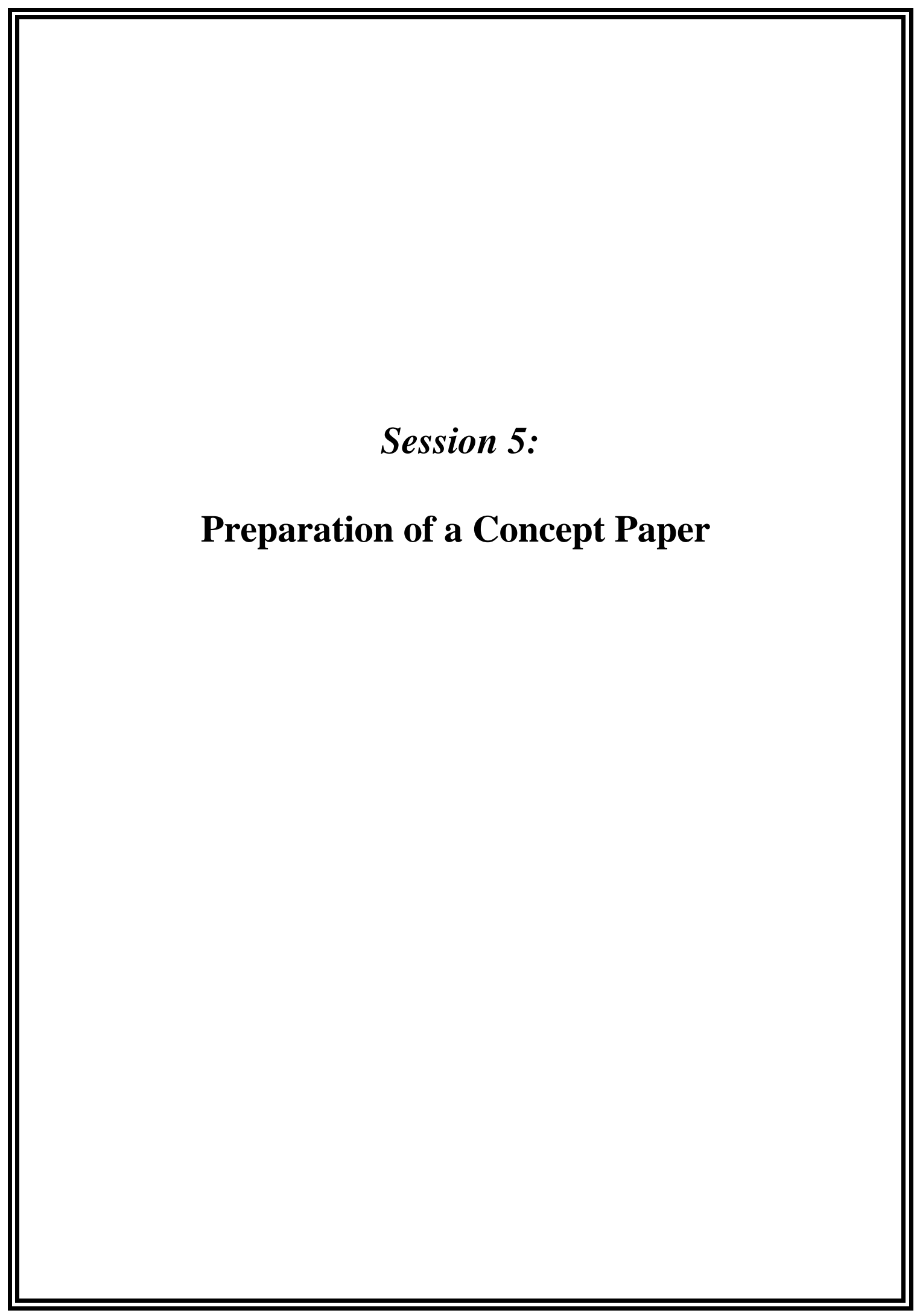




\title{
Elements of an OR Concept Paper
}

\author{
Dr. Michael Costello \\ RIMCU, Xavier University
}

This talk is supposed to be a sort of a wrap-up as we are coming full circle. We heard about the "paradigm shift" towards reproductive health and towards gender sensitivity, but I think there is a third paradigm shift, a change that we want to bring about within all of you. That is a shift towards OR. By the end of this workshop, everyone is supposed to understand something about OR and to appreciate it. Well, if I remember my Bible correctly, it says, "By their fruits you shall know them." So everyone has to come up with some fruit, an OR concept paper. And we hope your fruit is neither overripe nor sour.

Let me begin by just saying something about what you may call the "heart of writing a proposal." That is a word that makes some social scientists uncomfortable -- "heart." Because they'd think that, "Oh no, social science is a science, it is highly quantified, we have mathematical models, we are technicians." But I belong to the old school and I believe that there should also be an element of being a craftsman or a social philosopher. I think you have to know ideas and like ideas before you can come up with a really good social science output. Well, that's very vague, I'm sure, but I'll try to clarify it.

There is a book by C. Wright Mills called the Sociological Imagination. It has a very good appendix called "On Intellectual Craftsmanship". That is the first thing I wanted to bring out. We'll get in to some of the elements of an OR concept paper. You will have a little workshop and have a consultant. Don't worry, you're going to get it done. But first I wanted to say something about this idea of craftsmanship.

The point I'm really trying to get at is that every good proposal begins with an idea. It is not just an academic exercise, that you're doing it because you're told to do it. Where does this idea come from? It can only come to you, the program manager, if you have a sort of passionate love for your work. Program managers should feel that their job is very important, that there is a human dimension to it. I think that came out at Aida's talk. She talked about a sort of ethos - that we're talking about lives here, we're trying to save the lives 
of women and children, we're preventing AIDS, we're concerned about the spread of abortions in this country and it is even costing a lot of money. So these are really very important topics, and I think that is a message you should get out to your service providers, and that is something you yourselves should have. And if you have that sort of commitment you will be thinking of your program all the time, you will be very concerned about it, you want to talk with other people, you want to read up in the literature and you will get plenty of ideas. In fact, your problem will be that you can't do research on all of them. You'll have too many ideas and you'll have to prioritize them.

A concept paper should therefore be something that you are excited to do, something that is very important for you, something you've been thinking about for a long time. You've got to think about your concept paper and your measures very carefully, you've got to be sure that this is a power-packed idea which you think can change your program -- raise the CPR, save more lives, better $\mathrm{MCH}$, whatever.

By the way, these ideas do not necessarily just come from you. You've got to be willing to walk around and talk to people. You've heard the word "grassroots." You have to visit the clinics and talk to some of your clients. Don't just depend upon reports. You have to talk with your service providers and listen to them during meetings. What are the problems that are cropping up and what are your ideas for solving these problems? Talk to the funding agencies, what are their concerns, because they are in touch with the international community and a lot of these "buzz words" really are very important things that are missing in our programs today and which should be injected. Talk to advocates and NGOs. They also have a very passionate commitment to some little agenda that they want to push. You can't be their puppet, you can't do everything they want, but you've got to listen to them. In other words, you have to think, you have to listen, you have to meditate and reflect and then come up with a good concept for your concept paper.

The second thing I have noticed as a teacher in this country is that a lot of people have a difficult time in writing. They have a sort of a writer's block. We do this job and that job but the one we keep on postponing is sitting down and writing. Once you write it, you have to write a second draft and you really hate that, too. So you've got to work to overcome that problem because you can't have an OR concept paper until you sit down and write it. In this case, I think you can go to consultants. Write a second draft, circulate it for criticisms and accept criticisms humbly. 
We will move on now to the technical side of writing a concept paper. This can be briefly summarized by the following overhead. (See Figure 1.)

\section{Figure 1. -- Outline for an OR Concept Paper}

1. Title page

2. Project Overview
a. Study problem
b. Major objectives/hypotheses
c. Proposed intervention (if applicable)
d. Study design, techniques of data collection and analysis
e. Dissemination/utilization plans

3. Timetable

4. Budget

5. Appendix: Curriculum vitae of project directors

Go back to your handbook and look for the sections that have a little box for example on page 11. They are called the "what to do sections" and they look like a cookbook. Every chapter has one.

Go back this afternoon, no matter what the temptations are. Sit down in a group, have a brainstorming where everybody has something to contribute. Come up with a good idea, then prepare a paragraph or two for each of the topics in the above outline. Follow the guidelines in the "what to do" sections. Before too long, you'll be finished. 


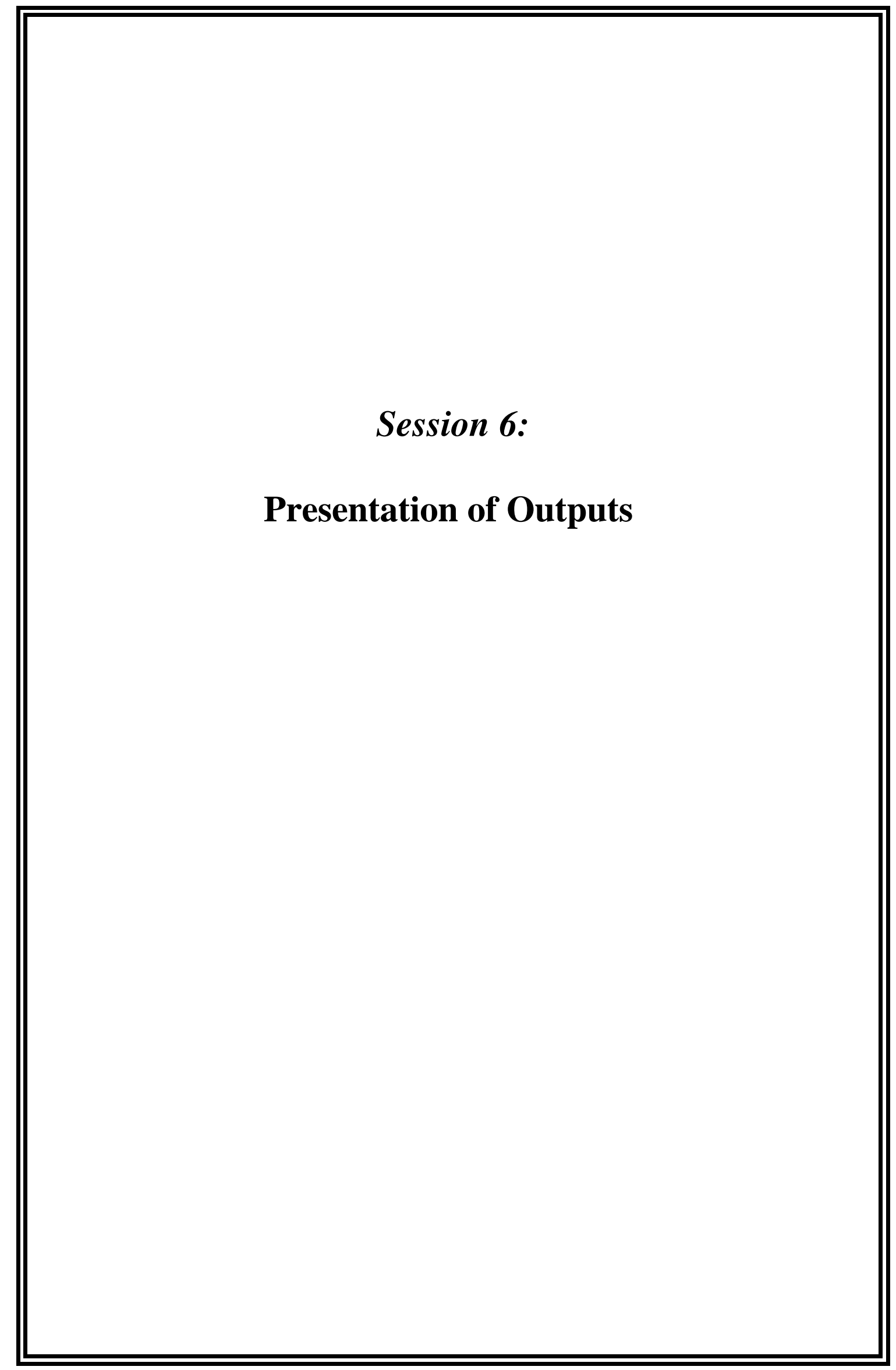




\title{
An OR Study on the Low CPR of Benguet
}

\author{
Esteban Piok, MD \\ Juliet Sacley \\ Provincial Health Office, Benguet
}

\section{A. PROBLEM SITUATION}

The contraceptive prevalence rate in Benguet is only $22 \%$ as compared to the national CPR of $50.7 \%$ in 1995 . The low CPR may be due to the inadequate KAs of service providers, low level of KAP among MCRAs, and inaccurate and nonupdated recording of new acceptors and current users.

\section{B. OBJECTIVES OF THE STUDY}

The immediate objective is to conduct an operations research study to determine the KAs of service providers and KAP of MCRAs and to assess the quality of FP statistics coming from various sources such as FHSIS and CDLMIS. The ultimate objective is to increase the CPR in Benguet.

\section{DATA COLLECTION/ANALYSIS}

A non-experimental, posttest only design study will be conducted by the Provincial Health Office, in collaboration with a research institution. All barangays in the province will be classified into clusters in terms of contraceptive prevalent rates. Thirty (30) clusters will then be selected through cluster sampling. Seven respondents aged 15-49 will be interviewed in each cluster. Only quantitative data will be collected, involving interviews for MCRAs and self-administered questionnaires for service providers. Service statistics will also be utilized. With the aid of a research consultant and a research institution, analysis of the data will be employed with the univariate or bivariate techniques. An in-depth assessment of the quality of service statistics will be employed.

\section{DISSEMINATION/ UTILIZATION PLAN}

A final research report will be completed before September 30, 1997. A report on this study will be discussed with the Municipal Health Officers and Public Health Nurses during one of the regular meetings conducted monthly at the Provincial Health Office. Likewise, a copy of this report will be furnished to all local health boards in the province.

\section{E. TIMETABLE}

April - September 1997

\section{F. BUDGET}

An amount of P200,000, taken from the LPP fund, will be alloted for the expenses incurred during the conduct of this study. 


\title{
Some Factors Affecting the Performance of Hospital-Based Family Planning Clinics in Eight District Hospitals in the Province of Ilocos Sur: A Diagnostic Study to Increase the Contraceptive Prevalence Rate (CPR)
}

\author{
Felipe Almachar, MD, MPH \\ Rosalinda Quisada, MD \\ Provincial Health Office, Ilocos Sur
}

\section{A. PROBLEM SITUATION}

The contraceptive prevalence rate of Ilocos Sur is low compared to the Regional CPR (33.67\%) and much lower than the national figure $(50.7 \%)$ despite the numerous family planning services and facilities available in the province.

The performance records of hospital-based Family Planning clinics have been varied but generally poor. The CPR has not significantly improved in spite of the fact that these clinics cater to both permanent and non-permanent methods of contraception.

Several factors could contribute to these problems, such as inadequate capability (knowledge, attitudes and skills) on the part of service providers, low service capability within the hospitals, and client-related reasons.

What factors contribute to the poor performance of hospital-based FP clinics? If performance is improved in these hospitals, will CPR of the province be increased?

\section{B. OBJECTIVES OF THE STUDY}

The immediate objective of this study is to investigate some factors affecting the performance of hospital-based FP clinics such as the following:

1. knowledge, attitudes and skills of service providers,

2. availability of supplies and materials,

3. adequacy of FP facilities and equipment, and

4. attitudes of clients.

The ultimate objective is to provide policy makers and program administrators with a better understanding of the reasons why the performance of district hospitals vary and how this could be improved. The study will also seek to determine if the provincial CPR will be increased with an improved performance on the part of the hospital-based FP clinics. 


\section{METHODOLOGY}

The study will be conducted between January and December 1997 by the Provincial Health Office in cooperation with the University of Northern Philippines, Research Group, Vigan, Ilocos Sur.

All eight hospitals (provincial and district hospitals) will be covered in the study. Review and validation of records and reports on FP performance of the hospitals will be conducted.

Questionnaires to determine knowledge, attitudes and skills of service providers will be formulated and administered. Questionnaires regarding clients' attitudes and knowledge on FP will likewise be administered to MWRAs visiting at the OPD, OB-GYN and Pedia wards of hospitals. A team of trained enumerators will be employed to collect the data.

The coding, editing and data processing will be done by the research group of UNP.

The computer facilities of UNP will be utilized to tabulate the data. A final research report will be completed by early 1998 .

\section{DISSEMINATION/ UTILIZATION PLANS}

The dissemination of the results of the research will be made immediately after the submission of the Research Report. A provincial consultative meeting with the Provincial Health Officer II, provincial key officials, FP coordinators of the the district hospitals, chief of district hospitals, and other LPP special members will be held.

The findings of the research will be the basis for the initiation of appropriate interventions at the different hospital-based FP clinics.

\section{E. BUDGET}

[The budget had not yet been finalized at the time this proposal was submitted.] 


\section{OPEN FORUM}

Dr. Marilou Costello, PopCouncil: I'd like some clarification on the second report. I think I'd like to know how big the volume of clients is in the hospitals of Ilocos Sur.

Dr. Felipe Almachar, PHO, Ilocos Sur: In the provincial hospital (the tertiary hospital) their average consultation in the $O B-G Y N$ is around 40-50 patients. They have an average of 5-10 deliveries in their wards. In the pediatric wards they have 30 to 40 in-patients on the average per day. The district hospitals have about a quarter of this.

Dr. Marilou Costello, PopCouncil: I missed some of your comments on funding the research. You said you are planning to undertake the research with funding already. Is this funding from LPP?

Dr. F. Almachar, PHO, Ilocos Sur: That's the reason we project this study as occurring in 1997. Ilocos Sur belongs to the blue LGUs, so funding will start in 1997. We intend to do a diagnostic study, knowing that five or ten years ago there was a department order stating that all hospitals should have functioning hospital-based FP clinics. This was implemented, but it is coming out now that not all these hospitals are performing at par. Some did not even have surgical sterilizations anymore although they have trained personnel. Even if you look at their performance in non-surgical sterilization they're not doing very well either. What we really want to do is to study the ability of the client providers stationed in the hospital-based clinics to do what they are supposed to do. For example, why is it that the patient who delivers in an area and wants to have a postpartum ligation transfers and reschedules herself in another district hospital, when it could have been done right there? Is there something wrong with the trained service provider in that area? We at the district hospital will be in a better position to check and implement the program rather than non-specialists at the municipal level. 
Dr. Dely Alcantara, University of New Mexico, USA: I think I have some general reactions to the two presentors. Both of you are going to do a KAP diagnostic type of study. Doesn't this information already exist where you come from? Is this information truly new? Like in the Benguet group, I think one of your objectives is to increase CPR in Benguet. Once you know the KAP, how do you move from knowing the KAP to increasing the contraceptive prevalence? I guess the question is: are you assuming that when you know the KAP, you can intervene? I know that these are just concept papers, but it is important to keep these things at the back of our minds. We have been doing KAP since 1972, so everybody else has already been doing KAP. I am not saying, "Don't do it". All I am saying is, think about why you are doing this.

On a more specific comment to the Benguet group, you said you are doing a cluster sampling. What clusters are you thinking of doing, is it barangay clusters? How would you choose your clusters? Within that cluster you're going to choose seven respondents. And if I understand you right, you said MCRA. Do you intend to interview couples, and how would you propose do that? Why would you want to do couples, would you not just want to do women? All of these things must be clear in your minds when you do research.

You also said that you want to do self-administered questionnaires for service providers, as opposed to an interviewerassisted or face-to-face interview with a MCRA. The design of the questionnaire must be specific so that the person who's answering the questionnaire knows exactly what to do. You have to think very carefully in terms of the instrument design so that even if there is no researcher there, they will be able to follow the questionnaire from one step to the other.

With the Ilocano group, you have different respondents doctors, women clients women. Again, methodologically, how would 
you choose the doctors, are you going to do a sampling? With the MWRA, are you going to choose them as they come to the clinic? Or will you go to your records and sample them from there? The kind of statistical analysis that you are going to do depends on how you choose your sample so that you can generalize it to the whole population.

Dr. Michael Costello, RIMCU: As a follow-up to Dely's criticism I must say I agree that doing another KAP survey may not really be needed, as there have been a lot of them. The presentors might want to consider talking to the group from Maguindanao that I was working with. They had a very similar problem. After we talked it over we agreed that maybe the Situational Analysis will be of more help than a KAP survey in checking the level of quality being offered. 


\title{
A Study to Determine the Reasons for the High Drop-out Rate of DMPA Users in Quezon City
}

\author{
Magdalena Ybanez, M.D. \\ Perla Dosayla, M.D. \\ City Health Office, Quezon City
}

\section{A. PROBLEM SITUATION}

In Quezon City, there is a very high drop-out rate of DMPA that amounts to almost 50 percent. We are trying to identify why there is such a discrepancy given the fact that there is support coming from the Department of Health and also from other funding agencies like CARE. In fact, we were already given two batches of training and we also have logistics coming from $\mathrm{DOH}$. So it is expected that this drop-out rate will be low.

The discrepancy is because of the following reasons:

- $\quad$ the fear of side effects and complications on the part of the clients;

- $\quad$ misconceptions and rumors such as a case in District IIA where the wife who belongs to a prominent family got pregnant in spite of taking a second dose of DMPA;

- $\quad$ inadequate counseling skills of service providers who give the DMPA;

- $\quad$ indifference of the service providers to the DMPA program; and

- $\quad$ lack of trained personnel, especially doctors, to manage the complications (usually the cases of complications are referred to Jose Fabella Hospital).

\section{B. OBJECTIVES OF THE STUDY}

This study aims to determine the different reasons why the drop-out rate is very high in spite of the fact that Quezon City is one of the pilot areas in the DMPA Reintroduction Program.

There will be a survey to determine the different reasons for the high drop-out rate. We plan to do the study as soon as funds are available. 


\section{VARIABLES}

The study variables are: number of trained personnel who are not providing the service; number of untrained personnel; number of health center staff who were trained in DMPA and in interpersonal communication skills; number of trained persons, especially physicians, who are capable of managing complications; and number of supervisory visits conducted by the health center nurses and follow-up visits conducted by the midwives.

\section{DATA COLLECTION/ ANALYSIS:}

The study will use one-on-one interviews using questionnaires. There will be fieldwork where we will utilize the services of a research institution. We are planning to get the help of the Population Council.

\section{E. TIMETABLE}

Since we expect to get the first funds by April 1997, the study will be conducted tentatively on June or July of 1997 . The study can be completed in two to three months. 


\title{
An Analysis of FP Practice and the Provision of FP Services in the Province of Capiz
}

\author{
Mr. Francisco Fuentes, Jr. \\ Ms. Cecille Tuazon \\ Provincial Health Office, Capiz
}

\section{A. PROBLEM SITUATION}

Capiz Province has a CPR of $35.8 \%$, which is much lower than the regional (49.3\%) and national $(50.7 \%)$ rates.

Given the available FP facilities, supplies and manpower, the CPR of Capiz should at least be comparable or higher than the regional or national rates.

The possible reasons for this discrepancy are the following:

On the part of the clients, there is a negative attitude towards contraception, dissatisfaction about methods, used previously, misconceptions and rumors, religious beliefs, and resistance on the part of the husband. On the other hand, for the service providers, negative attitude towards FP and clients, lack of KAs of health personnel and extension workers, and poor accessibility of potential FP user to information and services.

\section{B. OBJECTIVES OF THE STUDY}

The survey will be conducted to determine which of the above factors are bringing about the low CPR in Capiz Province. A cluster survey will be conducted within 16 municipalities and one component city of Capiz. Thirty barangays will be randomly selected for this purpose, with 7 respondents/barangay. Actual conduct of the cluster survey will be done during June-August, 1977. The respondents will be MWRAs who are practising FP and also the service providers.

In addition to the survey, observation of the facilities through site visits will be carried out.

\section{STUDY DESIGN}

To answer the objectives of the study, the survey design is proposed. The analysis of data is to be done by a research institution. 


\title{
D. DISSEMINATION/ UTILIZATION PLAN
}

We are going to conduct a meeting with the PHO, CHO, PPO, IPHO Technical Staff, MHOs and PHNs. The results of the survey will be presented to them. Furthermore, we will distribute the executive summary to all LGUs and Mayors so that findings can be incorporated into the provincial, city, municipal, and barangay development plans.

\section{E. TIMETABLE}

\author{
February - August, 1997
}

\section{F. BUDGET}

A budget of P70,000 (P50,000 from the LPP, P20,000 from the LGU) is anticipated at this point. Further discussions on costing will be held towards the end of 1996. 


\section{OPEN FORUM}

Dr. Fely David, SSRI: Why does the Quezon City study want to find out what the reasons for the high drop-out rate are? If you are already sure that these are the reasons for dropping out, what you need is an intervention that will address those reasons. However, if you are not yet sure, then a situational analysis or a survey would be necessary.

Dr. Perla Dosayla, Quezon City: We were thinking of doing research for both the clients and the service providers. If we do the client survey, we will be covering the MWRAs. If through the intervention we find out the reasons for these misconceptions, rumors and complications, maybe we can increase or strengthen our IEC activities for the MWRA. On the part of the service providers, we plan to survey at least one service provider in each of the 54 health centers, measuring their knowledge, attitudes and skills. If the problem is behavioral, it will take a long time to change their behavior, but if it is knowledge, we can just retrain them.

Dr. Michael Costello, RIMCU: This drop-out is a very tricky thing. The question is: does she continue to use some method of family planning? If it's really not working for her, then sure, she ought to drop out. That's my understanding of quality of care and following up the needs of clients. I agree with Fely in that if you think it's possible, you can already jump ahead to intervention, because there was a study on DMPA drop-outs and what mainly came out was the issue of sideeffects. One might conceive of an intervention, either to help women cope with side effects, or to help them shift to something else. You might want to go straight to the second stage and do an evaluation study.

Dr. Marilou Costello, PopCouncil: Dr. Dosayla should perhaps consider reviewing the PopCouncil study on drop-outs from DMPA. Maybe it will already be possible to devise the next step, which would be an intervention. 
Dr. Dely Alcantara, UNM: I am a little bit confused. You said that you did not have a hypothesis, but then you told us that you have a number of untrained personnel and that you also have visits conducted by midwives. I think there are already embedded hypothesis in those statements. I think you want to test something with respect to service providers who are not capable. You already have a hypothesis except that it is not stated in a testable form.

Dr. Saumya Rama Rao, PopCouncil: There are several CPR studies that occur to me. When you say you're studying the CPR because it is low, you should remember that it is doubtful that the CPR will increase dramatically after you put an intervention in place. The CPR usually does not increase by more than 5 percent at any one time. The increase will be very gradual, so just be cautioned. Don't think that just because you put your study in place, you're going to see your CPR going up like that.

Dr. Michael Costello, RIMCU: This is a similar comment. It's also hard to miss the fact that so many of the studies are very much alike. The country has been trying for already twenty-five years to increase the CPR and bring down the birth rate. It is a little bit like the analogy of not eating your steak in one bite. Instead, do it a little bit at a time. Often $O R$ is on a very clearly defined and somewhat "minor" problem. It doesn't have to be this way but often it is. The CPR is a sort of the sum total of everything going on in the program. It's kind of a hodgepodge of so many elements. While it is still okay to do that, sometimes you might think of dealing with smaller and clearly delineated problems where you can get a very clear answer. It is also quicker and sometimes not so expensive to do. You have to think very carefully about the objectives of your concept papers and be sure you are going in the right direction.

Dr. Dely Alcantara, UNM: With regard to the Capiz paper, it is the first time I heard the mention of husbands. This is a topic that is very close to my heart 
because my dissertation found out that if the husband objects, the wife will find every reason to dropout. Being Filipinos, there are many ways the wives beat around the bush since they don't want their husbands to lose face. When they say, "I have side effects", does it really mean they are having side effects? Start asking questions regarding the dynamics between husbands and wives. Probably with this Capiz study, you may just want to focus on husbands since they have been left out. Even when we ask the husbands questions, most of the surveys focus on the wives. The husbands are just mentioned peripherally. In truth, they are very important. Maybe this is something that all of us who are looking at drop-outs should consider -- it may not be access, it may not be logistics and it may not be trainings, but it could be the husbands.

Dr. Fely David, SSRI: Thank you, Dely for the additional information. I think she confirmed what I said this morning on male involvement in family planning. We need more studies on men. Probably we can add some dimensions of male involvement in family planning. 


\title{
A Study on Low Coverage Rates for Tetanus Toxoid (TT2+) in Bacolod City
}

\author{
Ms. Emma Castel \\ Mrs. Nilda Martinez. \\ City Health Office, Bacolod City
}

\section{A. PROBLEM SITUATION}

Tetanus toxoid has a low coverage among pregnant women in Bacolod City. As a program objective, at least $80 \%$ of the total population of pregnant women should be immunized against tetanus toxoid. Program records, however, show that this target has not been met.

\section{B. OBJECTIVES/ HYPOTHESIS OF THE STUDY}

The study will focus on the factors that contribute to the low acceptance of tetanus toxoid immunization. A survey will be conducted to determine the factors that contribute to the low acceptance of TT2+ immunization among pregnant women in Bacolod City.

\section{PROPOSED INTERVENTION}

Comprehensive counseling of mothers, IEC campaign on TT immunization, and training of service providers.

\section{STUDY DESIGN/ TECHNIQUES OF DATA COLLECTION/ ANALYSIS}

Sampling and survey will be done on pregnant women and service providers (doctors, nurses and midwives). Data collection will be through interviews on mother's age, education, number of children, and number of TT immunizations. As for service providers, information on training status, knowledge and attitudes will be obtained.

\section{E. TIMETABLE}

$$
\text { June - August } 1997
$$

\section{F. BUDGET}

P50,000.00 (to be sourced from LPP funds) 


\title{
A Diagnostic Study to Decrease the Number of Drop-Outs among MWRAs Who are Practicing Family Planning in the Province of Tarlac
}

\author{
Ms. Develyn Florendo, FP Coordinator \\ Ms. Angelina Duque, Health Educator II \\ Provincial Health Office, Tarlac
}

\section{A. PROBLEM SITUATION}

Based on the analysis of data from the 18 municipalities in the province of Tarlac, drop-outs among MWRAs who are practising FP methods increased from 9\% in 1994 to $15 \%$ in 1995.

The increased number of drop-outs may be attributed to the following reasons:

- inadequate KAs of BHWs on how to counteract rumors and misconceptions;

- health workers are overloaded with the many different health programs and are unable to concentrate on FP activities; and

- poor management by health workers of side effects/complications.

In spite of the available resources, facilities, supplies, and manpower in the area, there is still an increase in the drop-outs among MWRAs who are practising FP methods.

\section{B. OBJECTIVES OF THE STUDY}

1. A cluster survey among MWRAs will be conducted to determine what factors contribute to the increasing number of drop-outs.

2. Trainings among health personnel/BHWs will be conducted to counteract this problem. Topics to be emphasized during the training will relate to those issues brought out during the suvey.

\section{DATA COLLECTION}

1. Questionnaires

2. Interviews 


\section{DISSEMINATION/ UTILIZATION PLAN}

The results of the cluster survey will be disseminated to the LGUs, the IPHO/technical staff, the Regional Health Research Team and the National Research Team through consultative meetings.

\section{E. TIMETABLE}

The study will be completed by the third quarter of 1997 .

\section{F. BUDGET}

P200,000 to be allocated under LPP funds. 


\section{OPEN FORUM}

Dr. Fely David, SSRI: If you look at the Bacolod study, it seems that there are two studies. It has a diagnostic study on factors that influence tetanus toxoid immunization and there is also an intervention which they plan to implement, although details on this were not mentioned. Other than that, I think it is clear what you want to find out and what you are planning to do.

Dr. Eduardo Baguinon, Cagayan: We just want to ask them what their TT2+ coverage was before the abortion issue came out as compared to their present coverage.

Ms. Emma Castel, Bacolod: Our TT2+ coverage before the restraining order was $129 \%$. Before the changing of the guidelines on TT2+, we included single women. Now, only pregnant women are included.

Dr. Michael Costello, RIMCU: There may be a reason for conducting the study and asking, "Are you nervous because you read in the newspapers that this causes abortion?" While this is a possible explanation, we don't know for sure, which is why we want to ask. If we know that the coverage rate has gone down, if we have historical records, then that will be a really interesting data set. If you have official records, you can go back to those records and eliminate the single women and then recompute the rate. You do have a masterlist, but I am not yet certain if the masterlist has every pregnant women in Bacolod. It is not easy, especially in the urban context, to get this information on that. If you have a biased sample, it just messes up everything.

Dr. Dely Alcantara, UNM: I'm not sure if you can do the survey (pre-and post-surveys) with 50,000 pesos. In research, you have to be realistic about what you can do with a certain amount of money. 
Dr. Marilou Costello, PopCouncil: To be fair to the participants, I have to say that we really haven't had a chance to have an exercise on budgeting. Perhaps if we had done that, we would have given the participants an opportunity to take a look at how much it would cost. What Ms. Castel is saying here is that LPP has set aside 50,000 pesos for them and that is already something they can work with. If she finds out later on that that's not going to be enough, then they contact other funding agencies to support the study or perhaps ask for an $L G U$ counterpart.

Dr. Fely David, SSRI: I just want to clarify if the Tarlac study has two stages: first, a cluster survey and then an intervention?

Ms. Angeline Duque, Tarlac: I think we have to do the cluster survey. Then based on the results of that, training will be done.

Dr. Fely David, SSRI: In that case, you really have to describe quite clearly what this intervention will be.

Dr. Marilou Costello, PopCouncil: Why did you want to use the cluster survey? Is it because you are going to do it anyway?

Ms. Angelina Duque, Tarlac: As I have said earlier, JICA is with us and we are equipped with materials because their programs there are $\mathrm{MCH}$ and FP. In spite of that, we still have a high drop-out rate. Doing this cluster survey will help us see the real picture.

Dr. Marilou Costello, PopCouncil: Actually, I know a little bit about this proposal because we discussed it only last night. I was saying that we have many studies that uncovered the reasons why people are dropping out. It was found that the 40 to 50 percent who drop out say they do this because of side effects. It seems to me that we already have an idea about why people are dropping out, so maybe we can work on 
that. That is, maybe it is now time to do an intervention on these rumors and misconceptions. Or maybe you want to do something on the management of side effects and see if there will be a change in the level of drop-outs afterwards.

The reason I am saying that is because you have a dilemma here about when to use your cluster survey. If you want to take advantage of your cluster survey, perhaps what you can do if you have a limited amount of money is to begin with an intervention -e.g., training of barangay health workers to counteract rumors. Then, find out later on whether this helped bring down the drop-out rates. You will then have a sort of posttest design. It's better if you have a pretest and a posttest, control and experimental groups. You will need to take the design into account. The more complicated the design, the more expensive. It seems to me like you are "hitting two birds with one stone " by using your cluster survey. Maybe you should think about it this way so you could maximize your use for your cluster survey.

Dr. Dely Alcantara, UNM: It seems to me that most of you are saying that we already have this in place, like training, logistics, etc. But the drop-out rate is still rising, so we want to find out why. Maybe what we need to look at is the content of the training. We could be training people, but nobody is evaluating the training instruments, the process of the training, or the personality of the trainors. So maybe the experimental design could test the contents of the training. Wouldn't it be interesting to think of the training as the control and experimental group rather than do one more standard cluster survey?

Dr. Michael Costello, RIMCU: Another possibility is to take some barangays, train the BHWs of some barangays, while the BHWs of the remaining barangays are excluded from the training. I know that drives program administrators crazy because you think you want to implement it everywhere, all over Tarlac. But you can randomly 
select some barangays where the barangay health workers (BHWs) are trained and some are not trained, then you can conduct your cluster survey. Your hypothesis is that there will be fewer drop-outs in the barangays where the BHWs were trained. In other words, think a little bit about your design. You want a survey, that is fine. But remember, you don't have to do your training all over Tarlac. You can coldbloodedly leave half of them out. If you find that it works, the following year you could train all the remaining half. I mentioned this because a similar logic could be applied to many other LGUs where you want to use the cluster survey. 


\title{
A Diagnostic Operations Research Study on the Causes of Variation in the Performance of FP Services Among Rural Health Units and City Health Offices in the Province of Negros Oriental
}

\author{
Filemon Flores, $M D$ \\ Flordeliza Dublas \\ Provincial Health Office, Negros Oriental
}

\section{A. PROBLEM SITUATION}

In the Province of Negros Oriental, the Contraceptive Prevalence Rate (CPR) is 50.8 per cent, which is close to the national average. A closer inspection of RHUs/CHOs performance records, however, reveals that the percentage accomplishment performance for new acceptors ranges from $12 \%$ to $36 \%$ and for current users the range is from $46 \%$ to $200 \%$ as of March 1996.

The ideal situation should have been more or less an even distribution of percentages of accomplishments across RHUs/CHOs considering that all FP service outlets in the province have been provided similar support such as logistics and training of personnel by the national, regional and provincial governments.

The program management would like to determine the causes of variation in the performance of FP services in order to address the factors that contribute to low performance or high performance. Appropriate intervention programs can then be instituted so that performance levels are uniformly high in all RHUs/CHOs in the province.

\section{B1. OBJECTIVES OF THE STUDY}

The immediate objective of the study is to determine the variables related to the service providers, FP clients and level of LGU support associated with the variation of performance of FP services across RHUs/CHOs in the province of Negros Oriental.

The ultimate objective of the study is to provide the program administrators with reasons why FP service performance is high in some areas and low in others. The results of the study can be used to develop intervention strategies so that the level of performance is uniformly high in all areas of the province.

\section{B2. HYPOTHESES}

1. The higher the quality of services rendered by service providers, the greater the percentage accomplishment performance of the RHUs/CHOs.

2. The higher the level of LGU support, the greater the percentage accomplishment performance of the RHUs/CHOs.

\section{OPERATIONAL DEFINITION OF TERMS}

1. Percentage accomplishment performance - refers to the actual accomplishment against targets of a particular RHU/CHO. 
2. New acceptor (NA) - refers to an FP client who is new to the program.

3. Current user (CU) - refers to an FP client who is using an FP method at the time the study is undertaken.

4. Service provider - refers to health and FP staff members who are directly providing FP services.

5. Quality of services provided - refers to the mean rating on such factors as job commitment, interpersonal skills, counseling techniques, etc.

6. Level of LGU support - refers to the mean rating on specified factors like the LGU's provision for transportation, per diems and medical supplies, budgetary allocation for BHW allowances, and the like.

\section{STUDY DESIGN, TECHNIQUES OF DATA COLLECTION AND ANALYSIS}

The research design will be a survey utilizing stratified random sampling to denote high, medium and low RHU/CHO performers based on available office records. A simple random sampling will be drawn among the FP providers and their clients.

Personal interviews will be conducted using an interview schedule. Focus group discussions will also be conducted among selected service providers and FP clients, both male and female, tackling sensitive topics such as partner relations.

Frequency distribution, averages, crosstabs, and appropriate multivariate analysis will be used as needed.

\section{E. DISSEMINATION/ UTILIZATION PLANS}

Results of the study will be presented in a conference to be attended by the provincial and municipal executives, health officials, NGOs and selected service providers.

The conference participants will help develop an intervention plan to address the issues identified in the study.

\section{F. TIMETABLE}

The study will be conducted between July and December 1997.

\section{G. BUDGET}

The estimated budget for the study is $\mathrm{P} 250,000$. 


\title{
An Assessment of the Effectiveness of Interpersonal Counseling Services for FP Clients
}

\author{
Ms. Lorna Lagos \\ Ms. Redinah Poral \\ Provincial Health Office, Koronadal, South Cotabato
}

\section{A. PROBLEM SITUATION}

There is a high drop-out rate among FP users in South Cotabato. This is very much in evidence although we expect a high continuation rate for all methods. The reasons for dropping out are rumors and fear of side effects among clients and poor counseling skills and lack of follow-up on the part of Rural Health Midwives (RHMs).

\section{B. OBJECTIVES/ HYPOTHESES OF THE STUDY}

The objective of the study is to conduct an assessment of the effectiveness of the interpersonal counseling services of RHMs. The hypotheses are:

1. the higher the level of effectiveness of counseling services, the greater the client satisfaction, and

2. increased client satisfaction will likewise increase the continuation rate of all FP methods.

\section{METHODOLOGY}

The survey design will involve randomly selected RHMs and continuing users of FP. Personal interviews will be conducted using an interview guide. Coding and tabulation of results will be carried out and appropriate statistical tests will be conducted.

\section{DISSEMINATION}

Dissemination seminars will be held at the provincial and barangay levels. At the provincial level, the seminar will be attended by provincial and municipal program managers, while at the barangay level, the RHMs will attend.

The results of the study will be utilized for identifying possible interventions involving the participation of program managers, service providers and clients.

\section{E. TIMETABLE}

The study will be conducted between January and July 1997. 


\section{F. PROPOSED BUDGET}

Project Director

$\mathrm{P} 21,000.00$

Research Asst.

$15,000.00$

Secretary

$4,500.00$

Field Supervisor

$2,000.00$

Field Interviewers ( 8 for 5 days each)

$12,000.00$

Field Expenses

Transportation

$5,000.00$

Per diem

$5,000.00$

Communication

$1,500.00$

Supplies

$4,000.00$

Data processing

$5,000.00$

Computerization

$7,000.00$

Overhead

$8,000.00$

P 90,000.00

ニニニニニニ 


\section{OPEN FORUM}

Dr. Dely Alcantara, UNM: The Negros Oriental study is a good concept. There is an issue, though, that you would want to think about methodologically. Your question is differential performance at certain levels but the survey is individual. The question here is: if you are looking at differential geographic or rural clinics, you are thinking of an organization, you are thinking of performance at a certain level of geography or clinic or hospital. If you will interview individuals, will that answer the question on differential performance? That is not only true with this study, this is true for everybody who is looking at aggregate areas - hospitals, clinics, cities, etc. These are community level or organization levels. If you want to do the survey of individuals, it should be called multi-level study with two levels. There is both the aggregate or community level study and the individual study. There are methodological and statistical ways to merge those separate data sets. Clarify this issue because the methods of collecting information and the methods of statistical analysis are very different.

Dr. Marilou Costello, PopCouncil: You know, we had a similar problem for Cebu about variability in CPR reports for the different districts in the province. It turned out that it was really a problem of bad data. It might be good to take a look at the quality of the data which have been used to derive these CPRs.

Dr. Edwin Ylagan, PopCouncil: I think the CPR that you have in this province was mainly gathered from the FHSIS. That is one of their reasons for concern because the LPP has been telling them not to rely on the FHSIS, but to look at regional data. However, the regional data set doesn't give provincial breakdowns. This is why we get so many concerns about validating the CPR in their specific provinces. 
Mr. Gil Aganon, PopCouncil: The topic of differential performance is fine, but that would be a big project. Remember if we are trying to measure levels of contraceptive practice for the whole province, we are taking a sample of 30 to 210 for a cluster survey. Now, if we are going to find out the differential performance of RHUs in the province, it would mean you must have at least 210 respondents per RHU.

Dr. Saumya Rama Rao, PopCouncil: I am very happy that two LGUs mentioned dissemination and utilization of their findings. We think that's a very critical component of any study because that involves the next stage of the research process.

Dr. Marilou Costello, PopCouncil: I was wondering if Lorna (South Cotabato group) can explain about effectiveness.

Ms. Lorna Lagos, South Cotabato: Our midwives have been trained in counseling and have undergone an interpersonal communications skills training (ICS). In spite of this, there are still drop-outs. What we want to see is the quality of care which the client receives from the midwife and the type of counseling she receives.

Dr. Marilou Costello, PopCouncil: It seems to me that what you are trying to do is to evaluate the ICS. Is it possible to set do two groups, a kind of comparison where you take areas where there will be a training on ICS and compare these to other areas which there is no training? Is that the design that you are going to take?

Ms. Lorna Lagos, South Cotabato: Yes. There will be two groups, the control and the experimental groups.

Dr. Saumya Rama Rao, PopCouncil: It seems to me that you can do your study in two steps. First, your experimental and control groups will study the effect of training on improving the counseling skills of your rural health midwives. Once you have finished doing that, then you 
can study whether a good counselor is useful in helping a client continue the method. You will have to decide which one of these two study problems you will want to focus on, or if you want to do both.

Dr. Michael Costello, RIMCU: As a more general way of looking at it, let's recall the idea of a conceptual framework. For example, $X$ causes $Y$ which subsequently influences $Z$. It really didn't come out that strong in this workshop but there are some diagrams in the handbook which illustrate this idea. What Saumya was saying could apply to many other different studies as well. The $Z$ is your long-term effect, the contraceptive drop-out rate will become lower. That can be hard to measure, it's hard to see an immediate impact and it takes a long time because so many factors affect the drop-out rate. Maybe you should just focus on the immediate effect. Did the counseling skills improve after the training? Or, for some other place, are the outreach workers visiting more homes? The idea here is to measure the impact on the immediate effect that is called the intervening variable.

Dr. Marilou Costello, PopCouncil: I suppose what we're really recommending here is that if you're going to do this study, think of the immediate effects first so you can measure these. 


\title{
A Diagnostic OR Study to Increase Contraceptive Prevalence Rate (CPR) in Davao City
}

\author{
Miguel Oppus, MD \\ Elma Albay \\ City Health Office, Davao City
}

\section{A. PROBLEM SITUATION}

The Contraceptive Prevalence Rate (CPR) for Davao City is $40 \%$, which is lower than the national CPR, 50.7\%. This has been occurring in spite of the fact that each RHU has trained staff and is regularly supplied with commodities and other logistics.

The CPR of Davao City may be low because the figure does not include data from NGOs and private clinics. Besides, there is also the problem of weak supervision by the district supervisors in validating and following up reports submitted by their subordinates. In general, the community volunteer health workers (CVHWs) have not been used in updating the masterlists, especially for health facilities and personnel in far-flung areas.

We would no doubt have a CPR comparable to that of the national CPR of $50 \%$ if we could consolidate all the reports coming from GOs, NGOs, private clinics and industrial companies. This would also give us more accurate baseline data on the family planning program.

\section{B. MAJOR OBJECTIVES}

The immediate objective of this study is to validate existing data on family planning prevalence levels, in particular, to see whether there is significant difference between the existing FHSIS statistics and the cluster survey data.

\section{STUDY DESIGN, TECHNIQUES OF DATA COLLECTION AND ANALYSIS}

A cluster survey will be carried out in 30 barangays to be selected randomly from high, medium, and low prevalence rate strata. All currently married women aged 15-49 years will be interviewed in each barangay selected. A team of trained interviewers and supervisors will collect the data. At the same time, FHSIS reports will be collected and consolidated with FP records from the NGO and private clinics/hospitals.

All coding, editing and data processing will be done at the Ateneo de Davao University. The computer facilities of ADDU will be used to analyze the data.

\section{DISSEMINATION/ UTILIZATION PLANS}

A dissemination seminar among district health officers and PAs will be conducted to present the results of the cluster survey. A copy of the final research report will be given to Local Government Executives, the Regional Health Office and other interested agencies. 


\section{E. TIMETABLE}

The study will be conducted between June and October 1997 by the Ateneo de Davao University in partnership with the City Health Office. A final research report will be completed by October 1997.

\section{F. BUDGET}

Funds of P200,000.00 are required for staff salaries, travel, questionnaires, computer time, and the proposed dissemination seminar. 


\title{
A Diagnostic Operations Research Study to Know the Factors Affecting Low CPR in the Province of North Cotabato
}

\author{
Mrs. Charita Doyongan \\ Mrs. Virginia Laguihon \\ Provincial Health Office, Kidapawan, North Cotabato Province
}

\section{A. PROBLEM SITUATION}

Cotabato Province has a low CPR of $40.5 \%$ compared to the regional rate of $45.2 \%$ and national rate of 50.7\%. This is true in spite of the fact that each of the 18 RHUs has a trained staff and is regularly supplied with contraceptive commodities and other logistics.

Factors like KAS of service providers, KAP of women (MWRAs), fear of side effects, rumors and misconceptions still play an important role in this. Religious interference in some areas and the influence of men in FP practice are other possible reasons.

\section{B. MAJOR OBJECTIVES}

1. To determine:

a. CPR for program and non-program methods both for high-risk and non-high-risk women at the provincial level; and

b. CPR by method as well as method mix.

2. To know the level of:

a. Knowledge, attitude and skills of service providers; and

b. Knowledge, attitude and practices of MWRAs.

\section{ULTIMATE OBJECTIVES}

This study will help program managers develop a plan to improve the quality of FP service provided to men and women.

\section{STUDY DESIGN/ TECHNIQUES OF DATA COLLECTION}

The study will involve a survey of MWRAs using cluster sampling. It will be initiated by the Provincial Health Office in collaboration with a research institution and will be conducted between April and August 1997. 


\section{DISSEMINATION/ UTILIZATION PLAN}

The Provincial Health Office will call for a conference to be participated in by RHOs, FP Coordinators, SB Chairman on health, NGO administrators, PHO Technical Staff and PPO personnel.

Results of the study will be presented by the Research Project Officer. Each municipality will be provided with a copy of the report, which will be their basis/guide in improving their quality of service. Another meeting will be called for the preparation of an intervention plan.

\section{E. BUDGET}

Total cost of the research study is P200,000. This will be sourced from LPP funds, with all other expenses being charged to the LGU. 


\section{OPEN FORUM}

Dr. Dely Alcantara, UNM: The question in my mind is that when people talk about a cluster survey, are we talking about a new survey technique? Or are we talking about a sampling technique wherein you first sample a cluster of RHUs/barangays and then, within that, choose your sample respondents or households?

Dr. Michael Costello, RIMCU: There are seven respondents per cluster. I remember Mr. Aganon telling us last night that this number is too small. You cannot say much about a certain barangay if you've got only seven people. You can't really validate your FHSIS for such cases. I don't know how many you need but I would guess at least 50. But once you have that, we're now talking about 1,500 respondents and expenses will surely go up.

Dr. Edwin Ylagan, PopCouncil: If I remember correctly what Gil said, it's not easy to do that at this point unless you have some data with which you can judge what high or low performance is.

Dr. Eduardo Baguinon, Cagayan: As we know, there is a formula when we compute for the respondents. In order to come up with a research project, we first pilot it in an area. We then take the CPR if that is what is wanted or any rate that is possible. From that rate, you compute for the number of respondents. That was our initial understanding. During the lecture, however, they came up with formulas and we got lost because we were given a standard of seven municipalities and 210 respondents.

Dr. Marilou Costello, PopCouncil: My comments stem from the fact that conducting the cluster survey is part of the benchmark of the LGUs. It is something that they saw in their kits when they attended their LPP training. It is something they're supposed to do by 1997. Of course, the reason we brought this topic here is because we thought that this 
is an opportunity to provide them with some initial technical assistance or at least awareness of some issues that will come up in this cluster sampling. I would say this is a misnomer, but I did not want to confuse the participants. It stems from the terminology that was used in the guidelines given to them by the LPP. They call it a cluster survey. When I first heard of it, I said I was really confused about what they meant by a cluster survey. I think they meant a cluster sampling design, but since it came from the LPP, they probably know what they are talking about. This is why I said that this is a levelling exercise. So we need a better understanding of the terminologies that we are using here.

Dr. Jocelyn Ilagan, DOH: I think the identification of the cluster survey is very similar with what they did in the EPI. The rationale behind that is knowing how to go about the database information on the true picture of FIC, $C P R, T T$, etc. So these were the parameters that LPP had to agree on for undertaking the cluster survey.

Dr. Marilou Costello, PopCouncil: In a sense, this is like an imposed sampling design from the very beginning. Why this design was imposed is what confuses the statisticians and facilitators who are here. They are trying to determine whether or not this is really the most appropriate sampling design for the purpose of each LGU. As far as we are concerned, we just want to make sure that we try to help the LGUs to meet this benchmark.

Dr. Dely Alcantara, UNM: When I was still in graduate school and doing FP research, there was a very good justification for cluster sampling. When resources are limited, cluster sampling is a good way to go because the assumption is that the clusters that you identify are similar in characteristics. There is an assumption of homogeneity. Even if you choose one within that cluster, that one is a representative of that group and you can cluster them according to similar geographic characteristics or similar socio-economic characteristics 
or similar CPR or similar MCRAs/MWRAs. It is cheaper than conducting a survey because you are stratifying or clustering them according to similarities. However, the Davao presentation seems to be questioning the validity or reliability of the FHSIS. In fact, all of you seem to raise that issue. This Davao project wants to do a survey of its own to validate it. There is a question here on how to go about evaluating one set of data using another methodology. When you do that, what you really are evaluating are records. One thing to think about here is, how do you match the survey respondent with her record?

Dr. Saumya Rama Rao, PopCouncil: I just wanted to add that this type of cluster sampling that we are talking about is also done in India. It is also a centrally directed thing. All the centers were supposed to conduct the cluster sampling for EPI to evaluate vaccination coverage. It is a similar situation in the Philippines that LPP has asked all the LGUS to do it. It seems to me that there is very little that the LGUs can really do. Maybe the discussion we are having should be at a different forum. The LGUs are here to learn what it is and how to do it well.

Dr. Edwin Ylagan, PopCouncil: Yes. We want this to be a sort of levelling exercise to clarify things that may arise.

Dr. Michael Costello, RIMCU: Saumya's comments about the centrally directed rule about sampling indicates that an approach is being taken here which is different from the spirit of OR. The spirit of $O R$ is not a centrally planned thing. It's more like a free market economy where the local manager says "This is my problem and this is what I want to work on." This problem is not given to him or her from on high. So part of the mentality we want you to pick up here is to think in terms of your own problems and how you should be collecting data to solve them. Unfortunately, I am not so sure the cluster survey is going to allow you to do this in this case. 


\title{
A Non-Experimental OR Study to Detemine the Factors that Cause the Decreasing Trend of V.S.S. in Cagayan Province
}

\author{
Wilson Puyaoan, MD, MPH \\ Edgardo Baguinon, $M D$ \\ Provincial Health Office, Cagayan
}

\section{A. PROBLEM SITUATION}

According to statistics, Cagayan Province has experienced a significant increase in its CPR from $32 \%$ in 1985 to $42.5 \%$ in 1995 . However, there is a discrepancy in the trends of the various methods. While there is an increasing trend in the prevalence of the other methods, there is a decreasing trend in the V.S.S. prevalence.

\section{B. OBJECTIVES OF THE STUDY}

The immediate objective of this study is to conduct a cluster survey in randomly selected municipalities and barangays to determine the attitudes and skills among V.S.S. motivators and to gather ideas about the advantages and disadvantages of V.S.S., attitudes toward the method and access to service outlets among MWRAs not yet ligated and with three or more children. The ultimate objective is to provide information to policy makers and program implementors which will allow them to improve V.S.S. service motivation and acceptance by the MWRA clientele.

\section{DATA COLLECTION/ ANALYSIS}

A cluster survey technique will be utilized. Seven municipalities will be randomly selected among the 29 municipalities. Among the seven municipalities, 210 persons will be randomly selected for interview. Potential respondents will include qualified V.S.S. motivators and qualified MCRAs. The interview will be conducted by trained interviewers using a standard survey form during house-to-house and facility-to-facility visits.

All coding, editing and data processing will be done at CSU. The computer facility of CSU will be used to tabulate the data. A final research report will be completed by October 1997.

\section{TIMETABLE}

The study will be conducted between February 1997 and April 1997 by the Provincial Health Office in coordination with the CSU research staff.

\section{E. BUDGET}

A budget of P200,000 will be funded by the PHO to shoulder honoraria, training, travel, construction of questionnaire, use of computer time and miscellaneous expenses. 


\title{
A Situation Analysis of Family Planning Service Delivery at MHCs and BHSs in Maguindanao
}

\author{
Farida Uka, MD \\ Sabrina Abella \\ Provincial Health Office, Maguindanao
}

\section{A. PROBLEM SITUATION}

The contraceptive prevalence rate in Maguindanao is $21.2 \%$, which is lower than that of the neighboring provinces of North Cotabato $(40.5 \%)$ and Sultan Kudarat $(60.10 \%)$ and even lower than the national level (50.7\%). It is supposed to be higher considering that support from the DOH and from foreign sources in terms of trainings and logistics is equivalent in all areas.

The low CPR could be attributed to several factors. One is the seemingly lukewarm attitude of trained health workers towards the FP program. FP training courses for service providers may be inadequate in terms of content and communication skills. Another factor could be the poor client-provider relationships. Inadequate supplies and nonavailability of needed equipment could be preventing service providers from providing FP service. No data, however, are available as to which of these factors really explains the low FP performance in the communities. A situation analysis is therefore being proposed.

\section{B. OBJECTIVES}

The Provincial Health Office of Maguindanao in collaboration with Notre Dame University Socioeconomic Research Center (NDUSERC) will conduct a situation analysis to determine the availability and quality of services for clients at service delivery points. It also aims to determine the quality of FP service provided by trained service providers.

Data will be collected from service delivery points in randomly selected municipalities. Program managers can then utilize the SA data to pinpoint problem areas and to respond through administrative action.

\section{STUDY DESIGN, DATA COLLECTION AND ANALYSIS}

In order to answer the questions posed by the study, a combination of survey and qualitative techniques will be utilized.

Data will be collected from doctors, nurses, midwives and clients. Since there are only 11 MHOs and 27 PHNs in the province, all of these will be included in the study. A sample 
of midwives will be taken using systematic sampling. Client respondents will be chosen through cluster sampling. Seven MWRAs will be selected per barangay.

Data from service providers will be collected through in-depth interviews. Direct observation of operations and facilities will also be carried out. The clients will be interviewed using a structured questionnaire.

Data collection and analysis will be subcontracted to Notre Dame University - SERC.

The results of the study will be made available to program managers who can utilize them to identify areas where FP services need to be improved and to suggest interventions that can address problems and issues identified by the study.

\section{E. DISSEMINATION/ UTILIZATION}

Information will be disseminated through the conduct of a research utilization workshop. Copies of the study will be distributed to LGUs, other GOs and NGOs who might find the study findings helpful.

\section{F. TIMETABLE/ BUDGET}

A period of five months is needed for this study. Budgetary estimates will be provided after further consultations with NDU-SERC. 


\section{OPEN FORUM}

Dr. Michael Costello, RIMCU: The Cagayan group might consider interviewing women who have been ligated, because your concern there is that fewer women are going for sterilization. This might be because there has been a breakdown in service. So you might ask a small sample of women who were already ligated about how it went for them.

Dr. Edgardo Baguinon, Cagayan: In Cagayan we have a V.S.S. service that is nonfunctional in 60 percent of our hospitals. There is also a lack of skills among the V.S.S. providers. However, that is now currently being taken care of with help from AVSC and UNFPA. Besides, we will be focusing on the service provider resources and V.S.S. skills in our 1997 LPP plan.

Mr. Gil Aganon, PopCouncil: The cluster sampling was first started by using the simple random sampling at 10 percent margin of error, 95 percent level of significance. That gave us a sample of 96. That's fine, if it is simple random sampling. But that is not practicable because it is so expensive to generate your sampling frame. Under cluster sampling, the selection of the final informants or targets is no longer random. To make up for this, 96 is doubled and then rounded off to 210. Studies have shown that this is a valid approach. Another issue relates to the FHSIS. The reason they don't want to make use of this at the national level is because of its incompleteness. The only problem here is the acceptors coming from the private sectors. Somehow, you might have to establish some linkages with the medical associations to get that data. Or you might have to conduct a survey.

Dr. Marilou Costello, PopCouncil: I think that is a good point that Gil just brought up and something we can follow through. What he is really saying is that this concern about finding the real CPR could probably be solved right there in your own individual LGU. There will still be a problem, of course, at the national level but that is something which I can also bring up at MSH. They will have to consider if their purpose is to have an accurate or updated measure of CPR at 
the LGU level. I am sure that Dr. Jojie Ilagan here will also be willing to bring this up to the $\mathrm{DOH}$.

Dr. Eduardo Baguinon, Cagayan: We have a new implementation of the FHSIS which only began during the second quarter of this year. The concept involves collecting information for policy making. As for the information collection, the municipalities are in charge because they are the ones who will implement their programs. The analysis and all the details are with the municipalities. Even at the PHO level we do not have the details. This doesn't seem right because your data will not be comparable. Under the devolution set-up, the provincial government can not move in terms of financial matters but in terms of technical competence, when we are supposed to be able to move.

Dr. Michael Costello, RIMCU: A while back Marilou said she was going to bring up this angle to MSH. I have another angle because I am still grappling with this problem (which I think many resource persons have) concerning doubts about whether the cluster suvey, a very broad general purpose survey, is really going to help us as far as a practical, problem-oriented OR is concerned. Anyway, since it is a benchmark, I understand you still have to do it, so you're not so motivated to do another OR yet because you have to take care of this benchmark first. Let's go back to Maguindanao, and its situation analysis. This is a kind of a unique methodology. I think it is a useful one as well. In the situation analysis you go out to some clinics and take a random sample of clinics. Here comes my angle, on page 42 of the OR Handbook where it says, "Sampling can be simplified greatly by selecting clusters of elements... and then proceeding to study all elements in each of the sampled clusters. Most commonly the clusters are geographic units or organizational units such as clinics." I am just wondering if MSH would accept a situation analysis as fulfilling the benchmark because it really is a cluster survey. You would take a sample of clinics and then go out and see what's going on out there. So please bring up that angle, too. 


\title{
Providing Reproductive Health Counseling to Post-Partum Clients
}

\author{
Ms. Vilma G. Mendez. \\ Ms. Marilyn D. Jacot \\ Provincial Health Office, Misamis Oriental
}

\section{A. PROBLEM SITUATION}

There is a significant problem of unmet need in the province of Misamis Oriental. Many high risk women are not using a program method of family planning (FP). In particular, there is a large proportion of women who have recently given birth within the past two years who are not FP users.

In response to this situation the FP/MCH service of Misamis Oriental has designed an intervention to meet this need, namely a post-partum counseling service. Before upscaling this to the province as a whole, though, there is a need to pilot test this proposed intervention.

The intervention will aim to increase use of FP Program Methods (for spacing purposes) among women who have given birth within the last two years. This will be an improvement over the present situation which indicates a low CPR for spacing.

The discrepancy occurs because:

1. at present there is no such post-partum counseling program. Therefore, women who have recently given birth are not being reached; and

2. women are not coming to the clinic for post-partum check-up.

\section{B1. MAJOR OBJECTIVES}

The major objective of this study is to set up and evaluate a pilot intervention program in post-partum counseling in selected municipalities of Misamis Oriental.

The purpose of this study is to test the effectivity/impact of the proposed program with regard to improving family planning acceptance.

The program will be implemented in three municipalities, as will be compared to a control group of three municipalities with similar characteristics.

\section{B2. HYPOTHESES}

- FP acceptance among women who underwent PP counseling will
increase in comparison to those from the control group where there is no 
counseling.

- The interval between pregnancies will be longer among women who underwent PP counseling.

- $\quad$ Maternal/ reproductive-related morbidities will be fewer among women who underwent PP counseling.

\section{PROPOSED INTERVENTION}

The following activities will be undertaken in the experimental municipalities:

1. Formulate a counseling guide;

2. Train health providers on the use of the guide;

3. Do a masterlist of all pregnant women;

4. Mobilize barangay health workers to ensure contact and follow-up of all pregnant and post-partum clients;

5. Implement of the counseling program; and

6. Do a regular monitoring and supervision of RHU personnel by Provincial $\mathrm{MCH}$ Coordinator and $\mathrm{MHO}$.

\section{STUDY DESIGN, TECHNIQUES OF DATA COLLECTION/ ANALYSIS}

The design will be a pretest-posttest, quasi-experimental design with an experimental and a control group. Rural Health Units in three municipalities will be identified as experimental areas where post-partum counseling will be implemented.

The major socio-economic and demographic characteristics of the experimental areas will be matched with those from the control municipalities. A sample of 300 women from the experimental areas and an equal number from the control areas will be selected, as drawn from the pregnancy masterlist.

The survey will look into the following:

a. Background characteristics of the women;

b. Pregnancy outcome (date of birth, live birth or not, whether child is still alive);

c. Current FP status (user vs. non-user, type of method used).

d. Current pregnancy status (pregnant vs. non-pregnant); and

e. Maternal morbidity measures.

The intervention will be implemented for a nine-month period, starting January 1, 1997. Survey No. 2 (posttest round) would then take place during October. This will be for 
a random sample of 300 women from the experimental areas who gave birth between January 1, 1997 and March 31, 1997 (and who were counselled) along with a similar number of women from the control areas (who also gave birth between Jan. 1, 1997 and March 31, 1997). The survey will ask the same questions included in the pretest round along with some additional items for women from the experimental area about their post-partum counseling experience.

\section{E. DISSEMINATION/ UTILIZATION PLANS}

The potential users of the findings are the Regional and Provincial Health Officers, MCH/FP Coordinators, RHU personnel of the twenty-four municipalities and one city of Misamis Oriental. The potential users of these findings will be informed a meeting at the Provincial Health Office and they shall also be given a copy of the findings. The Regional MCH Coordinator will be informed as well.

\section{F. TIMETABLE}

The study will be conducted in January 1 - December 31, 1997, subject to the availability of funds.

\section{G. BUDGET}

Training (3 MDs, 3PHNs, 21 RHMs) on use of counseling guide

27 pax x $300 \times 1$ day

P $8,100.00$

Training materials

27 pax x 100/head

TEV for supervision $\&$ monitoring

2 coords. x P200 x 10 mos.

Dissemination seminar

32 MDs, 25 PHNs, 10 Tech. staff

67 x P300 x 1 day

$20,100.00$

P34,900.00

$====$ 


\title{
Evaluating the Effectiveness of Sangguniang Kabataan (SK) Members as Trainors in the Adolescent Development Program
}

\author{
Gil Mantilla, $M D$ \\ Provincial Population Office, Davao del Sur
}

\section{A. PROBLEM SITUATION}

The Population Office in Davao del Sur has developed a program using SK members as trainors for its Adolescent Development Program. They will participate in symposia on population and other issues for in-school and out-of-school youth starting 1996. However, there have been some criticisms of the SK concept in the past year, including calls for abolishing this institution. For example, there have been charges that traditional politicians are actively involved in SK elections. This indicates a need to validate whether or not this approach will really have the desired impact.

It is expected that the strategy will succeed and that SK members will be good trainors and effective communicators. But there are also reasons for expecting that some problems will come out, so we must evaluate the program. The following are some of the major concerns which might be raised:

- $\quad$ SK members were perhaps not serious in attending their trainings, so they never learned about the issues in the first place;

- $\quad$ There is a significant turnover in SK membership (due to the May

elections), so that newer members were maybe never trained; and

- $\quad$ Even if SK members were properly trained, there is still a need to validate the effectiveness of the training strategy.

\section{B. 1. OBJECTIVES}

The Social Research group of Ateneo de Davao University will conduct an evaluation study of the Adolescent Development Program in selected schools and barangays in the capital town of Digos, Davao del Sur by the year 1997.

The purpose of the evaluation study is to validate the effectivity of using SK members as trainors in the ADP. Samples of both SK members and targetted youth will be surveyed to determine their knowledge, attitudes and behaviors on issues such as drug abuse, sexuality, community participation, population problems and parent-youth conflicts.

\section{HYPOTHESES}

Under the assumption that the program has been working effectively during the period 
in question, several hypothetical outcomes may be suggested:

1) Participation among youths and SK members in symposia will be increased.

2) The involvement of youth and SK members in community activities will be increased.

3) The awareness of youth and SK members in the program will be increased/ improved.

\section{STUDY DESIGN, TECHNIQUES OF DATA COLLECTION AND ANALYSIS}

A cluster survey will be conducted among a random sample of youth attending colleges and schools in Davao del Sur. SK members will likewise be master listed and sampled.

The survey will look into the awareness/ knowledge, attitudes and behaviors of SK members and youth.

\section{DISSEMINATION/ UTILIZATION PLAN}

Results of surveys will be disseminated to government officials throughout the province. Academic institutions will also be provided a copy of the final research report.

Results can be used to formulate and redirect the program, in particular to evaluate the performance of the SK trainors.

\section{F. TIMETABLE}

March 1 - Dec. 31, 1997

\section{G. BUDGET}

P100,000 (P50,000 from LPP funds and P50,000 from the 20\% Community Development Fund). 


\section{OPEN FORUM}

Dr. Saumya RamaRao, PopCouncil: Usually when we talk of unmet need, it refers to a special category of women who have expressed a desire to either stop childbearing or who want to space, even though they are not using contraception. So we should not use the word to mean women who probably should be using FP but are not. So the Misamis group should be very careful when they use that term. My second comment is that you are really looking at the acceptance rates, the new number of acceptors among postpartum women, so don't talk about CPR. You should not use CPR because what you are really looking at is new acceptors. The third point is: I really like the study because it will help us achieve the goal of integrating family planning and $\mathrm{MCH}$. When a woman is postpartum, you said that she rarely comes back to the clinic for a check-up. Does she come back for the immunization of the child? Isn't it true that, within the first forty-five days, the child must be given the second BCG and OPV? So that may be a good time to do this family planning counseling as well.

Ms. Vilma Mendez, Misamis Oriental: Since I have been handling the program, I have noticed the same thing. There are really no reasons for these mothers to come back. The problem is that there are separate schedules for immunization and for postpartum consultation. Most of the mothers don't come back after immunization. The providers cannot do postpartum counseling at the time of immunization because of the great number of children at the center.

Dr. Marilou Costello, PopCouncil: These are implementation issues then. Saumya is leading you to say that these visits for immunization might be a good opportunity to do the counseling. So, in your proposal, how do you propose to do this?

Ms. Vilma Mendez, Misamis Oriental: In Misamis Oriental, we only do consultations in the morning. Only emergencies will be entertained in the afternoon because that is supposed to be scheduled for home visits, 
follow-up, and updating records. We have been discussing the observation that five hours in the afternoon is too long. It's just a matter of systematizing duties, I think. Since then, we've been trying to correct that practice because so far less than fifty percent came back. That is really alarming. Even for our prenatal visits we have a low percentage. That's the challenge for me being an $\mathrm{MCH}$ coordinator.

Ms. Aida Santos, WEDPRO: I like the proposal because of my bias for using the gender lens. I'm interested to find out the content of the counseling. Secondly, I'm a bit concerned about the comment that the mothers have no reason to come back. I do wonder about that statement because, during the past few days, we've been talking about women's role and responsibilities and what discourages them from not coming back to clinics for consultations and examinations. I'm surprised to hear that they would only come for the immunization of their children, but not for their own examination. That for me is an important point which needs clarification and examination. This is where you can apply a very good gender lens.

Ms. Vilma Mendez, Misamis Oriental: On the formulation of the counseling guide, I was trying to think about how we did it for the TB program. The provider used a flipchart in counseling. I still need some advice on that. I can make use of an FP guide but this has to be pilot tested first. That would take a lot of time and money. I was wondering if we could find something that we don't need to pilot test anymore, something that is already existing. Secondly, I'd like to address the issue on why mothers will come to the clinic for their children but not for themselves. Why do we let them go, why don't we entertain them? The problem lies in our lack of personnel. We only have one midwife and a nurse for the rural health center. Another thing is the attitude of the personnel. Since the LGUs are devolved, the providers always say they have many things to do. I am just trying to show you the scenario of our area, but I would like to assure you that we are not closing the door. 
Dr. Edwin Ylagan, PopCouncil: I think that situation is very true in most of the health centers all over the Philippines. In one morning you have about 200 who will be coming for MCH and only 40 for family planning and other concerns. Usually this is done in the morning and the health provider's concern is to deliver the immunization as fast as she can. She has no time for counseling and the mother would opt to do her work because the last time she visited the health center, she was not attended to. She then decides that she will just come back on her child's next immunization schedule, which is a few months after.

Dr. Eduardo Baguinon, Cagayan: I am worried because she said there are three municipalities in which she will make the counseling intervention. The problem there is that it is not only the guide that matters but also the technique of the counselor. How would you standardize the three so that they will be comparable? The second question is on acceptance - there are several factors aside from counseling which you have to control in the community. For example, the influence of the traditional leaders in the control area and the non-control area. The third question is - will your study be more efficient if it will be the prospective type of study?

Ms. Vilma Mendez, Misamis Oriental: Let me first answer the question on the service provider. We are scheduling a training for all those personnel who will be involved in using the guide. As for the experimental and control areas, we should be careful in the selection of the six municipalities. One of the things to consider is that they should have a similar demographic and socioeconomic profile. It's just a matter of selection.

Dr. Marilou Costello, PopCouncil: Not only that. They will also compare the acceptance before they did the intervention and after the intervention so that there will be a before and after comparison.

Dr. Michael Costello, RIMCU: I just want to comment on what Edwin said. There are some contradictions which show a need to go out in the field and see what's really happening. Sometimes we make judgements based upon hunches or stereotypes. Contradiction number one: we heard 
from Vilma that there is very low number (she said 50) who came for post-natal examination. Then we heard from Edwin that they're so busy, they have 200 in one morning. Now you said that it's more than family planning, but still there is sort of a contradiction. So, as a researcher, I think - what is the reality, are the clinics failing because nobody is coming, or are they failing because they are so busy that they can't give good quality service? Problem number two is that everybody says we need counseling. I am a big believer of counseling, but then we heard Edwin say that there is "no time for counseling". That was my original point. I said counseling is hard to implement because I agree that there is no time for counseling. How can you find the time?

Ms. Vilma Mendez, Misamis Oriental: Let me speak for both the provider and the client. Now let me answer it with one word - it is a matter of followup. They already have the masterlist of pregnant women. If you see in your list that the patient did not come to you, then you have to send somebody. The barangays have a lot of volunteers. It is just a matter of tapping them. What we are trying to do now is to become more community- based so we don't need to rely so much on the providers.

Dr. Jocelyn Ilagan, DOH: You mentioned to us that there are limitations in terms of providing the services among your health personnel. My thinking is, since most of these activities are being conducted together with the health volunteers, then perhaps we could also tap them as points for counseling or information dissemination among mothers.

Dr. Saumya RamaRao, PopCouncil: I have a very simple comment which you might consider. Is it possible to use the contact point between the system and the client during the antenatal check-up as a preparation for family planning or post-partum check-up later on? That is point one. This is a kind of strategy that we are now trying to implement in India also. UNICEF India has been trying to promote the saying that every contact of the client with the health system must be utilized. Even if it is not possible to use that particular opportunity, at least 
say, "Please come back later on." The second comment is, I was a little confused about your main concern. Was this that the women are not coming back for postpartum check-up or is it whether or not they are using family planning? These two are a little different, so the strategy that you might employ will likewise differ.

Ms. Vilma Mendez, Misamis Oriental : I find it very important that they should come back after one month to one-and-a-half months. These clients are the ones who really need the service. If they won't come back anymore, we don't know whether they are in good health or not. We aren't sure if they are using family planning. I really want postpartum mothers to come back so that the services we provide for them from the prenatal up until the postpartum period would be quality care.

Dr. Marilou Costello, PopCouncil: Another suggestion: you might also want to think very carefully about the content of your counseling. We have talked a lot about gender sensitivity and reproductive health, so you might consider those things as you develop some of those counseling charts and subject them to tests to find out how gender sensitive these are in the light of the inputs we received from our resource persons.

Ms. Elma Albay, Davao City: This is a follow-up to the reaction of Dra. Ilagan. Presently we have a project in our city where we train our CVHWs on interpersonal communication skills on family planning, safe motherhood and reproductive health. Those CVHWs were utilized in pre-natal and post-natal activities and were the ones giving information or counseling during those activities. It can be a big help if we train the volunteers on interpersonal communication skills.

Dr. Filemon Flores, Negros Oriental: $\quad$ My question is about this community-based concept. You said that supervisors still go to the barangay level, and yet you are community-based. My understanding of a communitybased program is that it is implemented in the community and the people there are responsible as far as the activities are concerned. I don't know how you can reconcile this.

Ms. Vilma Mendez, Misamis Oriental : We at the PHO level feel that we must still 
go down to see if they are doing all right, but most of the activities are already being handled by our local supervisor. We only go there quarterly to check.

Dr. Michael Costello, RIMCU: "All social science begins with comparisons." So the Davao Sur paper should think carefully about its sample of in-school youth. It will be good to have a comparison of the ones who attended the symposia compared to those who never attended. I don't think Dr. Mantilla mentioned that. Our hypothesis would be that the ones who went to the symposia have learned all these wonderful ideas about how to survive their adolescence, at least in comparison to those who didn't attend.

Dr. Saumya RamaRao, PopCouncil: When you are talking about youth, are you also making a distinction between girls and boys, and whether the concerns of girls are maybe a bit different from the concerns of boys? Wouldn't there be some element of gender on this?

Dr. Gil Mantilla, Davao del Sur: Yes, I am open to it. I don't have an idea yet what it could be but I will include it in the survey.

Dr. Eduardo Baguinon, Cagayan: In our area, we have a problem regarding the SK. The age level of the SK is the educational level. Most of them are attending school. As such, they are not usually available for trainings and community activities.

Dr. Gil Mantilla, Davao del Sur: We have not yet identified this problem but you may be right about that.

Dr. Edwin Ylagan, PopCouncil: We are now at the end of this session but still at the beginning of your OR journey. From the preceding sessions we know that this will be a journey that has a lot of detours. 


\section{CLOSING REMARKS}

Jocelyn Ilagan, M.D. Family Planning Service, Department of Health

Good morning, everybody. This will be the last time that I will be sharing my ideas with you. I am happy that you had excellent presentations in spite of the fact that it seemed like it was an impossibility. I know it has been a very challenging three days for all of you, but I can see that you are all committed, interested, and very much aware of the importance of OR. The Department of Health also has this focus and we really want the LGUs to have the capability of handling problems and identifying interventions. Perhaps this has been a success for all of us. I was really observing how all LGUs have put their time, their energy, and their minds into this whole thing. I bring again this challenge to you -- let's put OR right in the middle of all our perspectives and all our activities. Let it be at the back of our minds always that we already have this tool for problem solving.

I would also like to thank all of you for coming here. I know you had your own experiences during the first day, the travel day. For my part, I had my own added experience: I was able to ride a nine-seater plane. I hope that all of you are relieved that the three days are over and you are eager to go back to your own LGUs and start your OR.

Be rest assured, by the way, that we will raise your issues and concerns to our partner agencies. We will raise this with our program director so that we could have some clear guidelines on how to go about operations research and the cluster surveys. I know you have had your difficulties with the cluster survey as a benchmark but eventually we can thresh everything out.

Again, I am thanking all the resource persons who attended and shared their expertise, the Population Council who spearheaded this activity, and of course, all our trainees. I hope that you will take care of yourselves going back home and I am extending the warmest regards from our program director, Dr. Jovencia Quintong, and from Undersecretary Antonio Lopez from the Office of Public Health Services. Thank you very much to each and every one of you. 


\section{CLOSING REMARKS}

\section{Marilou Palabrica Costello, Ph.D.}

The Population Council, Manila

Actually, Jojie has already mentioned all the sentiments that I wanted to express to you this morning. We are very happy that you came to this workshop. It is heartening to see that you worked so hard during the last three days. You have been so patient and cooperative and you are a very good set of participants. I was very happy to see how you all cooperated and came up with well-thought outputs, some of which are truly excellent and others quite good. I hope that this will not be the last time that you are going to work on your proposed studies. This is just the beginning. I hope that we have only whetted your appettite for operations research. When you go back, I believe that some of the things which were not very clear to you initially will begin to get clearer as you work in your own set-up.

I am really thanking you and I hope that as you go back, you will think about the interesting things that we have learned here. I also want to thank the resource persons and our secretariat who have worked so hard. I think that everybody did such a great job. And I hope that, when you come to Manila, you could stop by the PopCouncil office. We would be glad to further discuss other issues that we have touched only briefly in this workshop because of time constraints. I know we have not resolved them all. Actually, this activity is only the beginning of the type of interaction that we would like to continue in the future with you. So salamat and have a good trip back home. 